\title{
Small Modular Reactors: Institutional Assessment
}

Joseph C. Perkowski

June 2012

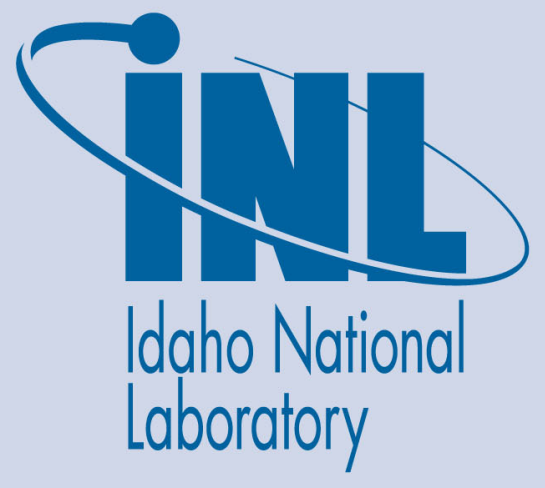

The INL is a U.S. Department of Energy National Laboratory operated by Battelle Energy Alliance 
INL/EXT-12-26412

\title{
Small Modular Reactors: Institutional Assessment
}

\author{
Joseph C. Perkowski
}

June 2012

\begin{abstract}
Idaho National Laboratory
Idaho Falls, Idaho 83415
\end{abstract}

http://www.inl.gov

\section{Prepared for} CAP and for the

U.S. Department of Energy

Under DOE Idaho Operations Office

Contract DE-AC07-05ID14517 
SMALL MODULAR REACTORS: INSTITUTIONAL ASSESSMENT [Final Report, 6/20/2012]

\section{Work Covered By This Report}

- Objectives include, among others, a description of the basic development status of "small modular reactors" (SMRs) focused primarily on domestic activity; investigation of the domestic market appeal of modular reactors from the viewpoints of both key energy sector customers and also key stakeholders in the financial community; and consideration of how to proceed further with a pro-active "core group" of stakeholders substantially interested in modular nuclear deployment in order to provide the basis to expedite design/construction activity and regulatory approval.

- Information gathering was via available resources, both published and personal communications with key individual stakeholders; published information is limited to that already in public domain (no confidentiality); viewpoints from interviews are incorporated within. Discussions at both government-hosted and private-hosted SMR meetings are reflected herein. INL itself maintains a neutral view on all issues described. Note: as per prior discussion between INL and CAP, individual and highly knowledgeable senior-level stakeholders provided the bulk of insights herein, and the results of those interviews are the main source of the observations of this report.

- Attachment A is the list of individual stakeholders consulted to date, including some who provided significant earlier assessments of SMR institutional feasibility.

- Attachments B, C, and D are included to provide substantial context on the international status of SMR development; they are not intended to be comprehensive and are individualized due to the separate nature of the source materials. Attachment E is a summary of the DOE requirements for winning teams regarding the current SMR solicitation. Attachment $\mathrm{F}$ deserves separate consideration due to the relative maturity of the SMART SMR program underway in Korea. Attachment G provides illustrative SMR design features and is intended for background. Attachment $\mathrm{H}$ is included for overview purposes and is a sampling of advanced SMR concepts, which will be considered as part of the current DOE SMR program but whose estimated deployment time is beyond CAP's current investment time horizon. Attachment I is the public DOE statement describing the present approach of their SMR Program. 


\section{$\underline{\text { 2. Perceived Value Of This Assessment }}$}

Examining the current institutional status of SMR configurations, with emphasis on their deployment potential, is of interest to CAP because:

- to provide some diversity of assets ("not putting all your eggs into one basket"), SMRs could be deemed worthwhile by CAP as a partial component of its generation mix even in an investment market that is currently highly biased towards natural gas;

- the current time horizon of interest to CAP for new prospective generation investments may allow for SMRs to be a viable alternative, and therefore cost and deployment schedules and performance criteria need to be understood in an unbiased manner;

- if investments in new fossil energy plants continue to be delayed in deployment for various reasons, there could be a pull by the marketplace for rapid certification and installation of smaller "modular" nuclear units. Market facilitation of this pull could be provided by smaller utilities or groups of utilities such as CAP in tandem with the financial community;

- helping to organize a consensus of real market customers and prospective financing professionals targeted at modular nuclear deployment could stimulate utility and vendor stakeholder interests to expedite design completion and regulatory approval regardless of other market or institutional trends. 


\section{Key Queries Posed To Stakeholders}

- What are the best available unit (overnight and life-cycle) cost and deployment (time to actual market) metrics to use for serious consideration of modular nuclear plant investments?

- How close are we to major capital energy investments decisions currently, in light of both forecasted grid generation shortfalls as well as the current and ongoing financial market volatility?

- What are the key constraints on alternatives to modular nuclear plants: presumably this includes delays in coal plant orders, continued risk of natural gas availability and pricing volatility, uncertainty of effectiveness of conservation measures, and uncertainty of aggregate renewable market share?

- Which major design features for modular (grid-appropriate) nuclear plants are most important for customer and investor confidence?

- Regardless of design, are there any public policy issues that are absolute constraints, i.e. must be resolved for customer and investor confidence prior to actual investment?

- Can you (the stakeholder) provide a specific commitment contractual relationship for the delivered end product (PPA and/or heat energy) as part of up-front financing to expedite deployment, and in what format?

- What other prospective stakeholders (users and/or financiers) do you know that have serious interest in this type of opportunity? 


\section{Summary Of Stakeholder Responses: \\ Five Creative Ideas For Near-Term SMR Opportunities As Offered By Stakeholders}

"Idea \#1": This idea is to aggressively pursue CAP's presumed (but definitely not certain or guaranteed in any way) intention to be a candidate individual customer not regarded as a conventional utility, but with a pragmatic demand for the basic value available from relatively near-term SMR deployment. SMRs could be very attractive because of CAP's need for small, distributed sources of power (35 to $100 \mathrm{MW}$ or larger), their concern that their current power source may be about to confront dramatic price increases, and their reluctance to rely on natural gas as an exclusive generation source. While CAP does not wish to own/operate any nuclear plant outright but rather use presumably some form of a PPA in order to avoid having to hire in-house nuclear operators, they also need a firm price, something no vendor can offer at present within the current forecast deployment time frame of interest. Beyond this report, it would be valuable for INL and CAP begin developing the framework for a business/technology plan in more detail that compares SMRs to CAP's other generation investment alternatives. This idea can be pursued in parallel to, but also completely independent of, follow-up to the current Federal Government (US DOE) solicitation on SMRs (as discussed in “Idea \#2”).

In addition, or perhaps rather as an extension of this idea, a zero-cost but highly positive public expression of interest from CAP (perhaps in conjunction with its partners involved in the Navajo plant) could help boost DOE's chances of securing full SMR Program funding over the five year-funding horizon. Nominally established at $\$ 450$ Million, Congress has already provided only \$67 Million in FY2012 and while the House of Representatives Energy Appropriations Subcommittee recently indicated support at \$115 Million for the coming year, the current "nominal" number is still \$67 Million (House and Senate conferees have yet to reconcile their opposing funding views with that of each other and also with that of the Obama Administration, as of the time of this writing).

"Idea \#2": Two of the serious vendor teams bidding for the current SMR Federal procurement (B\&W, with TVA, and Westinghouse, with Ameren) publicly have announced major utility partners on their teams*. CAP should choose an appropriate way to team with or both of them (if they are successful in winning an award) at any one of several levels of engagement, ranging from "interested observer" status to intimate collaboration, safeguarded by appropriate non-disclosure agreements) regarding proprietary information. Ultimately aimed at commercial applications, early SMR deployment efforts (whether sited at TVA or Ameren or elsewhere) could be a valuable source of information for other prospective investors (owners) such as CAP. In this context, it should be noted that Ameren has publicly announced that it "will apply" for an SMR license at its Callaway plant location, and that TVA has said that it expects a Power Purchase Agreement with DOE to be part of its SMR deployment approach. 
$\Gamma^{*}=$ Energy Northwest, while not yet formally part of the NuScale bid team to the best of our knowledge, has requested that DOE award one of the grants to NuScale. Energy Northwest and some public and investor-owned utilities assessed small modular reactors over two years as part of its long-term planning, according to a publicly released letter to DOE from Mark Reddemann, the CEO of Energy Northwest.]

A variation of this notion would be to team with a major utility with nuclear interests who (unlike TVA and/or Ameren) has not yet formally teamed (at least publicly to date) with any SMR vendor and therefore remain in a relatively presumably neutral analysis position at present (example: MidAmerican, even though they have representation on the NuScale Board). While a competitive approach for soliciting* an SMR from reputable vendors would be the standard approach for CAP in concert with its investment partners, early collaboration with a "motivated" utility could have substantial benefit. Another type of teaming would be for CAP to join the current non-profit entity based in the Southwestern United States (the STARS Alliance) involved in group purchases of nuclear-related goods and services, with an emphasis on those procurements related to SMRs.

$\left[^{*}=\right.$ In this context it is important to note that the specific SMR vendor and its related design team must be in place prior to submitting a license application for formal NRC review from a utility, which in turn is years before construction begins.]

Yet another variation of this idea is for CAP to team with a pro-active SMR-advocate-type utility such as TVA in a appropriate confidential fashion to learn lessons from the "SMR cash flow model" that they are apparently internally developing (reference: INSIDE ENERGY, 7/5/10, page 7). Whether this model has been explicitly incorporated in the mPower team proposal for the DOE SMR Program is not publicly known, although the chances are that some version of it will be part of the business plan section of that proposal. It is of course also not clear if CAP would ever gain direct access to this model, but by working together some useful information may be obtainable.

"Idea \#3": Since "up-front" and "all-in" NRC-related certification and license costs in excess of $\$ 100 \mathrm{M}$ (see discussion below on licensing issues) are recognized as a serious constraint on SMR deployment, with a somewhat unclear DOE budget commitment available to support this level of spending in the current solicitation arrangement*, minimizing the need for these funds while maintaining adequate regulatory oversight is essential to expedite deployment. Partial or full recovery of such costs however could be viewed by CAP (perhaps through teaming with other utilities) as a precondition for serious investment, and should be a high priority for discussion with candidate vendors who would have a strong interest in expediting their first SMR deployed unit.

[*Note: The current DOE SMR solicitation recognizes the importance of minimizing these up-front costs, and therefore work under this program could provide substantial relief for this constraint, but until awards are made and work scopes fully defined, the extent of this relief will not be clearly defined. Follow-up monitoring of this effort is recommended as a priority for CAP. In the interim, it should be noted that NRC discussions with some of the 
leading candidate SMR vendors have been underway for some time, preceding the issuance of the formal DOE SMR solicitation (reference: INSIDE NRC, 2/2/12).]

"Idea \#4": To support commercial business plans involving SMR deployment, CAP could directly enlist, as a strategic partner, State Government support having the following characteristics: a program educated workforce development in a high unemployment area with a talent base oriented towards engineering and manufacturing skills; an Economic Development Department with available funding allowing it to pro-actively participate financially in SMR deployment; and the current regulatory inclusion of nuclear power generation as within the formal definition of a Renewable Portfolio Standard (RPS) of certain jurisdictions (e.g. may be the case for the State of Arizona).

Certain State Governments with a current (or prior-legacy-type) orientation towards SMR opportunities may are viewed as more likely for this type of collaboration; the most obvious one at present is South Carolina, which has a well-defined entity in place (NuHub, an initiative underwritten by the nonprofit organization EngenuitySC) that is part of the team of two of the serious bidders on the Federal Government solicitation (NuScale and Holtec). NuHub claims to be offering in-kind services such as university technical collaboration and workforce development approaches. Discussion with Arizona officials may quickly establish whether support of this sort would be realistic and of interest to CAP, and whether the South Carolina arrangement can be emulated in an Arizona context.

Closely related to this point, on June 20 there is planned a privately sponsored "Nuclear Energy Future Peer Exchange" meeting in Washington to facilitate discussion of policy development for nuclear technology, with an emphasis on how to leverage nuclear support and expertise in and across communities. Attendees will discuss current initiatives underway in DOE, including outreach and the role for local communities and other stakeholders. Meeting sessions will also consider how the Blue Ribbon Commission on America's Nuclear Future's (BRC) final recommendations may be implemented, as well as the future of nuclear power in energy communities. The timing of the meeting is pertinent given the recent release of the Blue Ribbon Commission's final report and the support for small-modular reactor (SMR) development that exists at the local and federal level. Participants will focus on the potential role for local governments in siting new nuclear power, storage and waste facilities; to support DOE's nuclear R\&D efforts; and to help educate and develop a nuclear workforce for the future.

"Idea \#5": Regardless of the SMR solicitation outcome, it is possible that a foreign SMR vendor* may apply for US design certification using its own internal funding resources in an effort to get a jump on the SMR market over US-based vendors. CAP should actively monitor this possibility since the US NRC is available to consider any qualified applicant at any time, and an aggressive foreign vendor may propose a deployment within CAP's presumed investment time frame. To a certain extent this idea was suggested by several stakeholders based on skepticism that North American SMR advocates (even under the conditions provided by the DOE in its solicitation) would be sufficiently motivated in the near- to mid-term to take the necessary aggressive steps to deploy SMRs and thus provide sufficient incentive to domestic vendors. This viewpoint implies also that the domestic SMR 
effort has a limited "window" of opportunity, thus requiring accelerated attention if U.S.based vendors are not to lose a substantial share of the overseas SMR market.

[* = see Attachment F for background information on the South Korean SMR]

As part of this idea, CAP could become involved on an observer status with a reputable overseas SMR developer teamed with an overseas-based utility, but using an American SMR vendor. For appropriate markets in nations sympathetic to the U.S. approach to nuclear deployment, this is an ideal SMR application and would be boosted via availability of preferential ExIm Bank financing terms coupled with appropriate due diligence from reputable EPC firms and DOE National Laboratory services provided on a "technology neutral" basis. While ExIm has previously provided Westinghouse with assistance in China regarding conventional reactor sales, target areas of more likely near-term specific interest were identified by stakeholders as including Eastern Europe (emphasis on CEZ service territory where ExIm has had prior involvement with the Temelin plant), Chile (although recent informal communication indicates a reduced level of enthusiasm for nuclear investments in Chile), Vietnam, and northern Europe (via possible participation of Vattenfall). 


\section{Summary Of Stakeholder Responses: Additional Key Observations (includes major INL observations)}

- Any interested utility-type stakeholder such as CAP must examine the business case and performance schedule in detail of the winning teams for the DOE SMR solicitation (presumably after July 21 when award announcements are scheduled to be made, i.e. 60 days after the due date for the proposals)*. The business terms for joining these teams or at a minimum receiving full information from them as to their scheduled milestones and cost targets need to be carefully negotiated. For example, should the mPower team be selected, the role of Bechtel in the scheduling of the deployment of the initial mPower SMR unit or units will be critical, and their expertise should be accessed to the maximum extent practical once an award announcement is made.

[*= see Attachment E regarding the published DOE SMR solicitation formal decision criteria]

- DOE's decision on the two SMR awardees is widely viewed as a genuinely competitive event, and therefore may be viewed as a reasonably accurate determination of the two leading domestic SMR vendor teams*. In practical terms this means that any "handicapping" of prospective winners before the DOE decision is premature and not particularly helpful to CAP, especially in light of the multi-year actual deployment time needed for SMRs versus the July DOE announcement date. Further, although not being awarded formal scoring points, DOE does plan to include "other selection factors" (e.g. "early deployment") in their award decision, and DOE's judgment of these factors will be important to monitor, to the extent that this information becomes available.

$\Gamma^{*}=$ edited descriptions of the designs of two of the presumed candidate teams are provided in Attachment G]

It should be noted that a minority viewpoint regarding the solicitation outcome is that more than two awards might be made despite the formal intentions of DOE (these views are not supported by DOE in any way at present). In this opinion, the intention of one announced team (Holtec, as noted in an article within the 5/24/12 version of World Nuclear News) to publicly announced a "money-back offer" as part of its proposal (i.e. "we will refund every dollar of public's money spent on our staff if we fail to secure the license of our SMR-160 reactor") will make it difficult to refuse this proposal arrangement. As another variation on this minority viewpoint, it is possible that three of the existing four proposals may be too close in the final scoring to deny an award to one of those. Further views as to the relative competitive positions of the four leading bidders can be found elsewhere in reputable articles within the published industry literature (e.g. see pp. $4-5$ of the 4/30/12 issue of INSIDE ENERGY). 
- Regarding cost comparisons with natural gas for investment purposes, interviewees generally felt that gas has to reach the \$6-8 (per million BTU) range for SMR deployment to be cost competitive. If it does, power from new nuclear units (regardless of unit size) in the 2019 time frame will seem "somewhat expensive" but could through the life of the plant be ultimately profitable when viewed on a life-cycle basis. Regarding baseload nuclear investments, while most stakeholders did not make explicit predictions, some indicated that the new nuclear units in the Southeastern U.S. recently underway will initiate a nuclear "Wave 1" investment profile that may be followed by owners such as Progress Energy and possibly Dominion. This "Wave 2" in general may begin in the 2016-2017 timeframe and involve 4 or 5 more large LWR unit builds (i.e. baseload plants as versus SMRs).

- While all predictions of gas prices are subject to much contention, and interviewees were not in any agreements as to their relative forecasts, some stakeholders felt that the "internationalization" of natural gas on the global market will be a consequence of US exports due to excess supply based on new gas recovery techniques, which could well push gas beyond the current \$2 level to something approaching the current international level $(\$ 11) *$ by the time SMRs are available for deployment (these views were supported by a Bloomberg analyst at an April 2012 SMR meeting, where he forecast $\$ 11$ gas within 7 years). Another complicating factor is the possibility of somewhat unexpected other domestic market growth for gas use (resulting in more accelerated price growth than currently forecast) such as gas-to-diesel conversion innovations (as cited by Richard Meserve at the June 12, 2012 NEAC meeting). Further skepticism of the likelihood of continued very low gas prices can be found in the public statements of various utility executives (see for example comments as noted in pp.7-8 of the 3/12/12 issue of INSIDE ENERGY). By comparison, Ali Azad of the mPower SMR bid team can be paraphrased from his remarks at a recent SMR conference as saying that "if gas stays at $\$ 2$, we will never be able to sell any of these SMRs". On the other hand, the apparent movement to retire many older coal plants due to the upcoming EPA regulations was perceived by some interviewees as a greater incentive for SMR deployment than forecasted gas price volatility.

[*=It has been reported that TEPCO is currently paying as much as $\$ 15$ on the spot market due to its need for primary energy as a consequence of the Fukushima event.]

- Currently, in no case has an overnight cost for SMR been estimated at below $\$ 4,000 / \mathrm{kw}$ by a credible source (i.e. the MIT study of 2007). A more recent (end-2011) University of Chicago study indicates an estimate of about $\$ 4,700 / \mathrm{kw}$ for a six-module unit of $100 \mathrm{MW}$ modules. Most stakeholders and observers suggest higher numbers, some entering into the $\$ 5,000$ - $\$ 6,000$ range. However, the notion of "n th-of-a-kind" units in a "mass production" scenario (e.g. in the University of Chicago, an assumption of on e unit per month) holds the potential for substantial cost reductions, although these reductions cannot be precisely estimated at this point*; the DOE solicitation requires the winning bid teams to provide such estimates. As reported in the 12/01/11 Platts publication "Nuclear News Flashes", the University of Chicago study, for the "post-2020 timeframe", estimates levelized costs for combined cycle gas plants as being in the $\$ 60$ to $\$ 80$ per 
MwH range, assuming gas available between \$5.45 and \$7.98 per Million BTU. SMRprovided electricity is estimated at $\$ 80$ "after significant learning" and approximately $\$ 61$ "with full learning" i.e. after 54 modules have been manufactured. Various stakeholder interviewees, by and large, could or would not agree on a consistent range for projected levelized SMR costs, but some felt that overnight costs in the $\$ 4,000 / \mathrm{kw}$ range would be very attractive to overseas markets, if they became realistic. For contrast, the general consensus at a recent NEAC meeting was that only when designs are relatively finalized could one attempt a defensible estimate. Also, most interviewees felt that while levelized costs were generally viewed as a better comparative measure than overnight costs, comparative overnight costs were more meaningful at this relatively early stage of SMR studies.

[*= Some commonly used measures to gauge the effect of " $n$ th-of-a-kind" production which can be considered within the more umbrella notion of incremental investments related to SMRs have been cited as: cost savings for multiple units at the same site; cost savings for additional units built in series; the effect of shorter construction time on interest rates; cost savings from the better fit of new capacity to demand growth; and cost savings from the learning curve associated with continued simplification of a basic design over an extended time frame]

- Regarding economic comparisons with renewable energy sources, it is important to note that the capacity factor of nuclear plants (presumably SMRs would operate similarly in this regard compared to current large nuclear units) on the order of $90 \%$ compares favorably with that of renewables (wind and solar) which are often perceived to have capacity factors in the 30\% - 35\% range. For generating a total comparable MWh output over a total power plant lifespan, DOE does indicate a substantial edge to nuclear in this context. While no interviewees took issue to this point in general, and some emphasized it in discussions, a full formal economic comparative analysis was not part of this exercise.

- In terms of the absolute volume of capital needed for SMR investments, less total capital needs as well as shorter loan terms for SMRs were viewed as a critical prospective advantage, as was presumed SMR location closer to customer loads. In general it was also suggested that SMRs have an advantage in the market in that they can be described in some cases as an additional "uprate" option for utility generators, i.e. "when you run out of power uprate options, come to us for an SMR."

On a somewhat related point, SMR financing is at present apparently not well defined in the context of qualifying for any targeted or special financing mechanisms such as loan guarantees, production tax credits, or standby insurance provisions. At an SMR meeting in late April 2012, Steve Byrne, president of Generation and COO of SCE\&G, cited these items as needing reconsideration in the specific context of upcoming SMR financing proposals. The Secretary of Energy Advisory Board (SEAB), according to DOE at the June 2012 NEAC meeting, is examining the "full range" of possibilities for SMRs to engage with these mechanisms, with a SEAB report due sometime in Fall 2012. Also, the University of Chicago SMR study cited elsewhere in this report contains a reasonably 
complete discussion of some of the major aspects of these mechanisms as they may apply to SMRs.

- The deployment timeframe for SMRs is viewed to range between 7 and 10 years from now, i.e. 2019 - 2022. The 10-year estimate is partially based on the formal target requirement milestone used in the DOE SMR solicitation (although DOE acknowledges that shorter time frames may be possible). The 7-year estimate is based on the views of some individual stakeholders, although it is widely acknowledged as optimistic by almost all; it is somewhat supplemented by apparent informal discussions between some vendors and the NRC that the 5 year timetable for design completion in the solicitation, if successfully implemented by the winning vendor teams, could be followed by a construction period of as little as 2 years for the first unit (at least one vendor, Westinghouse, has claimed a possible construction interval of as little as 18 months, although this does not seem to be formally documented at this point and is viewed by many with skepticism). This is not an NRC view but is based on informal discussions with knowledgeable individuals involved. As part of the mPower team, Bechtel is investigating a construction management simulator package assuming a three year SMR full construction cycle (which perhaps may assume non-safety-related advance site preparation time being already completed). Proceeding sequentially through the "routine" steps associated with design certification, ESP, COL application review and license issuance, and construction and startup used in earlier years for nuclear plant deployment approvals was uniformly believed by interviewees as not going to be sufficient for either investment interest or political support and therefore advocates of SMRs have an advantage (by comparison to conventional nuclear plants) to the extent that the DOE SMR solicitation offers ways to expedite this design-license-build process.

Related closely to the above as relevant to CAP's presumed planning horizon, it should be noted that possible additional "waiver" time (or however the equivalent in formal regulatory terms might be defined) from the EPA or State authorities regarding the new pending coal plant emission rules was cited (by more than one interviewee) as a possible "constraint relaxant" to the above optimistic 7-year deployment estimate (if comparing timing requirements for SMR deployment versus coal plant retrofit requirements). In this context, the recently reported early draft version of a bill being considered by Senators Pryor and Alexander might extend compliance to 2019 (reference: INSIDE ENERGY 6/18/12 issue, pp.3-4), and EPRI has apparently asked for consideration to extend some deadlines as far as 2020 (reference: INSIDE ENERGY 5/31/12 issue).

Further to the above, it has been noted by some interviewees that either [a] the pending entry of a serious overseas SMR (most likely through the Korean effort) into the international (although quite possible not including the U.S. portion) marketplace, or [b] the natural competitive dynamic associated with two winning teams viewing each other's progress as the five-year DOE SMR program proceeds, could result in the expediting of a domestic SMR product. Should this happen, the five-year design interval currently called for in the DOE program could be truncated to perhaps four years, allowing another "relaxant" factor into the judgment regarding SMR availability in time to meet CAP's investment requirements. 
- In response to questions regarding general SMR investor appeal, separate and distinct from cost and schedule considerations, and therefore primarily regarding performance-type matters, the overall broad-based domestic market appeal of SMRs was endorsed with respect to factors such as continued perceived delays in coal plant orders. Technology-based features of SMRs needing further research were identified as (1) I\&C requirements for multiple SMR units operating together and (2) improving BOP (Balance of Plant) features of SMRs by comparison to conventional large nuclear plants (therefore provide substantial cost savings). The presumed advantage of reduced Emergency Planning Zone (EPZ) "footprints" was viewed as an important advantage over more conventional (larger) nuclear plants. Another prospective major advantage cited was proximity to load, and another was the prospect of minimal water use requirements. Regardless of specific SMR design characteristics, public policy issues that are regarded as major constraints to increase major customer and investor confidence in SMRs possible will include [1] pending greenhouse gas control legislation and regulation (however and whenever it should be implemented); [2] generic decisions regarding evacuation zone extent and security staff requirements (overall administrative staffing requirements are an important factor in calculating comparative SMR fixed costs); [3] PUC-type contentions that may relate primarily to local siting (land use) concerns; and [4] licensing and insurance costs for multi-module units.

- Relatively recent public statements by major outside private sector investors (e.g. Boone Pickens and Bill Gates) in favor of innovative new nuclear deployment may be an additional motivator for accelerated interest in modular configurations. Per a recent NEAC public meeting, interest in modular design and installation may be part of ongoing NEAC recommendations, and as a result NEAC members may constitute an additional set of important stakeholders. External NEAC members and advisors may provide additional supporting information leading to a continuation of support for a more substantial Federal Government DOE SMR funding plan. However, since this is subject to the annual Congressional appropriations process (as cited elsewhere in this report) and since Congress has not yet indicated a full level of support for SMR monies in FY13 consistent with the intention of DOE over a five-year period, this dynamic must be monitored.

Related to this point regarding formal Government interest in more closely examining the potential for SMRs, the Secretary of Energy Advisory Board (SEAB, a separate advisory entity not related directly to NEAC) is apparently beginning a Subcommittee effort to examine the manufacturing aspect of SMRs in detail, and it is expected that these finding may carry substantial weight in the continuing economic assessments of the real potential for SMR deployment.

- The current state of the banking-financial sector, coupled with the publicly cited high first costs of large nuclear units, indicates with some stakeholders that conventional (i.e. non-SMR) nuclear investments will have limited to no market appeal in the foreseeable horizon with the possible exception of sites in a few highly-regulated States. Put another way, SMRs are appealing to the marketplace to a large extent in current times because the investment hurdle rate is much lower compared to that for larger reactors. 
- As a general observation consistently made by interviewees, any SMR consortium must include at least a vendor, a utility, a source of substantial financial reserves for regulatory approval fees*, and the involvement EPC stakeholders. DOE National Lab resources, although not contractually essential, were generally viewed as worthwhile (to reduce engineering and construction risks involving critical subsystem performance as well as final installed costs) within the proper contractual framework. This observation was made independent of the final outcome of the DOE SMR solicitation process now underway.

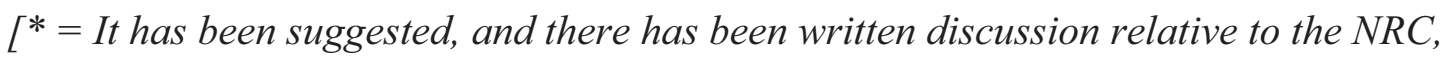
that regulatory fees be based on the size of the SMR; this item is not trivial and would be relevant is assembling a total cost profile for any SMR investment; there is an expanded discussion of estimated SMR licensing costs later in this report]

- The Electric Power Research Institute (EPRI) is undertaking a new "SMR Utility Requirement Program" focused on anticipating owner-operator requirements unique to SMRs. These will presumably include both research into SMR-specific features as well as common operator problem studies. Program details are closely held due to EPRI confidentiality policies that often largely restrict specific information to member utilities, but some of this information could become available to CAP if it were to enter into an information-sharing arrangement with an EPRI member utility that was endorsed by EPRI for this purpose. This effort is cited in this report as another indication of the varied types of work now ongoing relative to SMR assessments.

- The notion of using DOE sites for an "energy park" concept that could include SMRs needs to be noted in the context of this report. The Savannah River DOE site in South Carolina has been mentioned as a candidate for such as deployment (NuScale and Holtec, two of the bid teams for the DOE solicitation, were mentioned earlier in this report regarding their cooperative activities in South Carolina, which include siting and other collaborations with Savannah River). Specific to Arizona, the June 7, 2012 issue of NUCLEAR ENERGY INSIDER quotes a water resources consultant (Mark Lewis) regarding his suggestion for an Arizona-based "energy park" that might include some sort of hybrid configuration of renewable energy generation and SMRs. The article goes on to mention the establishment of an Energy Park Authority in 2010 by Arizona Governor Jan Brewer, but implementation plans were not provided. CAP may wish to investigate whether this generic "energy park" notion could be applicable to its deployment plans for at least some if its future investments, if these investments would involve decentralized sources of generation that could include SMRs in some configuration.

- There is an "omnibus" Memorandum of Understanding (MOU) between DOE and the Department of Defense (DOD) regarding collaborative efforts on energy issues that includes examining SMR feasibility from a DOD perspective. At this point it is not clear how relevant the DOD interest level is compared to CAP's apparent investment timelines; however, should DOD assign a high priority to SMR deployment in the near term, the feasibility of SMRs as a CAP option could improve, and therefore the progress within this MOU umbrella agreement bears monitoring. 
- In general, interviewees did not express strong interest in estimating overall SMR economic impacts at this point in time, but there is a recent economic analysis available from the Energy Policy Institute (Boise State University) that estimates the total economic impacts of SMR manufacturing, construction, and operation for a representative $100 \mathrm{MW}$ SMR unit. A prototypical $100 \mathrm{MW}$ SMR costing $\$ 500$ million to manufacture and install on-site is estimated to create (among other benefits) nearly 7,000 jobs and generate $\$ 1.3$ billion in sales, $\$ 404$ million in earnings (payroll), and $\$ 35$ million in indirect business taxes. The annual operation of each 100 MW SMR unit is estimated to create about 375 jobs and generate \$107 million in sales, \$27 million in earnings (payroll), and $\$ 9$ million in indirect business taxes. This information is included both for the sake of completeness and because some interviewees felt in general that the overall economic profile of SMRs in this context would be a useful institutional consideration. 


\section{Recommended "Go-Forward" Steps for CAP}

- Implement "Idea \#1" and "Idea \#2" above, via direct participation in a continued assessment of business and technology viability of SMR alternatives; this would include tracking of all cost improvement estimates and scheduled deployment plans; it would also include the initiation (and continuance) of discussions with various cooperatives and other interested stakeholders (such as the Arkansas Electric Cooperative, which has been mentioned as having interests in SMR progress).

- Implement "Idea \#5" above through direct discussions with representatives of CEZ, Vattenfall, the Chilean national utility, and ExIm regarding a business and technology verification plan in concert with other key stakeholders in each region. Place particular emphasis on engaging with KAERI and its teammates, partly to determine the potential for accelerated deployment planning on the part of domestic U.S. SMR vendors in light of the perceived overseas competition, and partly to determine if KAERI plans to apply for U.S. NRC certification within the investment time horizon of interest to CAP.

- Regarding "Idea \#4" above, follow-up on suggestions made for EconomicDevelopment-related stakeholders to contact within the State of Arizona in a manner parallel to that underway in South Carolina, to the extent that such activity would help advance CAP's deployment objectives for SMRs. In this context, CAP should also follow up any relevant offshoots from the June 20 meeting described above. 


\section{SMR Licensing Issues}

\section{(A) SMR Licensing Issues: Overview}

The US Nuclear Regulatory Commission (NRC) ensures public safety in matters of commercial nuclear energy. Historically, the NRC licensing structure for nuclear power plants focused on safe operation of large light water reactors (LWRs). Recent proposals for small modular reactors (SMR) have triggered an evaluation of the existing nuclear regulatory framework to determine how it can be adapted and updated for new designs. The review resulted in identification of several important issues regarding the licensing of modular SMR technology. Many of these issues were listed in the 2010 NRC document SECY-10-0034, "Potential Policy, Licensing, and Key Technical Issues for Small Modular Nuclear Reactor Designs." Since the issuance of this document, there have been a number of subsequent SECY papers released by the NRC (such as SECY 11-152 on emergency planning and SECY 11-0181 on decommissioning funding) that touched to some extent upon SECY 10-0034 issues and perhaps offered a bit more insight and discussion. However, none of the NRC releases to date have yet appreciably altered the key issue table contained in SECY 10-0034.

Because of the nature of SMR design concepts, these reactors will depart from the current LWR fleet in terms of size, moderator, coolant, fuel design, projected operational parameters and safety review approaches. Modification to NRC policies and guidance will be necessary to accommodate innovative features. Major regulatory issues at this time include;

1. Implementation of Defense-in-Depth (DID): This longstanding NRC philosophy emphasizes redundancy, reliability, and independence in important plant safety functions. It is an approach that is applied to all nuclear safety decisions. Although some SMRs may employ traditional approaches to provide DID, nonLWR SMR designers may propose different means to address issues like key equipment redundancy and radiological release containment. Uncertainty exists in the capabilities and robustness of new approaches. Reliability of key SMR structures, systems, and components (SSCs) must be verified and validated before a license will be issued.

2. Source term, dose calculation, and siting: Accident release radiological source terms are computed and used to assess the effectiveness of containment function capabilities and mitigation features at a nuclear plant. It is also used to determine site suitability, emergency planning requirements, and compliance with regulations. Because there will be differences in inherent and passive safety features, the basis for establishing SMR source terms and accidental release dose will differ from that presumed for prior LWR installations. Methodologies to develop bounding source terms must be established for single and multi-module facilities and adapted to include consideration of local population density, proximity to external hazards, seismology, and meteorology, in order to properly inform siting decisions. 
3. Operator staffing for multi-module SMRs: Current regulations do not address the possibility of more than two reactors being controlled from one control room. SMR designers are considering staffing compliments (including reactor operators) below what is currently required. Use of smaller crew size will be design dependent and must be justified for a worst-case array of power maneuvers, refueling and maintenance activities, and accident conditions.

4. Operational programs: Unique SMR features may challenge the development of programs such as in-service inspection and testing. New technologies often require new operational programs that have yet to be demonstrated as adequate. Adding modules at a facility where earlier installed modules operate raise questions about the stability of shared SSCs and operational programs during and after construction.

5. Security and safeguards: SMRs are expected to resolve many security concerns through design innovation. Reactor designers and license applicants will have to develop adequate emergency preparedness and integrate physical security protection, cyber security protection, and material control and accounting measures into functional parameters. Vulnerability to aircraft impact must also be addressed. Rigorous security assessments must confirm adequate levels of protection.

6. Offsite emergency planning: Emergency preparedness is an essential element of DID. In the unlikely event of an unplanned offsite radiological release, reasonable assurance must be provided that the public will be protected. A plume exposure pathway emergency planning zone (EPZ) of 10 miles and an ingestion pathway EPZ of 50 miles has typically been required for large LWRs. The smaller size, lower power density, lower probability of severe accident, slower accident progression, and smaller offsite consequence per module suggest that SMRs are capable of supporting a reduced EPZ but the reduction remains to be confirmed in terms of design, safety margins, and site factors. This issue is particularly significant concerning a first-of-a-kind deployment.*

*Note: very recently, a proposed rulemaking was released with respect to modifications of zone distances; the technical basis for the revised rulemaking has yet to be fully accepted by regulators.

\section{(B) Applicant Responsibilities Regarding Issuance of an NRC License}

The NRC issues a license to applicants for building and operating nuclear facilities. According to 10CFR50.33, the applicant may be an individual, partnership, corporation, unincorporated association, newly-formed entity, or an agent representing another person. A person that is a citizen, national, or agent of a foreign country, or any corporation, or other entity owned, controlled, or dominated by an alien, a foreign corporation, or a foreign government is prohibited from holding a NRC license (10CFR50.38).

The applicant is responsible for supplying accurate and timely information in the permit application. That application must include information about the parties sponsoring the 
applicant and be of sufficient detail to demonstrate financial qualifications to carry out licensed activities. The applicant must identify the source of funds which reasonably assure coverage of facility construction costs, operational costs for the period of the license, facility decommissioning, and related fuel cycle costs. The legal and financial relationship of the applicant with its stockholders or owners must be defined as well as the sponsors' financial ability to meet any contractual obligation which the applicant may incur. This includes maintaining insurance and indemnifying off-site liability claims of personal injury and property damage (10CFR140) as well as on-site property damage insurance to help cover cleanup costs after an accident (10CFR50.54(w)).

An NRC license can be transferred to another applicant. Transfer can be done in response to a variety of business strategies that include changes in partnership structure, mergers, formation of a parent holding company, or the sale of an entire power unit to realize economy of scale. Direct transfers involve transfer of ownership and operating authority from one entity to another; a plant sale is an example of a direct transfer. The NRC test of a proposed direct transfer focuses on determining whether the proposed new owner has the technical expertise to continue to run the plant safely and possesses the financial qualifications to both operate and decommission the plant. Indirect transfers generally involve transfer of ownership of the license rather than the facility; this might occur when a new parent holding company is formed above the licensee. All license transfers are subject to NRC approval.

\section{(C) NRC Licensing Procedures}

Refinement of a licensing framework for multi-module SMR facilities has been identified by the NRC as an issue needing further attention. New nuclear power plants can be licensed under either of two existing regulatory approaches. First is the traditional "twostep" process described in 10CFR50, "Domestic Licensing of Production and Utilization Facilities." This process requires issuance of both a construction permit (CP) and a separate operating license (OL). The second approach is a "one-step" process described in 10CFR52, "Licenses, Certifications, and Approvals for Nuclear Power Plants." This process provides a single combined construction and operating license (COL). Both approaches impose the same requirements, duties and standards on an applicant.

Developing a nuclear power plant license application requires major expenditures of time and resources. It is nominally comprised of 11 parts and supplemented by dozens of topical reports. Topical reports document technical safety topics submitted for NRC review and approval either in advance of or in parallel with an application. Topical reports also document information unsuitable for inclusion in the application itself (e.g., proprietary data, safeguards information) and serve as standard reference for multiple license applications. A modular SMR power plant application would consist of:

- Part 1: General and Administrative Information

- Part 2: Final Safety Analysis Report (FSAR), including the following chapters:

(1) Introduction/Description

(2) Site Characteristics

(3) Design of Structures, Systems and Components

(4) Reactor 
(5) Reactor Coolant and Connecting Systems

(6) Engineered Safety Features

(7) Instrumentation and Controls

(8) Electrical Power

(9) Auxiliary Systems

(10) Steam and Power Conversion Systems

(11) Radioactive Waste Management

(12) Radiation Protection

(13) Conduct of Operations

(14) Verification Programs

(15) Transient and Accident Analysis

(16) Technical Specifications

(17) QA and Reliability Assurance

(18) Human Factors Engineering

(19) Probabilistic Risk Analysis (PRA)

- Part 3: Environmental Report

- Part 4: Technical Specifications

- Part 5: Emergency Plan

- Part 6: Limited Work Authorization (LWA)/Site Redress Plan (if applicable)

- Part 7: Departures/Variances/Exemptions Report

- Part 8: Security Plan

- Part 9: Withheld Information (Proprietary and sensitive, if necessary)

- Part 10:Inspection, Test, Analysis Acceptance Criteria

- Part 11:Enclosures (e.g., documents incorporated by reference)

As mentioned elsewhere in this report, estimates of time ranges to construct an SMR module vary between a very optimistic 18 months and five years (follow-on modules may require less time and financial resources to fabricate); constructing the very first module is likely to exceed the low end of this range. Construction can commence only after NRC authorization has been issued for that specific unit. Therefore, licensing must be considered a major cost and schedule factor in establishing new commercial SMR power generation capacity.

The time and cost required to develop an SMR license application are predicated on many variables. Relevant items include local demographics, soil engineering characteristics, site groundwater regime, potential impacts to area flora and fauna, climatological and seismic influences, potential hazards created by nearby industries, availability of supporting infrastructure like roads, rail, and transmission lines, and the mitigations necessary to ensure safe plant operation using safety information about the selected reactor design.

The sponsor of an SMR facility licensing action should note that the licensing elements of a reactor core are supplied by the reactor design firm. This is in the form of a NRC pre-approved standard design certification (DC). The standard reactor DC, along with all topical reports which satisfactorily analyze and resolve safety matters of the nuclear design, must be compiled with site-specific information and analyzed by the applicant in order to comprehensively assess potential risks to the proposed facility and potential impacts to surrounding environs. This analysis, along with the technical inputs for the 
analysis, must be reviewed and accepted by the NRC. Once a design is accepted for review, no modification to the licensed plant design is allowed without NRC approval.

\section{(D) Available Licensing Approach Options}

The following outlines three available licensing process alternatives that lead to construction and operation of a modular SMR power unit:

1. 10CFR50 Licensing Process (CP/OL) - This approach begins with a CP application (10CFR50.35(b)) that contains site safety information, a complete Environmental Report, final plant design information, and a preliminary plan for operational programs. Once the CP is issued, an OL application is subsequently submitted which describes plant operational programs.

The NRC staff assumes that submittal of a final design at the CP stage of review should sufficiently address policy and technical issues such that no significant design change or construction delay would occur during the OL stage of review. However, this approach contains unpredictability in licensing and attendant financial risks. Because the NRC staff still must evaluate operational and procedural matters during the OL review, a prospect exists that the OL review may lead to unanticipated change. Major retrofit to the facility or programs could adversely affect overall plant schedules and costs. This process allows admission of design contention and opportunities for public hearing right up to the point of OL issuance.

Key review milestones and construction durations for a 10CFR50 licensing review $(\mathrm{CP} / \mathrm{OL})$ can be estimated through consideration of the following steps*:

Milestone

CP application submitted

(with final plant design information)

NRC staff conducts CP review

$\mathrm{CP}$ hearing conducted

$\mathrm{CP}$ issued
Time Increment Cumulative (months)

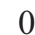

0

48 48

0

60

*Reader please note: at this point in this event sequence, construction will be allowed to start for an SMR that has successfully met all DOE and NRC requirements described in the current DOE SMR solicitation. Otherwise, the standard sequence would continue as follows:

Safety-related construction activities (begin concurrent with OL review) 
NRC staff conducts OL review

OL issued, construction complete

(assume no significant design change)

0

2. 10CFR52 Licensing Process (COL) - This approach begins with a COL application filed under Subpart C, "Combined Licenses," of 10CFR52. The application contains site safety information, a complete environmental review, final plant design information, and a description of operational programs. The COL review process (not including application development) could take up to 5 years.

Once the $\mathrm{COL}$ is issued and all applicable design criteria are demonstrated as met during construction (including completion of the Inspections, Tests, Analysis, and Acceptance Criteria, ITAAC), the licensee would be authorized to load fuel. This alternative greatly reduces both licensing risk and attendant financial risk because the NRC approves final plant design, the site, ITAAC, and the operational and procedural aspects of the application before construction begins. Opportunities for a public hearing after $\mathrm{COL}$ issuance but before loading fuel are limited to contentions that allege ITAAC were not met during construction.

Key review milestones and construction duration for a 10CFR52 licensing review (COL) can be estimated through consideration of the following steps*:

Milestone

COL application submitted

NRC staff conducts COL review

COL hearing conducted

COL issued
Time Increment Cumulative (months)

$\begin{array}{ll}0 & 0 \\ 48 & 48 \\ 12 & 60 \\ 0 & 60\end{array}$

*Reader please note: at this point in this event sequence, construction will be allowed to start for an SMR that has successfully met all DOE and NRC requirements described in the current DOE SMR solicitation. Otherwise, the standard sequence would continue as follows:

Safety-related construction begins

0

60

Construction complete

(assume no significant design change)

3. 10CFR52 Licensing Process (COL) with Early Site Permit (ESP) - This variant starts with an ESP application filed under Subpart A, "Early Site Permits," of 10CFR52. The ESP process is an optional method of packaging safety and environmental information required by 10CFR 52 licensing that can be submitted 
prior to the application. It exists primarily as a means to further manage licensing schedule risk.

An ESP application contains site safety information, an environmental review, plant design parameters, and a demonstration of emergency plan feasibility. ESPs allow an applicant to "bank" a site and offers Limited Work Authorization (LWA) to certain construction of structures and systems important to safe and secure operations. Allowed ESP activities include driving piles, subsurface preparation, and installation of foundations. ESPs are valid for 10-20 yrs with renewals possible.

An ESP helps ensure that key environmental and siting issues are identified and resolved early in the application review process. In this way, assumptions and proposed mitigations can be pre-approved and incorporated into the final safety analysis. Potential impacts to threatened or endanger species, adequacy of supporting infrastructure, effects on area populations, and the hazards posed by local hydrology or adjacent industrial facilities exemplify a few ESP review issues.

Attendant financial risks can also be further reduced by an ESP because the basic plant design envelope, the site, and certain verification criteria and operational and procedural aspects of the application are resolved prior to initiating a full application review. If an ESP is in effect, the submitted COL application references the ESP and expands the discussion to address remaining environmental information, final plant design information, and a description of plant operational programs. Once the COL is issued and all related ITAAC are demonstrated as met during the construction phase, the licensee would be authorized to load fuel.

Key milestones of a "conventional" ESP review (followed by a COL process) can be described in the following steps*:

Milestone

ESP application submitted

NRC staff conducts ESP review

ESP hearing conducted

ESP issued (valid for 10-20 yrs + renewal)

COL application submitted

NRC staff conducts COL review

COL hearing conducted

COL issued

Time Increment Cumulative (months)

0

24

12

0

0

48

12

0
0

96 
*Reader please note: All of the above steps may be satisfied in practice within 60 months by adherence to all DOE and NRC requirements described in the current DOE SMR solicitation. Construction would then begin (assuming no significant design changes).

Evaluations conducted by the INL Next Generation Nuclear Plant (NGNP) project concluded that the best alternative for licensing a commercial HTGR demonstration plant was to submit a COL application under Subpart C of 10CFR52. The recommendation was based on reduction in both licensing schedule risk and attendant financial risk when compared to the 10CFR50 licensing option. Furthermore, the NRC has indicated a preference to use the Part 52 approach. It was noted that an ESP, used in conjunction with a Part $52 \mathrm{COL}$, should be actively considered to resolve siting uncertainties early in the process.

\section{(E) Licensing Costs}

Estimating licensing costs without first understanding the overall SMR project schedule and associated project cost profile is very problematic. Despite this, a best estimate expert judgment model was developed at the INL concerning deployment of a first-of-a-kind HTGR (High Temperature Gas-cooled Reactor) demonstration module.

$\begin{array}{lcccc}\text { Licensing Element } & \text { Subtotal Estimate } & & \text { Cumulative } \\ \text { ESP/COL Application Development } & & \$ 70 \mathrm{M}^{*} & & \$ 70 \mathrm{M} \\ \text { ESP/COL Application Review } & & \$ 110 \mathrm{M}^{* *} & & \$ 180 \mathrm{M} \\ \text { Construction, Testing, and Startup } & & \$ 20 \mathrm{M} & & \$ 200 \mathrm{M}\end{array}$

The applicant pays all costs associated with NRC application review and any subsequent requests for additional information. If the ESP portion of an ESP/COL action were exercised up-front, that would incur roughly $20 \%-30 \%$ of the application development and review cost (i.e., $\$ 35 \mathrm{M}$ to $\$ 55 \mathrm{M}$ ). However, the final ESP cost is greatly influenced by the levels and quality of site information already available. Licensing costs of future (identical) modules installed at the same site would (likely) be a substantial fraction of initial module cost.

*** Notes: The bulk of DOE's portion of their $\$ 225 \mathrm{M}$ cost share under the SMR solicitation terms (assuming two winners, each getting half of the $\$ 450 \mathrm{M}$ assigned to DOE's obligations, and further assuming full Congressional funding over five years) could be devoted to these two costs; the remainder would be spent by DOE on various other tasks such as code development, accident analysis scenarios, business plan reviews of the plans submitted by the vendor teams, NRC liaison, contract management, basic 
R\&D if needed, and/or EIS-related work. It should however be re-emphasized (i.e. discussed above elsewhere in this report) that Congressional appropriations levels may well vary over the years, with the possible consequence of altering how these costs will really be covered, or even if they can be adequately covered, by the joint efforts of the winning teams and DOE.

\section{(F) “Manufacturing License" Notion}

The notion of an SMR "manufacturing license" as an alternative to (or possibly a complement of) a design certification has been advanced in one instance by an independent advocate (reference: January 2012 NUCLEAR NEWS, page 80), and apparently also has generated some interest due to the publication of a "white paper" on this topic by the American Nuclear Society (not inspected as of the date of this report). A large number of applicable regulations would apparently cover the same concerns, and therefore this is an approach that may merit more monitoring as SMR designs evolve and serious vendors approach more detailed negotiations and reviews with the NRC. Absent other information, the NRC seems inclined to rely on the standard approach to licensing at this point in time (other variants such as the use of a "modified exemption process" for some regulatory issues may also be explored over time). 


\section{SMR Siting Considerations}

Given sufficient resources and with the possible exception of certain site seismic hazards, most locations can be mitigated to allow siting a nuclear power plant. However, NRC policy identifies avoidance of major hazards to be preferred over mitigation wherever practicable. To this, a CP or ESP/COL application requires extensive regional and local characterization and data analysis. It also requires safety analysis based on design specifics of the selected SMR (or in the case of an ESP, a plant parameter envelope), preparation of an Environmental Report, and submission of that Report for review. The Environmental Report must address:

- Geology, Seismology and Geotechnical Engineering

○ Seismic Ground Motions

- Global Geohazards

- Site Geotechnical

- Hydrology

○ Water Availability

○ Flooding

- Nearby Hazardous Activities/Facilities that Could Affect Plant Safety

- Extreme Weather Considerations

- Radiological Considerations

- Atmospheric Dispersion - Accident Conditions

- Emergency Planning

- Population

- Ecology

○ Terrestrial

○ Aquatic

- Land Use

- Transmission Corridors and Transportation Routes

- Historic/ Archeological/Cultural Resource Issues

- Water Use

- Land Availability

- Site Constructability Factors

- Potential for Brownfield Contamination Issues

- Features that Could Affect Development of Security Measures and Adequate Security Plans

NRC review of the Environmental Report typically takes two years and is followed by public hearing(s) and release of an Environmental Impact Statement (EIS). Overall, it is reasonable to assume that the ESP portion of a COL application (from start of site characterization work through receipt of an approved ESP) could take up to 5 years. 


\section{Additional SMR Deployment and Investment "Risk" Factors}

There are institutional-level reliability issues regarding modular SMR power plants. The North American Electric Reliability Corp. (NERC) is a not-for-profit independent corporation overseen by the Federal Energy Regulatory Commission (FERC) in the United States and governmental authorities in Canada. NERC works closely with eight regional reliability entities and industry to establish best practices in planning, operations, maintenance, and training in order to improve reliability of the bulk power system.

The NRC maintains authority in all areas concerning safeguarding the public from radiological harm. The NRC mandate to maintain adequate nuclear safety margins is related to overall grid reliability. The following illustrates some aspects of this relationship.

\section{(A) Jurisdiction}

In January 2008, FERC issued Order No. 706 which specified Critical Infrastructure Protection (CIP) Reliability Standards to safeguard critical cyber assets for the bulk electric system. The order applied to certain users, owners, and operators of the bulkpower system and specifically exempted "facilities regulated by the NRC." However, the NRC interpreted their cyber security regulation (10CFR73.54) as requiring the protection of digital systems that, if compromised, could directly or indirectly result in radiological sabotage. The NRC did not consider certain balance of plant SSCs to be within their purview but rather in the scope of the CIP standard. It was later determined that the CIP exemption created a gap between NRC and FERC cyber security requirements at nuclear power stations.

In March 2009, FERC issued Order No. 706-B to address this gap. It clarified the status of balance of plant systems and equipment within a nuclear power plant that are subject to compliance with Order No. 706. The Order further directed NERC to conduct an analysis of nuclear power plant balance of plant systems in order to determine which SSCs should be subject to CIP Reliability Standards. The NRC also clarified that 10CFR73.54 cyber security requirements should be interpreted to apply in balance of plant SSCs that have a nexus to radiological health and safety.

As modular SMR power plants are deployed, the SSCs which support the nuclear island must be evaluated to determine which standards (such cyber security standards) may affect a particular plant system. In a larger sense, the issue of regulatory jurisdiction at a nuclear plant also applies to other (potentially conflicting) mandates that may be imposed by various enforcement agencies such as local, state, and federal environmental protection and worker safety and health authorities. 


\section{(B) Transmission Network}

The electrical transmission network depends on generators to provide power to customer loads, voltage support, and system stability. Most bulk power system problems are not seen by customers due to built-in resilience and redundancy that seek to prevent cascading electrical blackouts. However, when severe a problem on the bulk system does occur, it can cascade through the grid in minutes. Electrical blackouts can be triggered by extreme weather, equipment failure, human error, or some combination that leads to a loss of electricity supply to customers.

The FERC/NERC transmission reliability mission intertwines with the NRC mission for public safety at nuclear power generation stations. One well-established risk to reliable operation of a bulk power system is the sudden shutdown of a large nuclear power plant. Conversely, the loss of offsite power caused by grid failure is a major concern to the safe operation of a nuclear plant.

The current fleet of LWRs depends on the transmission network to provide a source of "preferred power" to station emergency equipment, to support plant operation, and to comply with NRC regulatory requirements. Due to their specification concerning offsite power, large LWR plants are susceptible to voltage variations and frequency swings that may occur in the transmission network. Ensuring safe operations at a large nuclear power station requires the nuclear plant operator to know the status of and the contingencies which can affect the reliability of their offsite power supply. Conversely, the loss of a large capacity power plant can be the largest single contingency faced by the transmission operator. Transmission system operators must be similarly aware of nuclear power plant requirements and employ procedures and standards which meet the nuclear plants' safety requirements.

When a large generator trips, there is an impact to the transmission grid - a loss of real and reactive power support. The transmission grid must react quickly to this loss because if multiple contingencies have already occurred, the grid may not be able to respond in a satisfactory manner. Nuclear plant risk and grid instability are interrelated - the tripping of a plant can cause grid instability and grid instability can result in tripping a plant. When evaluating how the grid affects nuclear power plants, most studies focus on lossof-offsite-power (LOOP) events where all offsite power lines into the plant are temporarily de-energized. A LOOP event typically results in an automatic scram of the plant and actuation of several safety systems. LOOP events represent a measurable fraction of risk based on plant-specific probabilistic risk assessment. Increasing the number of LOOP events directly increases the risk of damaging the plant. Reducing the number of LOOP events reduces the number of challenges to plant safety systems and reduces risk to the plant. Plant trips are also a concern from a nuclear safety perspective because transients are a large contributor to the risk of core melt; increasing the number of plant trips directly increases an LWR plant risk of core melt.

When multiple nuclear power plants are allowed to support the voltage in a given area, the post-trip voltage situation could be made much worse if the trip of one nuclear generating unit causes voltage to drop into the trip range of a second unit, then the second 
would trip; a cascading trip sequence could result. It is critically important for operators to know when they are on the threshold of such a scenario so that provisions can be implemented to ensure this consequence is avoided. FERC has issued standards for offsite power coordination which cover coordination between the nuclear plant and transmission system so that all involved entities are made aware of, plan to, and operate to the needs of the nuclear station as well as distribution customers. Interface agreements must be developed between the nuclear generating plant and the transmission operator to ensure that post-trip voltage is adequate to maintain nuclear licensing requirements. Evolving new reactor designs can incorporate advanced features that reduce or even eliminate the offsite power requirements for accident mitigation and the required bulk power system support. However, a stable bulk power grid is still required to prevent nuclear plant trips. Transmission facilities and system improvements may be necessary to ensure new generators are interconnected with the bulk power system in a reliable manner and that their offsite power requirements are met. In addition to new transmission lines, the reliable integration of these units may require new switching stations, new transformers, and upgrade or replacement of existing circuit breakers to handle the higher short-circuit currents imposed on the system by large nuclear power units.

\section{(C) Transmission System Stability}

The NRC has historically not allowed automatic load-following at nuclear plants due to the affect such a system may exert on the stability of an operating reactor core. Nuclear plants in the US have generally not helped to regulate transmission system frequency with automatic governor control. If new generation capacity comes on line that does not contribute to stable frequency regulation, the bulk power system's response to frequency variations can decline and deleteriously impact reliability.

It is possible that new SMR plants could be designed to be less vulnerable to transmission voltage excursions, enhance transmission system capabilities to regulate system frequency, and provide automatic generation load control. Ideally, advanced nuclear designs should support the grid by regulating voltage, responding to frequency deviations, and supplying dynamic reactive reserve. Requirements for generator voltage ride through are being developed in some regions for wind plants; these requirements may find an application in forthcoming SMRs.

\section{(D) Refueling \& Availability}

Reactor refueling is a predictable source of disruption to nuclear power generation capability. Refueling outages typically last several weeks at large LWRs. Some SMRs may be designed to operate five or more years without refueling while others could operate on a 1.5-to-3-year refueling cycle. A multiple modular system that requires refueling on a 1.5-to-3-year cycle affords the chance to refuel one module at a time and thereby avoid complete interruption of power supply to the grid.

Another feature the SMRs offer operating utilities is elimination of a single shaft needed to generate power. Modular reactors can be bundled to operate with multiple generators. This makes continued operation of other modules or generators possible in the event of an outage in a single module or generator. Hence, modularity can enhance reliability in 
maintaining power to the grid during single unit refueling, maintenance, or unplanned events.

\section{(E) Liability Coverage: Overview}

Power reactor licensees are required by the Price Anderson Act to obtain the maximum amount of insurance against nuclear related incidents which is available in the insurance market (as of 2011, \$375 million per plant). Any monetary claims that fall within this maximum amount are paid by the insurer(s). The Price-Anderson fund, which is financed by the reactor companies themselves, is then used to make up the difference. Each reactor company is obliged to contribute up to $\$ 111.9$ million per reactor in the event of an accident with claims that exceed the $\$ 375$ million insurance limit. As of 2011, the maximum amount of the fund is approximately $\$ 12.22$ billion $(\$ 111.9 \mathrm{~m}$ for each of 104 reactors) if all of the reactor companies were required to pay their full obligation to the fund. This fund is not paid into unless an accident occurs. However, fund administrators are required to have contingency plans in place to raise funds using loans to the fund, so that claimants may be paid as soon as possible. Actual payments by companies in the event of an accident are capped at $\$ 17.5$ million per year until either a claim has been met, or their maximum individual liability (the $\$ 111.9$ million maximum) has been reached.

If a coverable incident occurs, the NRC is required to submit a report on the cost of it to the courts and to Congress. If claims are likely to exceed the maximum Price-Anderson fund value, then the President is required to submit proposals to Congress. These proposals must detail the costs of the accident, recommend how funds should be raised, and detail plans for full and prompt compensation to those affected. Under the Act, the administrators of the fund have the right to further charge plants if it is needed. If Congress fails to provide for compensation, claims can be made under the Tucker Act (in which the government waives its sovereign immunity) for failure by the federal government to carry out its duty to compensate claimants.

Price-Anderson also covers DOE facilities, private licensees, and their subcontractors. Any payments from the fund for accidents arising at DOE facilities come from the US treasury. The fund size for such installations is set by legislation (also at $\$ 11.6$ billion), rather than being based upon the number of plants contributing to the fund.

Changes to liability terms to accommodate the various sizes and configurations arising from SMR designs are now being considered, but without any definitive rulings as of the time of this report.

\section{(F) Priority Allocation of NRC Resources for SMRs}

Section B-2-4-2 of the University of Chicago study contains a succinct yet well-thoughtout discussion of a topic that can often be overlooked in concerning the feasibility of relatively rapid SMR deployment, but which has been emphasized in several comments 
by our interviewees, namely, the availability of the NRC to promptly execute SMR review, simply due to limited resources and conflicting priorities. The text of that section is worth repeating as follows:

The NRC staff planning process for resolving SMR licensing issues appears to be transparent and methodical, with provision for participation by interested parties. However, a more focused, prioritized, and accelerated process likely will be needed to achieve the goal of a commercial U.S. SMR industry in the 2020 timeframe.

For example, by seeking to address a very broad scope of issues affecting not only SMRs but also other advanced reactors, the NRC staff may not be able to give appropriate attention or priority to those issues of greatest importance to near-term SMR commercialization. In addition, the proposed sequencing of the white papers does not reflect any specific set of regulatory or SMR business priorities. Finally, the NRC staff plans would defer consideration of SMR issues affecting engineering design and economics, such as off-site emergency planning, decommissioning funding, and use of probabilistic risk assessment, until the stage of project specific COLAs. Another key SMR licensing issue, namely, the determination of the need for and value of licensing an SMR manufacturing plant, would be postponed until FY 2013 or later.

The current NRC staff schedule would not permit full resolution of the inventory of SMR licensing issues in a timeframe to support SMR vendor development schedules. For example, both SMR vendors anticipate submitting DC documents to the NRC late in 2013, with the submission of COLAs as early as 2013.

Preparation of NRC staff white papers in FY 2010 or FY 2013 would not provide the needed guidance to the vendors on a timely basis. Thus, meeting the objectives set forth in this strategic business plan will require some combination of an accelerated schedule, and a modified process that ...... will allow for case-by-case exemptions absent new regulations and guidance. 


\section{Attachment A:}

\section{List of Individual Senior Stakeholders Providing Viewpoints on SMRs}

[alphabetically by organization]

- AIG

Robert Percopo, Executive Vice-President, Project Finance

- Bechtel Corporation (Bechtel Financing Services, LLC)

Arthur Pilzer, Vice-President

- BNP Paribas

Timothy Chin, Director, Power \& Energy Project Finance(*)

- C-Change Investments Management

John Preston, Managing Partner

- Citigroup

Andrew Safran, Vice Chairman, Global Banking(*)

- Clean Air Task Force

Mike Fowler, Director, Advanced Technology

- CMEA Capital

Maurice Gunderson, Senior Partner(*)

- Constellation/Unistar

Joseph Turnage, Senior Vice President, Generation Group (recently retired)

- Elmrock Capital

David Elliman, Chairman

[reputedly the only private, individual investor in U.S. commercial nuclear plants]

- ExIm Bank of the United States

James Mahoney, Vice-President, Engineering \& Environment Division(*) 
- First Albany Corporation

George McNamee, Managing Partner, FA Technology Ventures(*)

- Geocapital Securities Inc.

George Fink, Chief Executive Officer(*)

- Goldman Sachs

John Gilbertson, Managing Director(*)

- Idaho Power

Karl Bokenkamp, General Manager, Power Supply Operations \& Planning(*)

- Massachusetts Institute of Technology (MIT)

Richard Lester, Chair, MIT Nuclear Engineering Department

- Morgan Stanley

Caren Byrd, Executive Director, Global Power and Utility Group

- Polaris Venture Partners

Bob Metcalfe, Partner(*)

[recipient of the National Medal of Technology]

- Southern California Edison

Dan Breig, Director of New Project Development(*)

- United States Department of Energy

Matthew Crozat, Program Analyst (SMR Economics)

- Utah Association of Municipal Power Systems (UAMPS)

Douglas Hunter, General Manager(*)

- Verdigris Capital LLC

Andrew Paterson, Principal

$(*)=$ key viewpoints as provided prior to project study period 


\section{Attachment B: \\ IAEA Statement, Summary Description of "SRWOR" ("Small Reactor Without Onsite Refueling"), with minor edits}

What is SRWOR?

SRWOR stands for Small Reactor (of 300 MW(e) or less) without On-site Refuelling.

What are the SRWORs?

SRWORs are reactors designed for infrequent replacement of well-contained fuel cassette(s) in a manner that impedes clandestine diversion of nuclear fuel material Small reactors without on-site refuelling could be:

- Factory fabricated and fuelled transportable reactors; or

- Reactors with a once-at-a-time core refuelling at a site performed by a special team that brings and takes away the core load and refuelling equipment

- Specifically, SRWORs will reduce obligations of the user for spent fuel and waste management

What are the features of SRWORs?

- A key feature could be absence of the refuelling equipment present permanently in the reactor or at the site

- Another key feature is that no fresh or spent fuel is being stored outside vessel at the site during reactor operation

- SRWORs incorporate increased refuelling interval (from 5 to 30 years) consistent with plant economy and considerations of energy security

- Strong reliance on passive safety design options and a potential for simplified operational control (passive load follow operation)

What could be the market for SRWORs?

- Cities in developing countries with small electricity grids and insufficient infrastructure

- Autonomous small settlements

- Power sources for district heating and desalination plants

- Power sources for advanced non-electric applications, such as hydrogen production, coal liquefaction, etc.

- Remote areas in the North with complicated access and high cost of energy from fossil fuel

- Dispersed or remote islands; mountainous areas, etc. 
Why do we consider SRWORs?

- Through adding a certain degree of independence on fuel supplier, SRWORs could, perhaps, secure a motivation for a state to skip the development of the indigenous fuel cycle

- SRWORs may provide an attractive domain for fuel or even NPP leasing

- SRWORs could facilitate implementation of adequate safeguards in a scenario of expanded deployment of nuclear power, through:

- Operation with weld-sealed reactor vessel and remote monitoring,

- Absence of refuelling equipment and fuel storages at the site,

○ Streamlined safeguard missions, etc.

What could be energy systems with SRWORs?

- The proposers of SRWORs often consider them in conjunction with centralized, perhaps, regional fuel cycle centres, probably, operated under an international control:

- When systems with SRWORs and regional fuel cycle centres are added to an overall energy system, this would reduce the degree of worldwide dispersal of enrichment, reprocessing, fuel fabrication and, possibly, waste repository facilities

- An integrated fuel cycle and SRWORs offer the potential for improved management of LWR-SNF - via relatively (compared to LWR-MOX) long sequestration in power-producing SRWORs

What are the design approaches to ensure long-life core operation?

- Reduced core power density

- Burnable absorbers (in thermal reactors)

- High conversion ratio in the core (in fast reactors)

- Refuelling performed without opening the reactor vessel cover (on this way a large-capacity reactor without on-site refuelling might evolve)

SRWORs end at the same or less values of fuel burn-up and irradiation on the structures, although obtained over a longer period than in conventional reactors 
What is the status of SRWORs?

- More than 30 concepts and designs of SRWORs are being developed worldwide; the majority are at a conceptual or a pre-conceptual design stage, but some have reached basic or even detailed design stage

- The targeted dates for prototype deployment range from $\sim 2010$ to $\sim 2030$

What are the R\&D needs for SRWORs?

- Most of SRWORs need validation, testing and demonstration of safety and reliability under long-life core operation, e.g. the available experience of marine reactors is limited by 7-8 years of continuous operation; some SRWORs target 25 years or even longer core lifetime

- In addition to this, technologies of remote refuelling would need to be developed; safety of spent fuel load/reactor transportation should be validated for short cooling periods after operation

- Construction and operation of a prototype plant will be a must for all SRWORs

- An approach to licensing for long-life core operation should be elaborated and established (e.g., based on License-by-Test)

- Economic competitiveness of SRWORs should be proven for anticipated market conditions of certain markets (especially in developing countries)

- Legal, institutional and infrastructure provisions for operation with regional fuel cycle centres should be more defined, i.e. leasing, BOT, BOO, etal 
Attachment C:

International Context ("Developing Country" Interest Level)*

*(compiled from INL and other sources)

Per Alvin Trivelpiece (personal communication), Russian willingness to collaborate on a 300-MW joint design could be facilitated in a manner to accelerate international deployment and certification. Sergei Kiriyenko (FAEA Director) has publicly claimed in interest in providing reactors at all sizes. GA is apparently working on a Russian prismatic concept. In contrast, RosEnergoAtom is reported to have already begin construction of a series of $35 \mathrm{MW}$ reactors for offshore (barge type mounting) for coastal areas, i.e. not having the feature of subsurface protection against terrorists (New Scientist, August 2, 2008). The Nuclear Power Corporation of India is reported to be considering an export version of a 220MW heavy water reactor that produces plutonium and needs multiple refueling, therefore also subject to concern on security grounds (ref: ibid). Argentina and South Korea are also reported to have designs for modular reactors under consideration, and France is reported to have a mature design with an output in the range of $100 \mathrm{MW}$ to $300 \mathrm{MW}$ (ref: ibid).

Approximately forty nations have stated their interest in the acquisition of nuclear energy to meet a significant portion of their growing electricity needs without carbon emissions. The IAEA offers assistance with consultations, expert advice, and networking to the countries with this interest. Barriers to deployment include (1) financing, (2) skilled work force and safety culture, (3) regulatory agency development and skilled inspectors, (4) infrastructure for nuclear and related equipment manufacturing and construction, as well as for heavy component transport, (5) electrical grid capacity and reliability, and (6) legal and administrative frameworks to support a nuclear industry. It is critical to note that the IAEA currently cannot offer financial assistance or incentives for most of what's needed beyond consultation.

Almost all countries requesting assistance are considered to be "developing" (i.e., average per capita income greater than $\$ 10,000)$. Collectively, these countries use $15 \%$ of the world's electricity - but they are projected to grow to a $21 \%$ share by 2030 , far exceeding the energy growth rate of the developed world. If the energy growth of these countries is met with fossil fuels, they will have a considerable impact on greenhouse gas emissions globally. These countries seek proven reactor designs and regulatory models from the developed countries (note: larger "developing" countries (e.g. Egypt) may only be interested in large-size reactor designs and therefore may not be part of this group).

Beyond technology evolution, there would be great value in pilot projects with developing countries to directly address the planning and development of nuclear-related infrastructure, workforce, safety culture, regulatory expertise, legal and policy frameworks, and supply chain. With a successful initiative, more of the developing world would begin nuclear power deployment sooner. Most of the interested countries have stable and cooperative governments that would be appropriate for this initiative. 


\title{
Attachment D: \\ Additional information Regarding International SMR Development
}

\author{
A summary of the IAEA project 1.1.5.5 "Common Technologies and Issues for SMRs" \\ has been updated and now additionally includes a draft of a new report titled \\ "Approaches to Assess Competitiveness of Small and Medium Sized Reactors." This \\ draft is downloadable from the section "Project Publications under Preparation", but the \\ reader is advised that it is still a draft and cannot be referenced as IAEA publication. The \\ overall message of this new report is that small (nuclear power) projects could be \\ competitive in a variety of applications.
}

In particular, the IAEA indicates that:

Small and medium sized reactors (SMRs) may provide an attractive and affordable nuclear power option for many developing countries with small electrical grids, insufficient infrastructure and limited investment capability. Multi-module power plants with SMRs may offer energy production flexibility that energy market deregulation might call for in the future in many countries. SMRs are also of particular interest for co-generation and many advanced future process heat applications. Some SMR designs may reduce obligations of the user for spent fuel and waste management and offer possibly greater non-proliferation assurances to the international community.

The Agency's role is to coordinate efforts of its Member States to facilitate the development of SMRs of various types by taking a systematic approach to the identification and development of key enabling technologies to achieve competitiveness and reliable performance of such reactors, and by addressing common infrastructure issues that could facilitate their deployment. To achieve this goal the Agency continues a regular budget project 1.1.5.4 "Common Technologies and Issues for SMRs".

Several Member States have SMR designs ready for deployment. These include the pressurized heavy water reactors CANDU6 (706 MW(e) net) by AECL in Canada and PHWR-220 and PHWR-540 by NPCIL in India, and they include the $610 \mathrm{MW}(\mathrm{e})$ and $325 \mathrm{MW}(\mathrm{e})$ Chinese pressurized water reactor designs. Recent construction of pressurized heavy water SMRs in India and Romania has been on schedule and on budget.

In Russia, construction of a pilot floating cogeneration plant of $300 \mathrm{MW}(\mathrm{th}) / 70 \mathrm{MW}(\mathrm{e})$ with two water cooled KLT-40S reactors began in June 2006. Its deployment date is 2012. Plant construction is ongoing in line with the schedule. Plans were announced to build five such plants and also two plants with $11 \mathrm{MW}(\mathrm{e})$ $\mathrm{ABV}$ reactors for customers in the Russian Federation.

Several small- and-medium sized water cooled designs are of the integral type with the steam generator, pressurizer and, in some cases, control rod drives housed in the same vessel as the reactor core to eliminate primary system piping, minimizing the scope of possible loss of coolant accidents (LOCA) and reactivity initiated accidents (RIA) .

The Argentinean CAREM (from Spanish: Central ARgentina de Elementos Modulares) reactor is cooled by natural circulation, and has passive safety systems. Argentina plans to construct and operate a small prototype of $27 \mathrm{MW}(\mathrm{e})$ by 2015 , followed by larger projects with higher power ratings of up to $\sim 300$ MW(e). Site preparation activities for the prototype have started at the Atucha site. 


\section{Attachment E:}

\section{Decision Criteria, DOE SMR Solicitation}

\section{Initial Review Criteria}

Prior to a comprehensive merit evaluation, DOE will perform an initial review to determine that (1) the applicant is eligible for an award; (2) the information required by the announcement has been submitted; (3) all mandatory requirements are satisfied; and (4) the proposed project is responsive to the objectives and stated goals of the funding opportunity announcement. Applications that fail to pass the initial review may be eliminated from further consideration.

\section{Merit Review Criteria}

The following evaluation criteria and the associated weighting factors (in parentheses) apply to the objective merit review:

Criterion 1 (40 points). Likelihood of achieving SMR Program objectives Feasibility that the applicant team will achieve NRC approval of the SMR design (nominally $300 \mathrm{MWe}$ or less per unit) and subsequent approval of the associated operating license applications in the timeframes specified.

a. Overall plan to complete design, engineering, testing, and analysis for SMR design and interact with the NRC (pre-application, design certification application, response to additional NRC inquiries, technical reports, etc.) to achieve the design certification of the proposed reactor plant design.

b. Overall plan to complete site licensing requirements and interact with the NRC (pre-application, operating license development, response to additional NRC inquiries, technical reports, etc.) via either 10 CFR Part 50 or Part 52 for the proposed SMR nuclear plant.

c. Current status/demonstrated progress of interaction with the NRC regarding the proposed certification and licensing effort.

d. High-level detail of the proposed design including an evaluation of the design with respect to the SMR design goals identified in Attachment A of the FOA, and including feasibility of successfully achieving the proposed design. Special emphasis will be placed on Part 1 of the Attachment (Safety/Licensing) and specifically on the SMR design's ability to safely withstand natural phenomena hazards and design basis accident scenarios.

e. General discussion of the approach to completing design finalization for the selected SMR design following the certification, including the FOAK engineering required. 
f. General discussion regarding the plant siting approach, and plans to complete permitting, if necessary.

Criterion 2 (20 Points). Potential value of business plan to U.S - The applicants are expected to provide a long-range vision that quantifies the overall strategic value of the SMR deployment to the U.S. economy as both a power provider and a potential technology exporter. Applicant business plans will be evaluated based on the following elements:

a. The extent or degree that government funding provided for certification and licensing activities under the award will be allocated primarily to the U.S.based companies comprising the applicant team or consortia, and that the majority of sub-contracts are awarded to companies located within the continental U.S.

b. Clear evidence of corporate commitment and a schedule of key decision points that will lead to initial project implementation, as well as an indication of longer-term commitment and vision.

c. The existence of additional foreign or domestic utilities or utility consortia who have expressed interest or taken specific action to select the SMR vendor's technology for an energy project within the next decade.

d. Extent or degree to which project funds, particularly government funds, are allocated to U.S. supply chain companies, corporations or subsidiaries for project activities performed in the U.S., including the potential to enhance the capabilities of domestic nuclear suppliers and vendors.

e. Potential for commercial success of the SMR project and follow-on projects to establish sustained support for or create new domestic nuclear suppliers.

Criterion 3 (20 points). Applicant Team Capabilities and Experience, including management capability - Capabilities and qualifications of team entities, project managers, key personnel and subcontractors; and of the adequacy of U.S.-based resources applied by participating organizations as they pertain to successfully accomplishing this project. The applicant team's demonstrated successful experience/past performance, knowledge and understanding of the business requirements for projects of similar size, scope and complexity in achieving project technical success within budget and on time with no significant safety and quality issues. The recency, relevancy and depth of the applicant team's experience and capabilities, together with that of each team member, will be evaluated as it relates to the likely successful performance of this project; this includes an assessment of the likelihood that the experience and capabilities will translate into successful project completion. 
Criterion 4 (20 points). Technical quality of the application and proposed work - This includes the quality of the proposed project management plan, completeness and clarity of the technical application, as well as the adequacy and appropriateness of the following: the proposed methodology or approach; the schedule including sequence of project tasks, principal milestones, and time for each task; planned assignment of responsibilities; and level of resources. The technical quality of the application and project management plan should demonstrate the applicant's knowledge and understanding of the business requirements for the proposed project, merit/realism, feasibility, efficiency, and ability to maximize/achieve the program requirements using available funds, and overall quality.

\section{Other Selection Factors}

The selection official may consider the following program policy factors in the selection process:

a. The extent to which the project principals have proposed acceptable approaches to return value to the Federal Government and the public, as discussed in the Background section, including suitability of these approaches and the feasibility/likelihood of successfully implementing these approaches.

b. Cost/Budget considerations, including reasonableness of the proposed project cost as well as plant cost estimates (both the initial SMR plant as well as nth of a kind plants). The extent to which the project and estimated plant costs are economically competitive with other applications.

c. Extent of industry cost-share (i.e., proposed contributions greater than $50 \%$ ).

d. Extent to which flexibility in the vendor's design will support additional potential missions such as steam for process heat, load-following capability for specific grid applications, waste transmutation, fuel resource extension, or mobile deployment.

e. Extent to which the proposed SMR design, licensing and deployment can be completed prior to 2022 .

These factors, while not indicators of the Application's merit, e.g., technical excellence, applicant's ability, etc., may be essential to the process of selecting the application that, individually or collectively, will best achieve the program objectives. Such factors are often beyond the control of the Applicant. Each Applicant should recognize that some very good applications might not receive an award because they do not fit within a mix of projects that maximizes the probability of achieving the DOE's overall research and development objectives. Therefore, the above factors may be used by the Selection Official to assist in determining which ranked application shall receive DOE funding support. 
Attachment F:

\section{Korean SMART SMR Program}

The SMART (System-integrated Modular Advanced ReacTor) SMR, as described by KAERI (Korean Atomic Energy Research Institute), its primary sponsor entity, is a small nuclear reactor intended for electricity generation and/or seawater desalination. The standard thermal power of $330 \mathrm{MWt}$ (roughly $90 \mathrm{MWe}$, as cited by KAERI) is presumed to be suitable for locations within limited electric grid size. SMART is an integrated pressurized water reactor of which reactor vessel contains major primary components, such as core, steam generators, reactor coolant pumps and a pressurizer.

The standard design of SMART was to be completed at the end of 2010, and the SDA (Standard Design Approval) will be obtained during 2012 from MEST (Ministry of Education, Science and Technology) of Korea, as announced by a senior KAERI executive at a recent industry meeting (apparently meaning full licensing approval sometime in 2013). This would include testing using an Integral Test Loop (ITL) that will be finished by 2012 so that the results of the tests will be applied to prospective design upgrades.

Korea Electric Power Corporation (KEPCO) is reported to have formed a consortium of Korean organizations to support the final design approval by Korean regulators, and also to determine the most appropriate export marketing strategy for the SMART system (KEPCO apparently plans a massive increase of its overseas business). This consortium would pay for initial deployment and receive ownership of the SMART technology in return. KAERI has forecast an operational start date for the first (based domestically in Korea) SMART unit as sometime in 2017, but also forecasts first unit construction to take as long as 50 months, underscoring the challenging nature of this forecast (an earlier pilot version of SMART was suspended in around 2005 due to apparent lack of industry interest at the time). 


\section{Attachment G:}

\section{Illustrative Background Information, SMR Concepts}

The following information is illustrative of two of the major candidate SMR designs. These designs are widely viewed as serious candidates for DOE awards via the current solicitation that is the key part of the DOE SMR Program from CAP's perspective. Awards have not yet been determined as of the date of this report. INL makes no determination of the relative suitability of these designs; this information is illustrative only and is extracted in a slightly edited form largely from information compiled by the firm Ux Consulting; many other sources of information are accessible. Most important to note is that design details may change substantially during the next five years of development under the DOE Program.

As a general overview statement, for the so-called "integral reactor" concept, major reactor systems are inside the reactor vessel, eliminating the need for coolant piping, providing for design simplicity, and also enabling relative ease of fabrication and construction.

\section{(A) mPower SMR Major Design Features}

\section{Integral Reactor Pressure Vessel}

The mPower design employs an integral RPV inclusive of the whole primary coolant loop (see Figure 1). The core shroud and RPV internals provide structural support and cooling flow pathways for a $2 \mathrm{~m}$ diameter $\mathrm{x} 2 \mathrm{~m}$ high squared-cylinder core utilizing standard PWR-type fuel. More specifically, the integral RPV includes:

- Compact steam generator

- Control Rod Drive Mechanisms

- Electrically-driven recirculation pumps

- Pressurizer

The RPV is formed by a $3.6 \mathrm{~m}$ diameter, $23 \mathrm{~m}$ high cylindrically shaped pressure vessel, with the supporting skirt reaching a diameter of approximately $4.5 \mathrm{~m}$. The integral RPV is centralized within reinforced concrete structures based on a relatively small footprint Nuclear Island (NI), and forming the reinforced structures of an underground containment. 
Figure 1. Integral mPower RPV

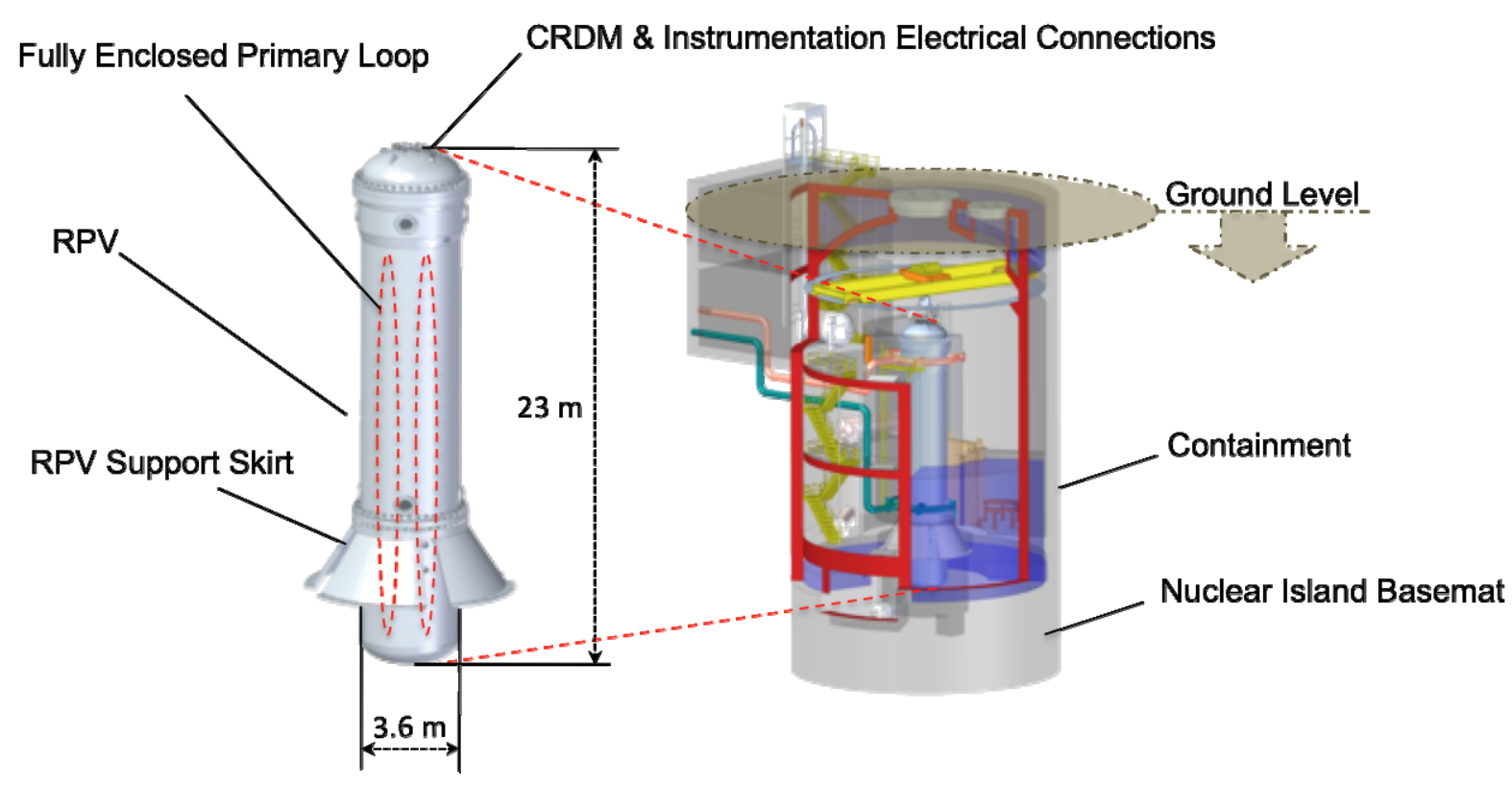

Primary Integral Loop

The mPower primary loop is fully enclosed within the integral RPV. With reference to Figure 2, as water coolant circulates through the core it increases its energy content as a result of thermal exchange with the core. During normal operation, under the effect of forced convection, the heated coolant moves upward through the CRDMs guides fully immersed in the coolant, and all the way to the top of the RPV until it reaches the bottom of the pressurizer obtained by dedicating a controlled volume for water expansion within the top RPV head. At an elevation of approximately 18-20 meters from the core bottom, the coolant flow is reversed downward as it begins to exchange thermal energy through thousands of tubes forming the integral steam generator heat exchanger. While highpressure heated water coolant flows through the tubes, it exchanges thermal energy as the inner surfaces of the tubes are in thermal contact with lower-pressure and cooler feedwater returning from the turbine-condenser circulating through a secondary external loop. To ensure water remains liquid throughout the primary loop, the primary loop pressure is maintained at $\sim 130$ bar (1,900 PSI). 
Figure 2. mPower Design Simplified Functional Diagram

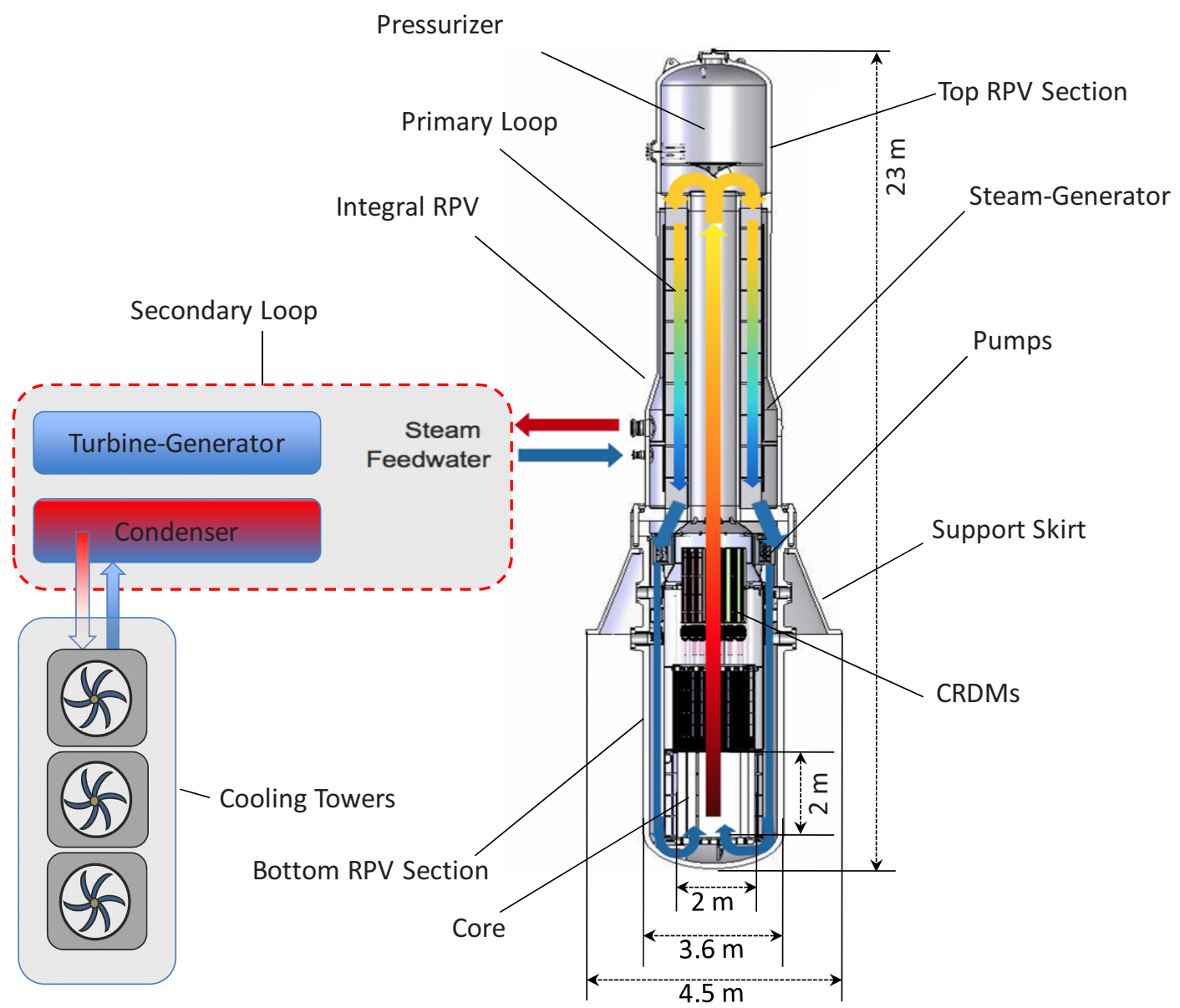

As high-pressure primary loop coolant exchanges thermal energy with the secondary loop water, it cools down prior to entering the suction side of multiple pumps (see Figure 4 for higher detail on pumps configuration) also fully enclosed in the integral RPV. This configuration represents a thermal-hydraulic optimization when compared to other SMR designs based on integral PWR pressure vessels (e.g. IRIS and SMART). Mainly as a result of forced circulation driven by the in-vessel RCPs, coolant is directed towards the bottom of the core through the annular down-comer region outside the core toward the lower plenum and then back to the core, after having inverted its direction, thereby restarting the primary loop circulation pattern.

As shown in Figure 2, the primary coolant loop is represented by the simplified fluidflow pathways superimposed onto a cross-sectional view of the RPV internals. It should be noted that the mPower RPV internal components configuration is somewhat similar to the SMART SMR (Korean) design, wherein the primary loop is also fully integrated within the primary pressure boundary formed by the RPV. These integral PWR configurations allow for the elimination of:

- External hot- and cold-legs piping and relative welding and flanges; 
- External Reactor Coolant Pumps (RCPs), suspended motor and impeller-casing, and their supporting seismic-resistant structures; and

- Free standing extra-loop Pressurizer, relative expansion piping and supporting structures.

\section{Integral Steam Generator}

The integral steam generators are positioned above the CRDMs and are fully submerged in the primary loop coolant.

The integral steam generator heat exchangers are derived from naval designs and are sufficiently compact to fit within the annulus formed by the inner RPV walls and the riser surrounding and extending upward from the core. The assembly formed by the integral steam generators can be removed all together with the top RPV section as it is separated from the bottom RPV section by a sealing flange. In this manner the steam generator can be disconnected from the core-bearing RPV section so that it can be temporarily repositioned away from the core during refueling and maintenance activities.

With reference to Figure 3, we found two mPower rendered cross-sectional 3D representations with different types of steam generators we identified as "Configuration A", and "Configuration B". As shown in these representations, feedwater enters the steam generator heat exchangers from the bottom as it flows against the direction of the primary coolant flow (counter-flow configuration). Configuration A is consistent with Figure 1 representations. For this configuration, steam is collected through multiple tube headers flanged at the top of the RPV cylindrical section (below the pressurizer). The heat exchanger employed in this configuration could be cassette-type heat exchangers as each section of these heat exchangers is independent and bundles of tubes are heading to independent inlet and outlet flanges.

Configuration B is consistent with the RPV represented in Figure 2. In this case, feedwater inlets are provided at the bottom of the RPV section, below the RCPs, all together with the steam outlets. For this configuration, the steam generator appears to be formed by a single assembly formed by tubes converging on common top and bottom tube-headers. We do not have sufficient information to determine which of these configurations will be ultimately adopted by the mPower designers. However, Configuration B will appear to be simpler to manufacture, and as inspection of steam generator tubing during refueling and/or maintenance requires the disconnection of the whole top RPV section integrating the steam generator heat exchangers, it would seem practical and cost-effective to adopt this simpler configuration. 
Figure 3. mPower Possible Steam Generator Configurations

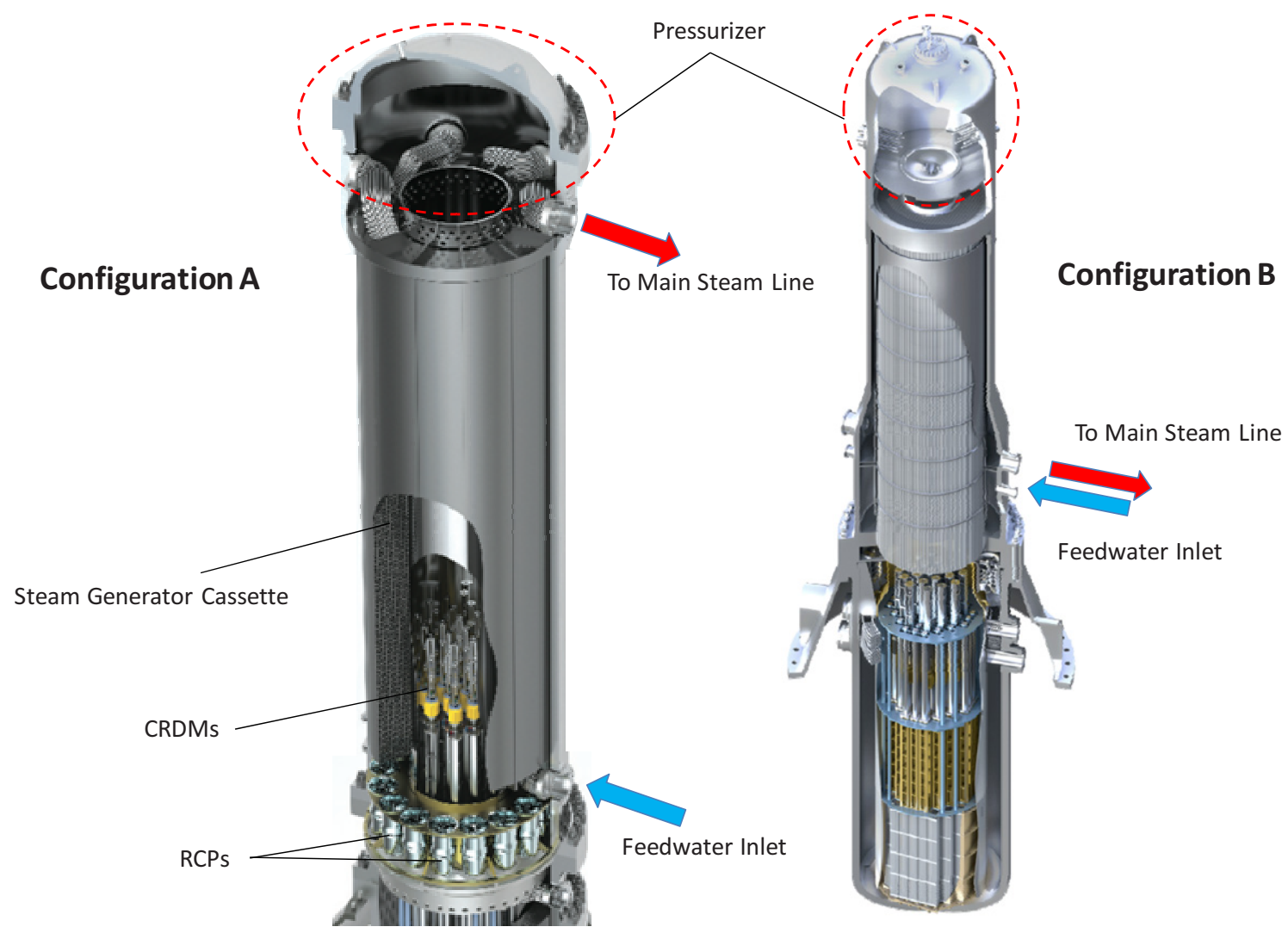

\section{Integral Reactor Coolant Pumps (RCPs)}

After exchanging thermal energy from the core through the thousands of tubes forming the integral steam generator heat exchanger, coolant is directed into an annular plenum between the extended core barrel and the RPV inner walls and enters the suction sides of multiple RCPs. As these pumps do not generate significant pressure differential, they may also be referred to as "coolant circulators."

As mentioned, the positioning of these components with respect to the inlet and outlet of the integral steam generator represents an optimization when compared to SMR designs employing integral reactor coolant pumps. For example, the IRIS' integral RCPs suction side is configured to intake heated water coolant directly from the core prior to entering the steam generator cassettes; this water is at the highest temperature in the primary loop. A very similar "hot suction" configuration is also adopted by the SMART SMR design. In the mPower design, the RCPs suction side is configured to intake water coolant after it has exchanged thermal energy through the integral steam generator, thereby suctioning coolant at the lowest temperature available in the primary loop. This RCPs configuration naturally results in higher pumping efficiency while subjecting the RCP components to less pronounced temperature-induced material stressors. 
Based on visual inspection of the mPower RPV cross sectional view provided in Figure 4, the RCPs supporting structures appear to be part of a "sealing ring" positioned between the bottom- and top-RPV flange. As a result, the electrical connections, needed to provide motive electric power and control to each individual RCP, appear to be obtained by penetrations through the sealing ring rather than through the RPV walls. In this manner, the RCPs along with the sealing ring form an independent assembly that while providing pressure boundary sealing features along with structural support and electrical connection to the RCPs, it can also be removed for inspection, maintenance, or even total substitution. The expanded image of the mPower bottom-RPV section shown in Figure 4 emphasizes the penetrations for the electrical leads required for the connection of the integral RCPs electro-magnetic windings (windings not shown in the simplified representation) to the external power and control cabling.

The integral RCPs of the mPower design represent a significant novelty with respect to licensed RCP designs and configurations. As a result, extensive testing to fully characterize the long-term impact of vibrations and harsh operating conditions for the RCP electrical leads and their insulating materials might represent technical/regulatory challenges.

More generally, in most areas within a nuclear power plant, the actual ambient environments (e.g., temperature, radiation, or moisture) are less severe than the plant design environment. However, in a limited number of localized areas, the actual environment may represent more severe environment conditions. Electrical conductor insulation materials used in cables and connections may degrade more rapidly than expected in these potentially adverse localized environments. An adverse localized environment is a condition in a limited plant area (i.e. could be an extremely reduced area surrounding the RCP electrical connectors) that is significantly more severe than the specified service environment for the cable(s). An adverse variation in environment is significant if it could appreciably increase the rate of aging of a component or have an immediate adverse effect on operability. As a result, all innovative aspects (i.e. adoption of electrical power leads and penetrations through the RPV boundary) may represent sufficient novelty to grant new regulatory criteria or technical challenges. In most cases, material degradation issues can be addressed through material degradation management programs. 
Figure 4. mPower Bottom-RPV section and Reactor Coolant Pump Assembly

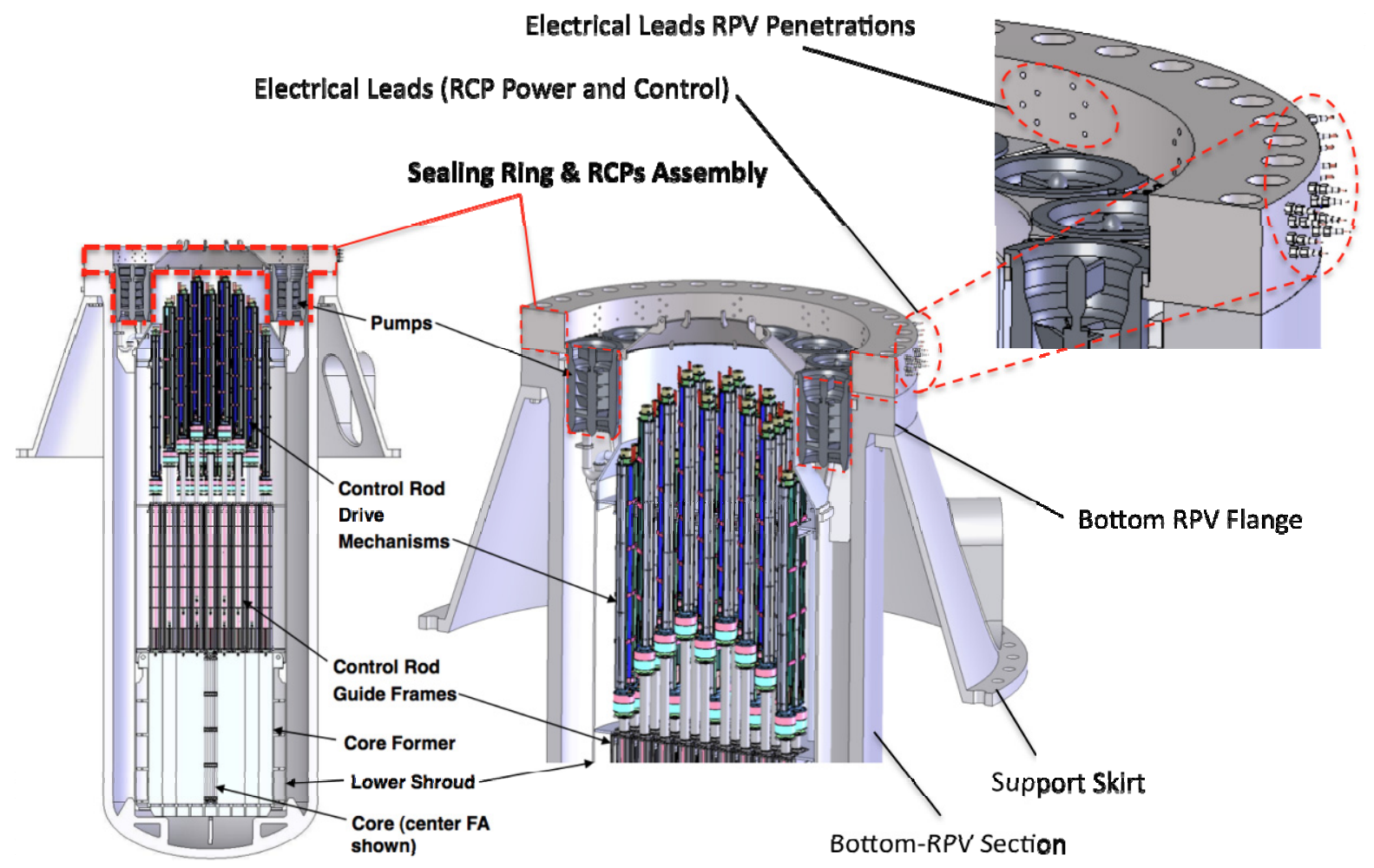

It should also be noted that commercial PWR pressurizers (external loop configurations) are normally equipped with electrical leads representing penetrations through the primary pressure boundary. For typical pressurizers the electrical leads are designed to provide controlled electric power through power cables to relatively high-power electric heaters at the bottom of the pressurizer and within a harsh environment. The heaters are activated to increase the primary system pressure. The electrical leads through the pressurizer and primary loop pressure boundary have been employed and operated for decades without significant engineering and material degradation challenges that could not be resolved. The electrical leads that will provide control and motive power to the RCPs, as adopted by mPower designers, will face requirements and technical specifications very similar to those utilized for the electrical connection of heaters of PWR pressurizers, thereby the innovation of adding small penetrations to the RPV should not represent insurmountable technical and/or regulatory challenges.

From inspection of Figure 4, it is not possible to determine whether the mPower integral RCPs will require cooling for the in-vessel motor winding and bearings. If cooling will be required, additional penetrations will have to be employed to accommodate for an external cooling loop, piping, and pumping systems. It should also be noted, that although these multiple RCP-related penetrations are positioned at a high elevation with respect to the core, they always represent a potential for Loss Of Coolant Accident (LOCA) events - Small-Break (SBLOCA) specifically in this case. Integral Control Rod Drive Mechanisms (CRDMs) 
The $\mathrm{B} \& \mathrm{~W}$ mPower reactor uses a unique CRDM design that employs fewer parts than conventional light-water reactor as the mPower CRDM's components are located entirely within the reactor pressure vessel, and do not serve as a boundary for reactor coolant. This configuration provides inherent safety advantages (i.e. there cannot be control rod ejections as the whole CRDM system is operating at the same pressure), and it also represents challenges as materials and electrical connections will need to be fully submerged within the primary coolant environment.

All design functionality, material selection, and test plans that $\mathrm{B} \& \mathrm{~W}$ intends to utilize for the CRDM assemblies are discussed in document number R0003-96-002506 (NP) titled:

"Control Rod Drive Mechanism Design Details and Development Plan Technical Report" containing proprietary information submitted to the NRC in October 2010. In the accompanying affidavit, $\mathrm{B} \& \mathrm{~W}$ explains that it intends to complete as much of the testing as possible prior to the Design Certification Application (DCA) submittal. The motor tests and CRDM life tests will continue for years after the DCA submittal. As this information is confidential, we limit our analysis to visual inspection of the mPower cross sectional views of various 3D models publicly accessible.

As shown in Figure 5, the CRDMs are fully immersed in the primary coolant and enclosed within the RPV boundary. As a result, accident scenarios involving control rod ejections (due to pressure differential) are eliminated. The adoption of this type of CRDMs requires electrical connections (with insulating materials) that have to cross the RPV boundary through relatively small penetrations. The top sections of the CRDMs will have to be equipped with water, pressure, and temperature resistant electrical plugs with electrically insulating cabling extending and crossing the pressure boundary either through the RCP supporting ring or all the way through the top RPV head (perhaps 16-18 meters away from the CRDMs top sections). However, adopting integral CRDMs requiring RPV electrical penetrations versus standard CRDMs requiring hydraulic much larger penetrations should translate into a reduction of the probability for CRDMs related LOCA events. Overall, 57 CRDMs will be employed by this design.

The final design solution will have to provide for rapid disconnection and re-connection of the integral CRDMs electrical systems, since they have to be removed for refueling and maintenance operations. As these technical solutions represent a departure with respect to licensed CRDMs electrically operated outside of the RPV boundary, technical and regulatory challenges will have to be met. 
Figure 5. mPower Integral CRDMs and Electrical Connections

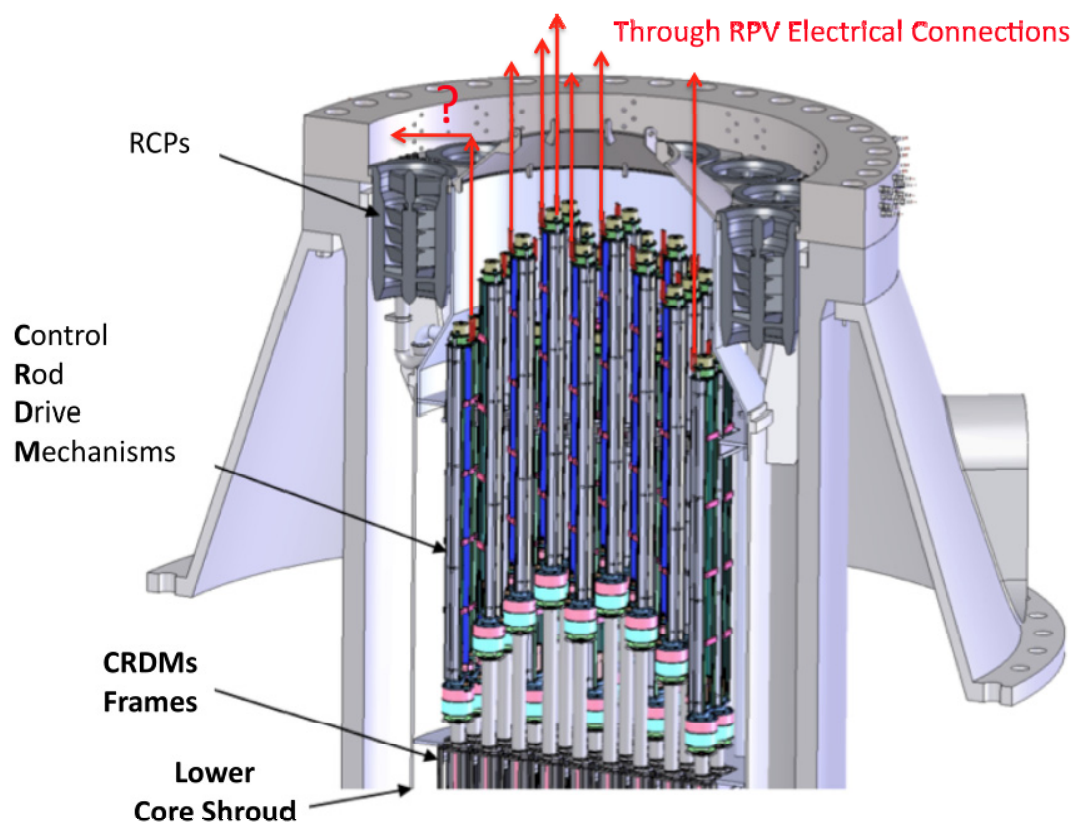

Core

The mPower core is a conventional PWR-type core with standard fuels enriched to 5\%, with burnable poisons for a five-year refueling cycle, with an estimated burn-up of approximately $40 \mathrm{GWd} / \mathrm{t}$. After the operating cycle of five year, refueling consists of replacing the entire core. The reactor uses approximately one-half-height PWR fuel rods (less than 5\% enrichment) arrayed in $17 \times 17$ bundles. The mPower core does not utilize soluble boron for normal reactivity control. Core characteristics are best summarized in the Table 1, extracted from a February 2010 B\&W presentation.

Table 1. mPower Core Characteristics

\begin{tabular}{|c|c|}
\hline General Reactor Core Design Parameter & $\begin{array}{c}\text { B\&W mPower }{ }^{T M} \\
\text { PWR }\end{array}$ \\
\hline Thermal/Electrical Power Rating (MW) & $425 / 125$ \\
\hline Active Height (m) & 2.025 (79.72 in) \\
\hline Active Core Volume $\left(\mathrm{m}^{3}\right)$ & $6.46\left(228.2 \mathrm{ft}^{3}\right)$ \\
\hline Number of Fuel Assemblies in Core & $69(17 \times 17)$ \\
\hline Average Core Power Density (MW/m³) & $65.8\left(1683 \mathrm{~kW} / \mathrm{ft}^{3}\right)$ \\
\hline Fuel Heavy Metal Inventory (MT) & 16.54 \\
\hline Average Core Specific Power kW/kgU) & 25.7 \\
\hline Average Fuel Burnup Before Refueling (GWd/MTU) & 35 \\
\hline Operating Cycle Length Before Refueling (yrs) & 4 \\
\hline
\end{tabular}

Source: B\&W 
The mPower pressurizer is integrated with the RPV top head. Figure 6, extracted from mPower presentation material, provides a simplified representation of the pressurizer internals. A series of electrically-driven linear and independent fully immersion heaters provides the means for increasing the primary coolant pressure. This heater configuration allows for rapid maintenance and substitution of the heating elements.

Figure 6. mPower Integral Pressurizer Internals

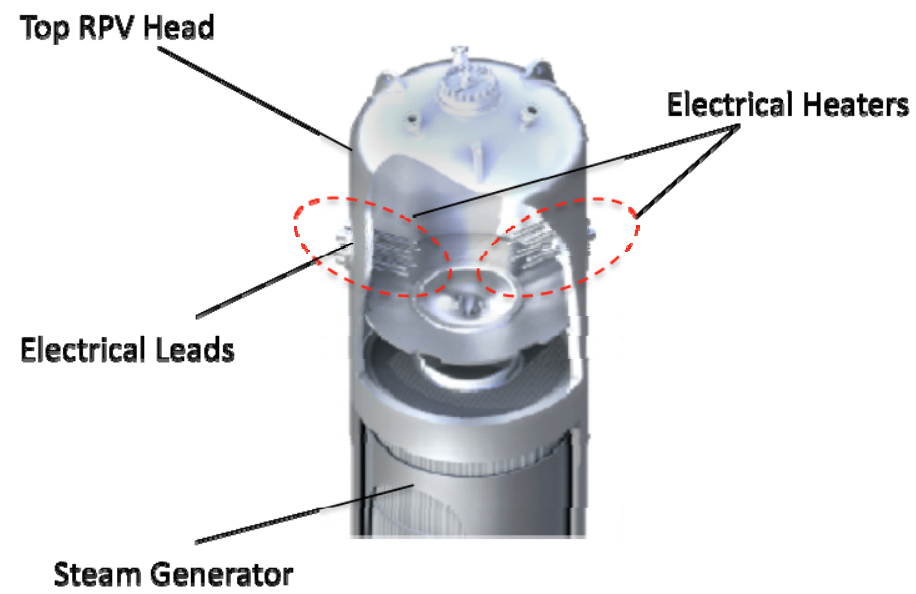

Secondary Loop

The secondary thermal-hydraulic loop configuration for the mPower SMR mimics that of standard PWR designs and follows the very basics steps outlined in Figure 2. In these configurations, low-pressure (relative to the primary loop pressure) cooler feed water is increased in temperature as it flows in contact with the surfaces of the steam generator tubes. As the pressure in the secondary loop is approximately 825 PSI ( $~ 57$ bar) feed water remains liquid at the steam generator inlet where temperature is approximately $163^{\circ} \mathrm{C}\left(325^{\circ} \mathrm{F}\right)$. As this water flows through the steam generator, its temperature increases beyond the saturation temperature at the given pressure and the result is superheated steam at approximately $300^{\circ} \mathrm{C}$ at the outlet of the steam generator. This mildly superheated steam then enters the external secondary loop and flows through admission valves for expansion into a turbine-driven generator set. Exhausting, lowenergy content, wet steam is then condensed by thermal exchange with condenser tubes that are in turn cooled by air-cooled cooling towers.

Depending on site-specific Ultimate Heat Sink (UHS) characteristics, the air-cooled cooling towers may be replaced by water cooling. In this configuration the power station will need to include intake and outfall water-cooling structures as seen for power plants sited by the coast, or at sites near large bodies of water (lakes or artificial ponds). The 
secondary loop includes the Main Steam System which supplies steam from the steam generator to the turbine during normal operation. Main steam isolation valves isolate the secondary side of the steam generator to prevent uncontrolled blowdown and to isolate non-safety related portions of the system. Main steam safety valves provide overpressure protection for the secondary side of the steam generator.

\section{Power Conversion System}

The power conversion system is formed by a modular turbine-generator also transportable by rail or barge. If the Ultimate Heat Sink (UHS) is represented by coldwater for condenser cooling, the plant thermodynamic efficiency can be enhanced and the reactor module capacity allows for power ratings increases from $125 \mathrm{MWe}$ to $136 \mathrm{MWe}$. Similarly, for all other SMRs design whose core allows up-rating, if the SMR (regardless of the design) is operated at sites with UHS characterized by cold temperatures, capacity boosting and/or efficiency increases are also possible. The designer is considering whether to utilize 2 x125 MWe mPower reactor units sharing a common turbinegenerator module, or have an independent turbine-generator set dedicated to each mPower module.

The B\&W mPower reactor steam and power conversion system comprises the following key systems and equipment:

- Turbine-Generator - The turbine operates at $3600 \mathrm{rpm}$ and is a tandem compound double-flow unit containing one high pressure turbine and one low pressure turbine. The generator is a 125 MWe unit rated at approximately 139 MVA (Mega-VoltAmpere). Turbine-generator support systems include a turbine bearing lubrication oil system, an electro-hydraulic control system, a turbine gland seal system, turning gear, over-speed protective devices, a generator rectifier section and a voltage regulator. The turbine-generator serves no safety related functions;

- Condenser - The condenser cools and condenses steam from the turbine and returns the resulting condensate to the condensate and feedwater systems. According to mPower designers, the condenser serves no safety related functions;

- Condensate and Feedwater Systems - The condensate and feedwater systems provide feedwater at the required temperatures, pressures and flow rates to the integral steam generator heat exchangers. 


\section{Containment}

The containment building and other critical structures are located below grade level. Figure 7 is a 3-D cross-sectional model of a single mPower module underground containment, along with a 2-D cross-sectional view of the containment building providing qualitative scaling in relation to the height of an operator. This containment configuration includes and protects the spent and fresh fuel storage pool, water storage tanks for prolonged passive decay heat removal, and accommodates sufficient room for simultaneous refueling and NSSS equipment inspection activities.

The mPower containment building is a low-leakage, reinforced concrete, steel-lined, seismic resistant structure fully located below grade level. As for all designs adopting reinforced large-volume concrete containments, the mPower containment building is designed to confine radioactive material released in the event of a design basis accident. Access to the containment is ensured by two personnel hatches, and a removable equipment hatch (access dome) on the top of the building provides access for large component replacement.

Figure 7. mPower Containment Building and Ancillary Structures

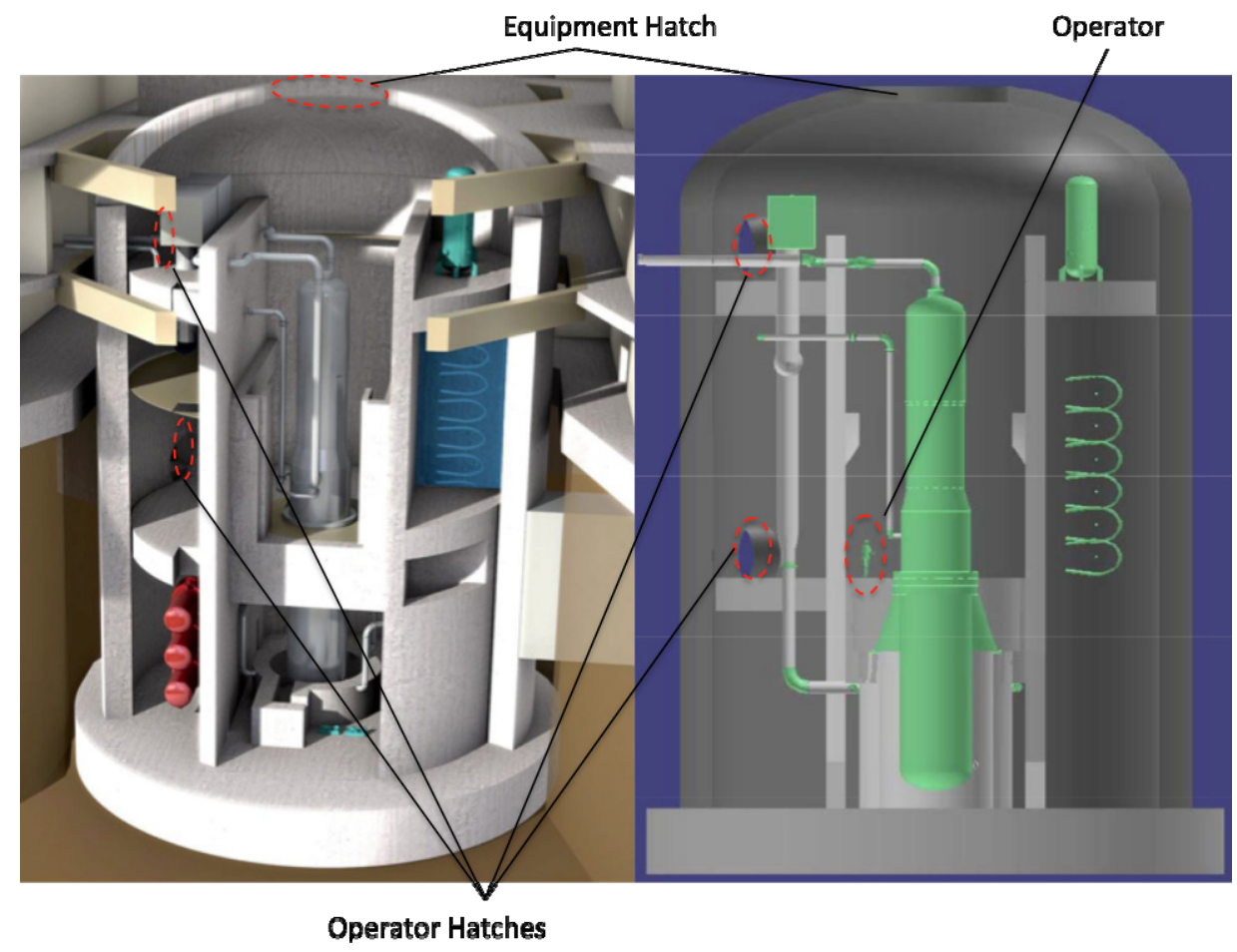


As discussed before, and referenced in the table in Table 1 this SMR design uses relatively standard PWR fuel adapted for the smaller RPV. More precisely, these are the main fuel features:

- 17 x 17 PWR-type fuel assemblies (FAs) made with zirconium alloy cladding

- 69 total FAs in the core

- FA length of $2.025 \mathrm{~m}$ (79.72 in)

- $\mathrm{UO}_{2}$ fuel pellets with less than $5 \%$ enrichment

At the same time, a few questions remain about the fuel for the mPower. Specifically, it is unclear how the design will realize a 4-year operating cycle while maintaining enrichment levels below 5\%. Moreover, the design has very low thermal efficiency even though it uses forced circulation, which should lead to levels around $34 \%$.

The B\&W mPower design includes a number of technological enhancements when compared to commercial PWR and BWR designs, the result of which is to preclude the need for active engineered safety features, and the reduction or elimination of the possible consequences resulting from several design basis accident scenarios. These enhancements are summarized as:

- Adoption of an integral RPV arrangement

- No active safety systems

- Below-grade containment

- No reliance on emergency AC power or operator action for at least 72 hours following a postulated accident

Furthermore, emergency core decay heat removal is executed by the Emergency Core Cooling System, which places reliance on large in-containment water storage tanks to provide long term passive decay heat removal (see Figure 42) and has the following additional characteristics:

- Provides automatic primary loop depressurization in the event of LOCA so as to allow for long-term coolant injection (mainly by means of pressurized tanks) 
- Provides long-term Reactor Water Storage Tank (RWST) and containment cooling with flooding capability of the reactor cavity

- Provides soluble boron injection through pressurized tanks (does not require electrically driven pumps to execute this function)

Figure 8. mPower Passive Decay Heat Removal System

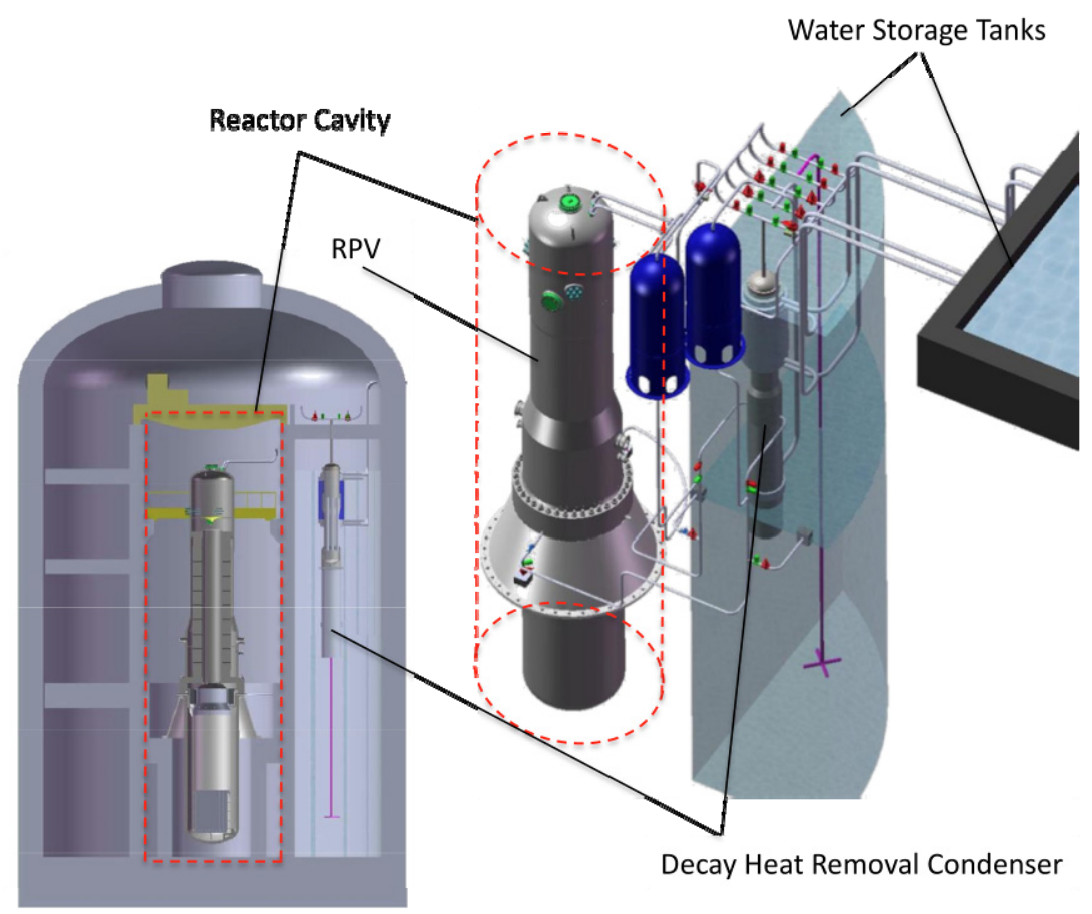

In addition to the emergency core cooling system, the Reactor Coolant Inventory and Purification System (RCIPS) provides mechanisms for decay heat removal.

It is noteworthy to reiterate that one of the distinct features characterizing the mPower design is the placement of the full containment all together with cooling water reservoirs below grade. A prospective design discriminator factor regarding the mPower underground containment is its ability to rely on fully enclosed reservoirs of cooling water for at least 72 hours.

Some SMR designs proposing an adequately reinforced concrete containment appear to show sufficient protection to the mechanical aspects of an air-crash scenario, however, the decay heat removal features, passive or active, rely upon thermal-hydraulic connections with the Ultimate Heat Sink (UHS). The UHS is represented for most cases by heat exchangers (i.e. cooling towers) thermally coupled with environmental air, or large bodies of water through structures positioned outside of the containment, thereby in 
areas usually not heavily protected. Additionally, some SMR designs offer re-circulation pathways for cooling air or water to provide decay heat removal hydraulically connected directly with the reactor cavity inside the containment. These same pathways (if not damaged by the mechanical aspects of the air-crash) have the potential to carry heat energy into the reactor systems protected areas. This could occur, for example, if prolonged jet fuel-induced fires develop near or internally (via jet fuel entrapment) the very structures engineered to cool the core. These structures could in essence act as siphoning systems transporting hot combustion products, or air and jet-fuel mixtures (which if not already ignited can cause explosive combinations) right into the containment protected structures, and near reactor systems that require the most cooling. Based on the above considerations the mPower design appears to feature strong resistance to air-crash scenarios, even when air-crash mechanical, dynamic, and jet fuel parameters are considered as per the more restrictive "post 9/11" technical requirements.

NRC Aircraft Impact Rule 74 FR 28112 requires design and license applicants for new nuclear power reactors (small and large) to perform a rigorous assessment of their designs to identify design features and functional capabilities that could provide additional inherent protection to avoid or mitigate the effects of an aircraft impact. Accordingly, all SMR designers are required to identify and incorporate design features and functional capabilities that avoid or mitigate, to the extent practical and with reduced reliance on operator actions, the effects of modern aircrafts impact on key safety functions. As for all SMRs applying for a U.S. NRC license, every SMR design will be required to show that, with reduced operator actions:

- The reactor core remains cooled, or

- The containment remains intact, and spent fuel pool cooling or spent fuel pool integrity is maintained

\section{Multiple mPower Module Configurations}

The mPower SMR can be deployed as a single power unit or as clusters of multiple independent power units. The only equipment that could be possibly shared by each two $\mathrm{mPower}$ units is the turbine-generator set.

Figure 9 shows the top view of a mPower based station capable of generating approximately $500 \mathrm{MWe}$ (4 x $125 \mathrm{MWe}$ units). The turbine building (3) shown appears to provide an independent turbine-generator set for each mPower reactor. In this case, each power unit is completely independent of one another (no shared equipment). Figure 10 provides a rendered 3-D representation of the power station shown in Figure 9. 
Figure 9. 500 MWe mPower-based Nuclear Power Station

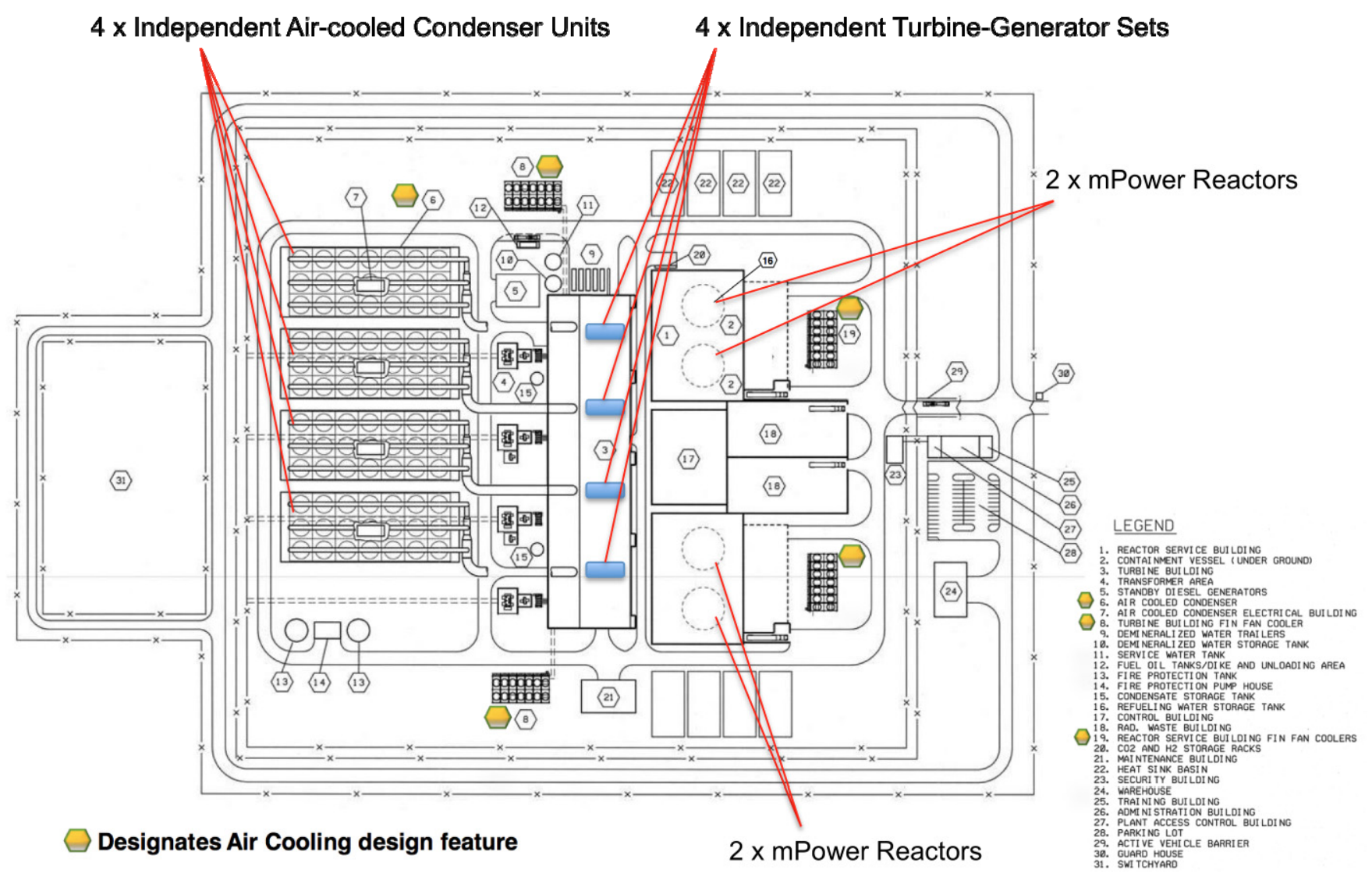


Figure 10. 4-module mPower Nuclear Power Station

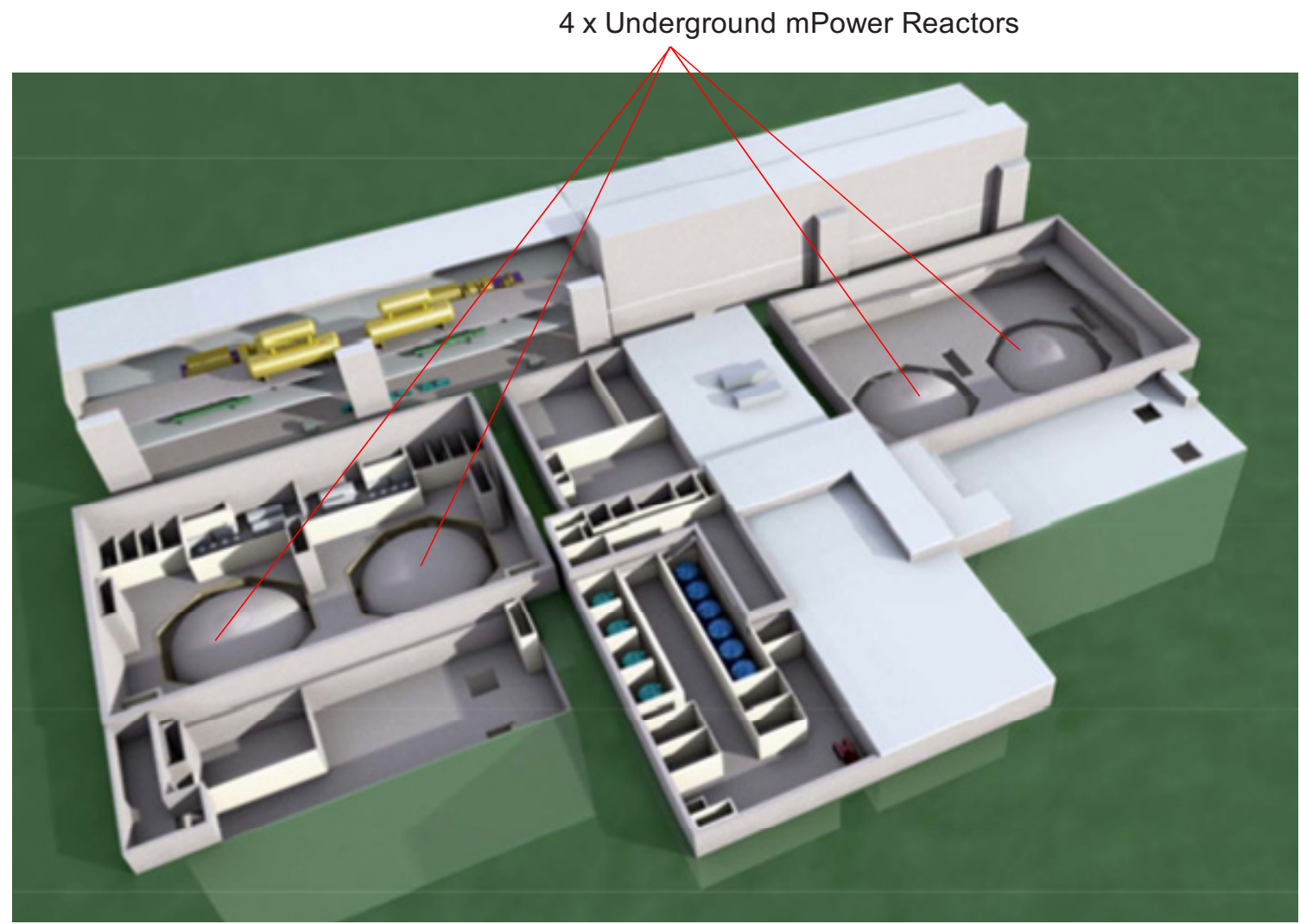

B\&W is currently the sole supplier of nuclear fuel to the U.S. Navy for its nuclear propulsion program since it bought Nuclear Fuel Services (NFS) of Erwin, TN, in 2009. With fuel fabrication and uranium processing facilities in both Lynchburg, VA and Erwin, B\&W should have the complete package to test, qualify, and manufacture the fuel for the mPower. As the main unique feature of the mPower fuel is the half-length PWR fuel assembly (FA), the only issues that can be contemplated at this time relate to validating the shortened length FA. Moreover, it is worth noting here that $\mathrm{B} \& \mathrm{~W}$ has the only licensed facilities in the U.S. capable to fabricate fuel enriched at levels greater than $5 \%$. Although the mPower is expected to use fuel at current commercial enrichment levels below $5 \%$, this aspect of the company's capabilities may mean that additional SMR vendors will be looking to B\&W for their own fuel fabrication needs. Still, B\&W is currently only a supplier to the U.S. government for fuel and has much less commercial experience in this area.

The mPower is designed for 60 -year service life with on-site spent fuel storage capacity dimensioned to accommodate all of the spent fuel produced during the lifetime of the module. Figure 11 shows the location of the spent fuel pool within the containment building and with respect to the RPV and other equipment. 
Figure 11. mPower Spent and Fresh Fuel Storage Pool

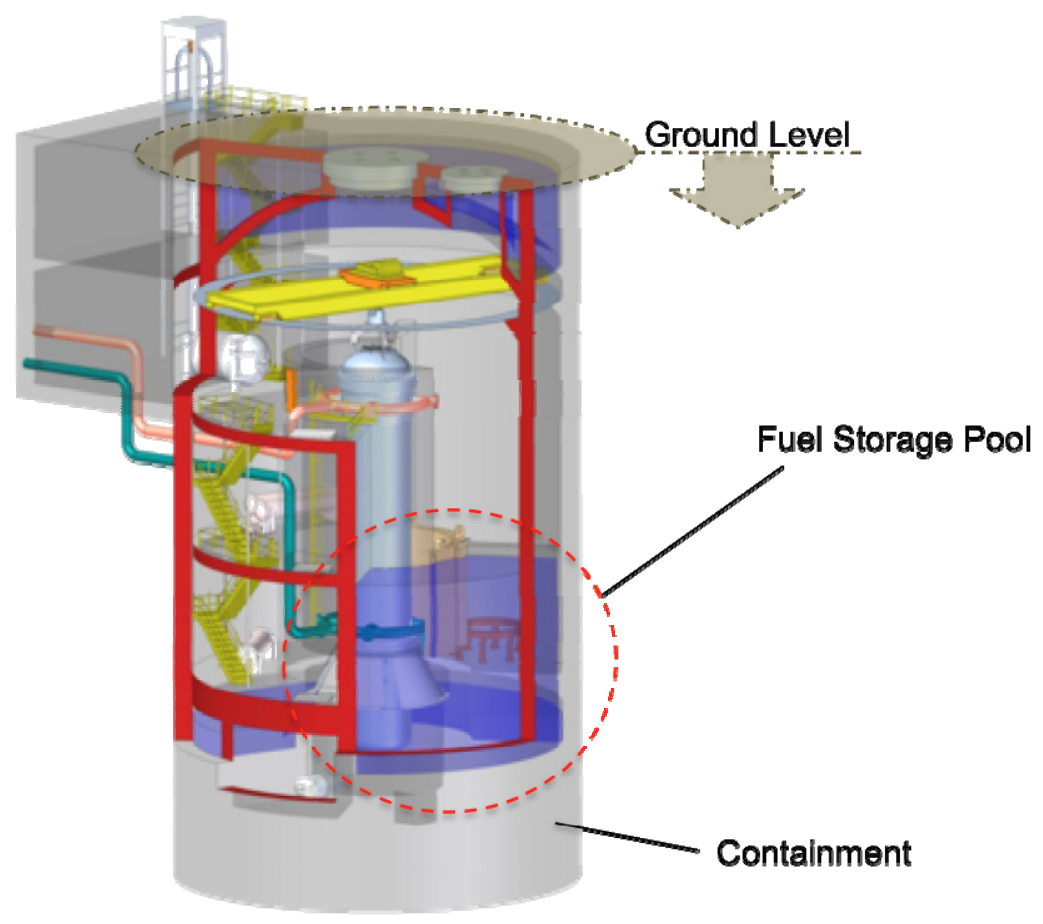

Construction and Manufacturing Issues

From a manufacturing standpoint, the large integral RPV components will require specialized forging capabilities. "Large" RPV is a relative term when compared to other LWR RPVs as the actual diameter of these sections as proposed for the mPower design allows for rail transport. All other components required to assemble complete mPower reactor units do not represent foreseeable manufacturing challenges. On the construction side, the B\&W alliance with Bechtel provides the mPower team with one of the leading nuclear power plant EPC companies having a proven track record of designing, engineering, constructing, and commissioning at least 150 NPPs around the world.

Further, B\&W offers production capabilities to supply all NSSS components. As a result it can reduce manufacturing costs and streamline construction activities and schedule. More specifically, for the mPower modular construction B\&W will utilize:

- Heavy forgings from Lehigh Heavy Forge 
- Component fabrication at B\&W's Mt.Vernon, Indiana facility (220,000 $\mathrm{ft}^{2}$ with up to 1,000 tons lifting capacity)

- Fuel fabrication at B\&W's Lynchburg or Erwin facilities

- CRDMs will be fabricated at B\&W's Euclid and Barberton, Ohio facilities $\left(548,000 \mathrm{ft}^{2}\right.$ of manufacturing area and $119,000 \mathrm{ft}^{2}$ of office space)

- Large modules and heavy components will be fabricated at B\&W's McDermott's Morgan City facility equipped with waterway barge access

- Steam Generator and other heat exchangers will be fabricated at the B\&W's Canadian facility (Cambridge, Ontario)

Examples of B\&W's nuclear component manufacturing capabilities are shown in the photos in Figure 12.

Figure 12. B\&W Broad Nuclear Components Manufacturing Capabilities
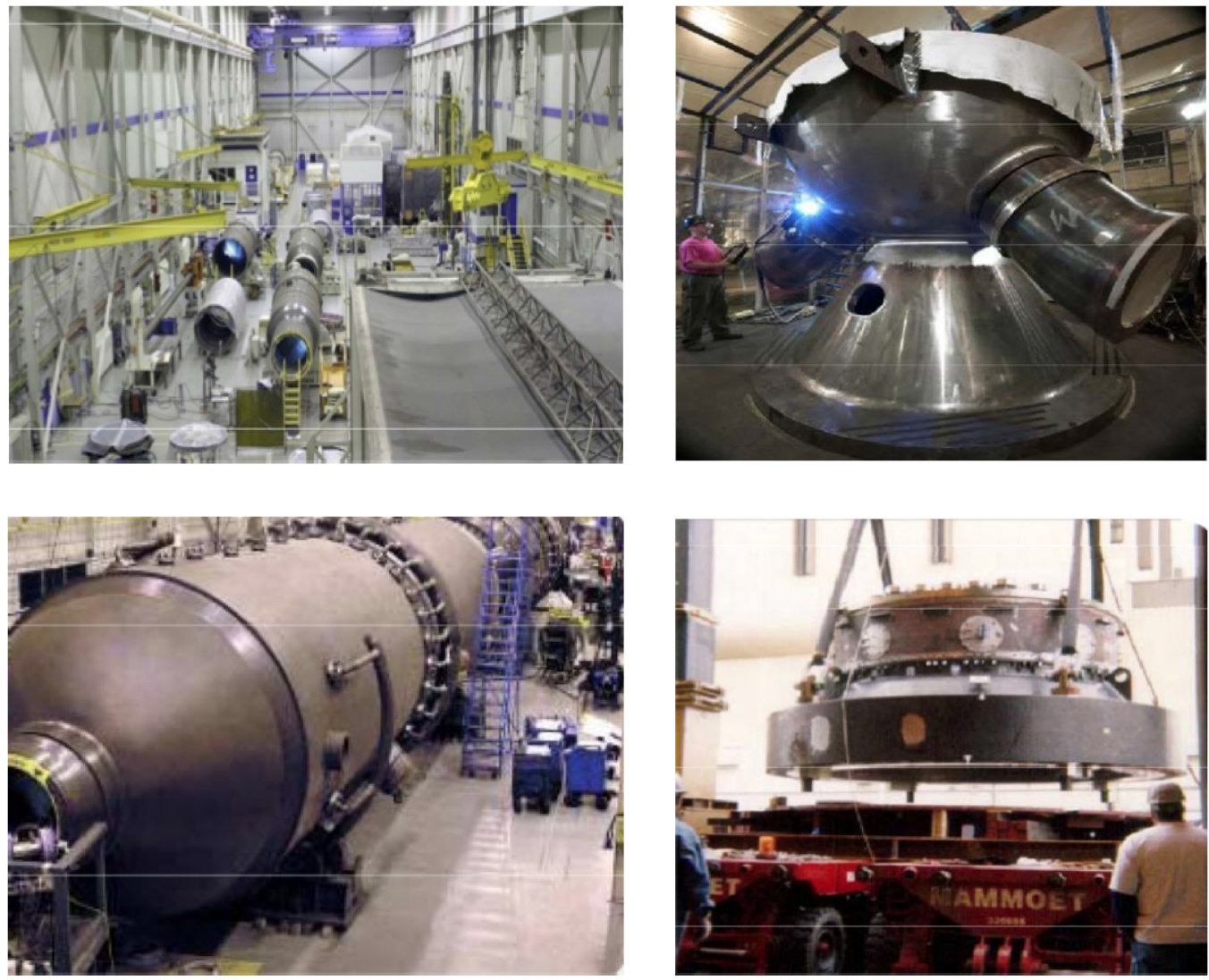


\section{Supply Chain Issues}

Given the above broad and deep capabilities in manufacturing and construction in the $\mathrm{B} \& \mathrm{~W}$ and Bechtel team, there appear to be few, if any, major challenges in completing the mPower design and deploying it in the market. The only critical questions may be whether B\&W will choose to set aside dedicated manufacturing capacity for the mPower components while it continues to supply steam generators for existing and new large LWRs around the world. Another issue that has come up with larger reactor designs is the need for ultra heavy forging, but since the mPower RPV and other components are much smaller, the capacity at the only U.S. forger - Lehigh Heavy Forge - is big enough, so there should be no delays in supplying the necessary mPower forgings.

\section{(B) NuScale SMR Major Design Features}

\section{Power Conversion Configuration}

As for most of the modular reactor designs, the NuScale design can be configured as one or multiple modular units each thermally coupled to a dedicated turbine-generator set. Starting with a single module 45 MWe unit, the core represents the "heat source" of an indirect steam-cycle (Rankine) as shown in Figure 13. In this configuration water circulates through the core by natural convection. As water heats up due to thermal exchange with the core it flows upward across the "Hot Leg Riser" and exchanges heat energy without mixing with water circulating in the secondary loop represented by the tube side of the integral steam generators. These are integral steam generators as they are positioned within the Reactor Pressure Vessel (RPV). As a result of thermal exchange through the steam generators, water cools down leading to a decrease in water density which, under the effect of gravity, provides the passive driving force causing it to flow downward, thus executing and resetting a recirculation flow pattern through the core and the integral steam generators. 
Figure 13. NuScale Single-module Core-to-Power Conversion Configuration

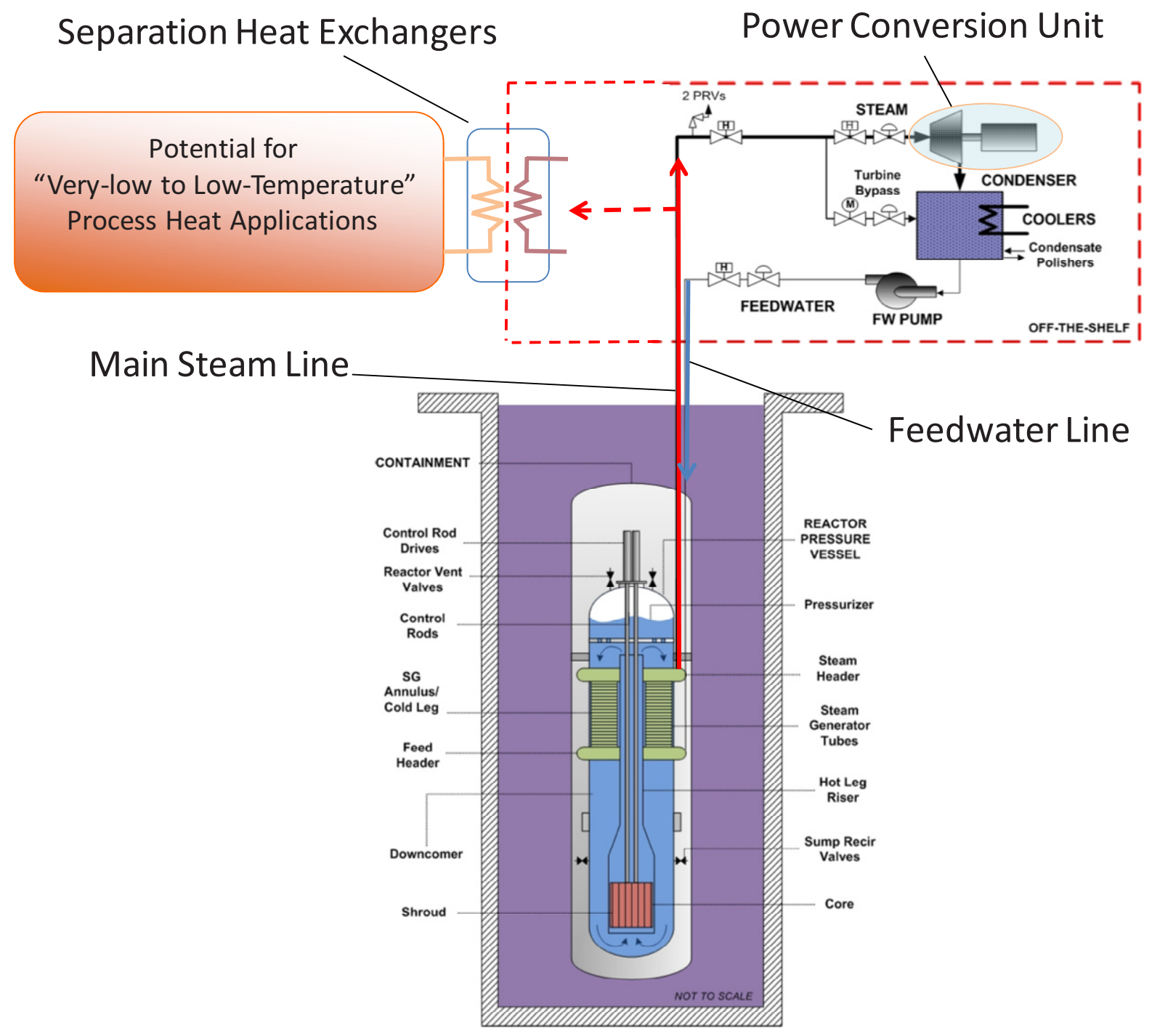

The top hemispherical RPV head is designed with sufficient volume to accommodate for water expansion from cold start-up to normal operation temperature. This volume is also equipped with heaters and cold-water injection nozzles (not shown in Figure 13) so as to execute the same functions of a pressurizer as employed in conventional PWR designs. Integrating the pressurizer within the RPV pressure boundary eliminates piping and supporting structures normally connecting the primary external loop of a PWR to an external pressurizer. As for all SMR designs proposing integral RPV equipped with integral pressurizers, the pressurizer obtained at the top of the RPV will require relatively high-amperage and high-voltage cabling connections through multiple penetrations. Insulated electric leads will have to cross the primary pressure boundary represented by the RPV, have flexible attachments to connect to another set of insulated electric leads that will have to cross the pressure boundary represented by the containment vessel ${ }^{1}$, and

1 High-power electric cabling, relative connectors, pressure fittings, and penetrations as required in this case to supply electric power and control to the pressurizer heaters through the RPV's walls and through the containment walls have a high potential to develop into long-term maintenance and operational challenges. 
most of these electrical connections will be under water and exposed to relatively hightemperatures. As for all SMR designs, electric penetrations need to consider various types of aging stressors including, for example, the impact of electric leads/connectors exposure to corrosive environmental conditions, vibrations, Electro Magnetic Interference (EMI) generation and shielding, with electrical connectors interface expanding and contracting. To summarize, for the design configuration shown in Figure 13 , power and control/sensor cables will need to go through multiple pressure interfaces and penetrations represented by the:

- RPV walls;

- Pressurized "containment" (another Pressure Vessel containing the whole RPV);

- Pool environment; and

- Pool-liner-concrete structures plugs and penetrations prior to reaching the electric buses supplying power to the pressurizer heaters and their control systems.

At the secondary side of the steam generators sub-cooled liquid water, pumped through the auxiliary feedwater pump, circulates within the tubes of the integral steam generators. Inside the steam generator tubes the feedwater changes thermodynamic state from subcooled liquid to superheated steam as a result of thermal heat exchange with the primary water circulating through the core via passive re-circulation mechanisms. As the passive natural recirculation loop cannot achieve the relatively high heat transfer coefficients generally characteristic of designs equipped with forced recirculation via Reactor Coolant Pumps (RCPs), the superheating level of the steam exiting the steam generators at the operating pressure is relatively low at the operating pressure. This is the main reason why the design performs with a relatively low thermodynamic efficiency. Because of the relatively low steam temperature at the outlet of the integral steam generators if this design were to support process heat capabilities the most suitable process heat applications would be desalination, district heating, and all industrial applications requiring relatively low-process heat temperatures.

The steam-turbines utilized in this design will operate at 3,600 RPM, or at different RPM to match local grid frequency requirements, and under a single pressure (no multistage turbines dedicated to High-Pressure (HP), Intermediate-Pressure (IP), and Low-Pressure (LP)). If multistage, high-efficiency turbines venting to sub-atmospheric condensers are adopted the overall design efficiency can be increased.

\section{Multiple Containment Concept}

As discussed in previous sections, an additional large pressure vessel, identified as "containment" in Figure 13 and Figure 14, surrounds the RPV so as to maintain a vacuum in the annular environment between the RPV and the containment walls during normal operation. This feature diminishes heat losses from the RPV to the surrounding 
environment, thereby prevents heating of the water contained in the water pool formed by the concrete reactor cavity and the containment. In case of emergency, or during normal decay-heat removal operations, the containment is flooded so as to provide a passive heat removal mechanism. Once the containment is flooded, heat transfer can occur from the core, through the RPV walls, and the containment by means of natural convection in the pool. Although not shown in these figures, it is likely that additional non-passive heat exchangers ${ }^{2}$ will have to be thermally coupled with the water contained in the pool for long-term decay heat removal and to avoid high rates of evaporation ${ }^{3}$ of this cooling water.

The containment proposed in this design represents a drastic reduction in volume, construction time, and cost when compared to typical large containments utilized in PWR and BWR designs. Additionally, as the containment is designed to hermetically seal the RPV it provides an additional barrier to the potential escape of radioactivity. However, it appears that if a potentially radioactive leakage develops from the primary circuit into the secondary loop of the integral steam generator heat exchanger, the containment barrier would be by-passed and potentially contaminated water could be transported into the turbine building.

2 These heat exchangers operate with forced circulation obtained via electric pumps (active systems), thereby requiring a source of electricity independent of the reactor-turbine-generator unit.

3 If the water in the pool begins to exchange heat with the RPV it will also begin to heat up and evaporate with potential depletion of the minimum water volume required to maintain the core in a safe shutdown mode. To ensure the evaporation rate is maintained at minimum the water in the pool will need to be maintained cooled by means of cooling towers or other cooling mechanisms exchanging thermal energy with the Ultimate Heat Sink (UHS). All of these systems are "active" and require a source of electricity to operate. As these features are required with the module in a shut down condition, the source of electricity cannot be represented by the turbine-generator set. 


\section{Figure 14. Multiple Pressure Boundaries \& Possible Engineering Challenges for NuScale}

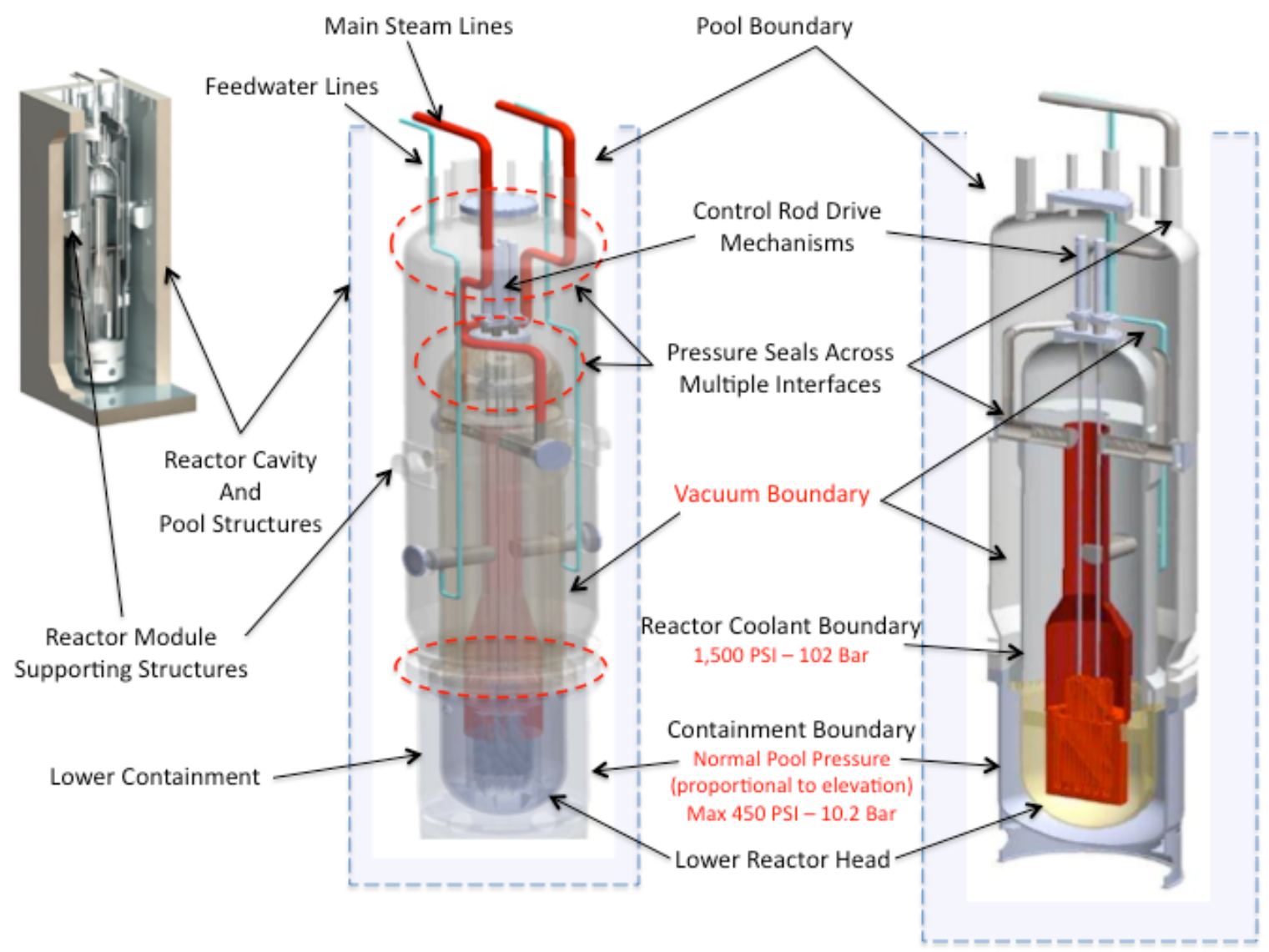

The NuScale proposed containment is very innovative and represents new engineering challenges. For example, during normal operation the containment constitutes a large semi-buoyant system for which supporting structures will need to be designed to prevent upward motion under all credible accident scenarios. Normally, the buoyant effect caused by the water volume displaced by the containment - fully immersed in the pool is counterbalanced by the weight represented by the RPV, its internal components, and the weight of the cooling water circulating in the primary circuit. The net result is that the loads on the seismic supports (see Figure 14) are generally directed downward. Additionally, as soon as the containment is flooded the loads on the anchoring and supporting structures increase proportionally to the amount of water volume filling the annular gap formed by the RPV and the containment, in essence voiding the buoyant effect. However, assuming a very unlikely sudden depressurization of the integral primary circuit combined with a main steam line or feedwater line failure, it is reasonable to expect transient scenarios leading to mechanical load oscillations. A sudden primary integral circuit depressurization could be caused, for example, by a leakage developing between primary circuit and secondary loop if a sufficiently large number of steam generator tubes fail.

Similarly, if a leakage develops from the reactor boundary (see Figure 14) into the "zero pressure" (vacuum) area represented by the annular spaces between the RPV and the 
containment, several complex transients could develop. In these events, sub-cooled liquid water at relatively high pressure $\left(1,500^{4} \mathrm{PSI}-102\right.$ bar $)$ potentially leaking from the primary boundary into the compartments under vacuum will experience a sudden change of thermodynamic state by flashing into super-heated steam. Most likely, these events would then be rapidly followed by sudden condensation phenomena due to mixing of the super-heated steam with cooler water from the pool if the containment is flooded, or simply due to heat transfer between the super heated steam and the cooler inner containment walls (maintained at lower temperature by the water in the pool). All of these events can cause significant pressure/load variations before reaching equilibrium. During such excursions the RPV-containment structure could experience load oscillations exacerbated by the combined effects of a dynamic partially buoyant system. Such transients can also have a complex impact on all cabling, piping penetrations/supporting structures, and seals across the multiple pressure interfaces this design represents (i.e. interfaces between RPV, containment, pool, and atmospheric environment within the reactor building). More generally, these transients have a high potential to develop into specific challenges requiring dedicated PRA approaches, investigations, analyses and testing.

Maintaining hermetically sealed compartments between the RPV and the containment will also represent some technical challenges. In this design, there are in essence two pressurized vessels positioned one inside the other with multiple penetrations across both vessels and different pressures at each interface. The penetrations will be characterized by expanding/contracting piping, welding, and fittings that should remain hermetically sealed across both vessels and with respect to the pool environment. Piping, fittings, weld-joints and seals expansion and contractions need to take into account dimensional variations induced by cold start-up temperatures all the way to normal operating temperatures, and possibly temperature excursions induced by transients. Should a minor leakage develop in any of these compartments at different pressures there seems to be minimum or no room for maintenance/repair crew intervention. Based on publicly available information, it appears that the only way for inspection, maintenance, and/or repair requires full disconnection of all hydraulic and electric circuits crossing the containment/RPV interfaces, and removal of major components forming the module. Additionally, if leakages, potentially carrying coolant with fission products, develop within the compartments under vacuum these regions would no longer be accessible by personnel. In such cases, inspection, maintenance and repair could solely be executed via specialized robotic equipment. Such equipment might represent another layer of challenges, in terms of robotic performance, reliability, and time to execute even a simple repair. All of these factors translate into added operational cost.

Of course, these challenges are suggested through the observation of preliminary and incomplete technical information publicly available. Clearer aspects, procedures, and design characteristics will be available once NuScale submits the Design Certification

4 Technical specifications are extracted from NuScale documents publicly available. However, different NuScale documents and presentations report inconsistent technical specifications. For example, according to a presentation made public on September 2009, the operating pressure is 1,850 PSI. The 1,500 PSI data is relative to a more recent document. Most likely the design is undergoing optimization reviews and the final technical specifications will be reported in the Design Certification Application. 
Document (DCD) to the NRC. In these official documents, all of the technical and operational challenges are normally addressed or provide the means for technical problem identification by NRC staff. 


\section{Containment Technical Specifications}

Figure 15 illustrates additional containment technical specifications and dimensions as provided in publicly accessible NuScale presentation material.

Figure 15. NuScale Containment Technical Specifications

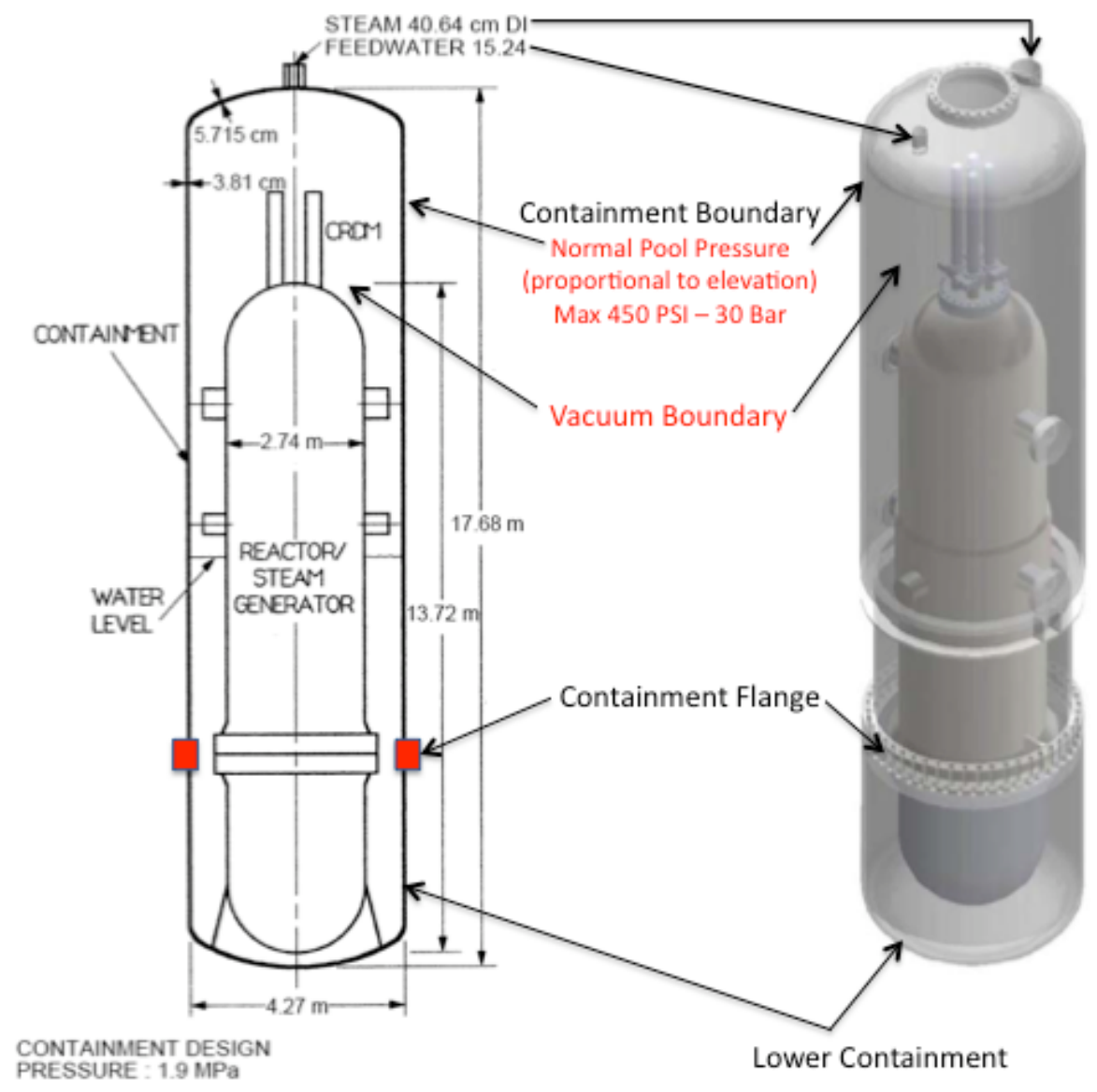

According to NuScale designers, the containment is constructed with carbon steel alloys with walls thicknesses ensuring pressurization capabilities up to 450 PSI (approximately $\sim 30$ bar). During normal operation, the pressure differential across the containment walls will be the result of the compound effects caused by a vacuum inside the containment and the pressure caused by the water head increasing with depth from pool surface level to the bottom of the containment (see Figure 13). The feedwater and main steam lines are hydraulically connected to the RPV internal steam generators through containment penetrations. For most operational purposes, the top containment is mechanically coupled $^{5}$ to the top sections of the integrated RPV.

The RPV is inclusive of instrumentation and power and control cables. For example, power cables will supply electric power to the pressurizer's heaters, additional cables are needed to control opening/closing sump-, auxiliary water, and sparger injectors valves, as

\footnotetext{
${ }^{5}$ Based on publicly available literature review it is not clear how the top portions of the RPV can be safely accessed without requiring massive overhaul and downtime.
} 
well as motive power cables and sensors will be connected through the containment penetrations to drive the Control Rod Drive Mechanisms (CRDM), and sensors cables will be required for connections with the in-core instrumentation. Overall, short-term monitoring, maintenance, and repair activities perhaps prompted by a faulty sump valve or CRDM might be significantly impaired by the NuScale containment configuration, or could require long down-times to allow for the containment to be at least flooded, disconnected from all piping as well as power and sensor cables, disengaged from its supporting structures after separation from the bottom sealing flange, lifted all together with the top portion of the RPV inclusive of the integral steam generators, and all of this to repair a potentially malfunctioning sump valve, or any other in-containment component. Possibly a mitigating strategy for these type of operations will be based on adoption of extremely high reliability equipment, as well as equipment redundancies (which again affects PRAs and might require additional regulatory scrutiny).

NuScale designers offer a containment vessel that in case of pressurization will be capable of safely reaching 450 PSI ( $\sim 30$ bar). Should coolant from the RPV leak into the containment, the initial vacuum and the equilibrium pressures allowed within the containment will favor relatively high condensation rates, as long as the water in the pool is maintained at the proper temperatures and the containment remains submerged in the cooling pool. Another advantage offered by this design is represented by the elimination of hydrogen combustion due to absence of oxygen. Hydrogen is produced under severe accident scenarios when PWR-type fuel cladding is overheating in the presence of steam. As the annular compartments between the RPV and the containment walls are under a vacuum (no air-oxygen), should hydrogen form and escape into the containment there is no possibility for this gas to ignite.

However, although very unlikely, a combination of failures could present an accident scenario in which the core is poorly cooled, hydrogen is formed and finds its way into the turbine building through failed steam generator tubes, or into the nuclear building as a result of misalignment of proper valve opening/closing in response of an emergency. These events can occur for all SMR designs as well as for commercial reactor fleets. The total estimated carbon steel mass for the NuScale containment (assuming 7.9 gram $/ \mathrm{cm}^{3}$ and approximated dimensions provided in Figure 15) is approximately 360 tons, placing the total amount of carbon steel-per-megawatt for this design at approximately 8 tons/MWe. Comparatively the carbon steel required to construct the liner of a large AP1000 reactor design is approximately 3,340 tons. As a result, the total containment carbon steel for the AP1000 is approximately 2.8 tons/MWe. If these estimates are extrapolated to a 12-module $540 \mathrm{MWe}$ NuScale-design based power station, requiring proportionally $12 \mathrm{NuScale}$ containments, the total amount of carbon steel required will be approximately 4,320 tons, for a station with less than one half the electric power capacity of the larger design used in this comparison. Figure 16 summarizes these aspects. 
Figure 16. Carbon Steel Requirements for NuScale vs. AP1000 Containment Steel Liner

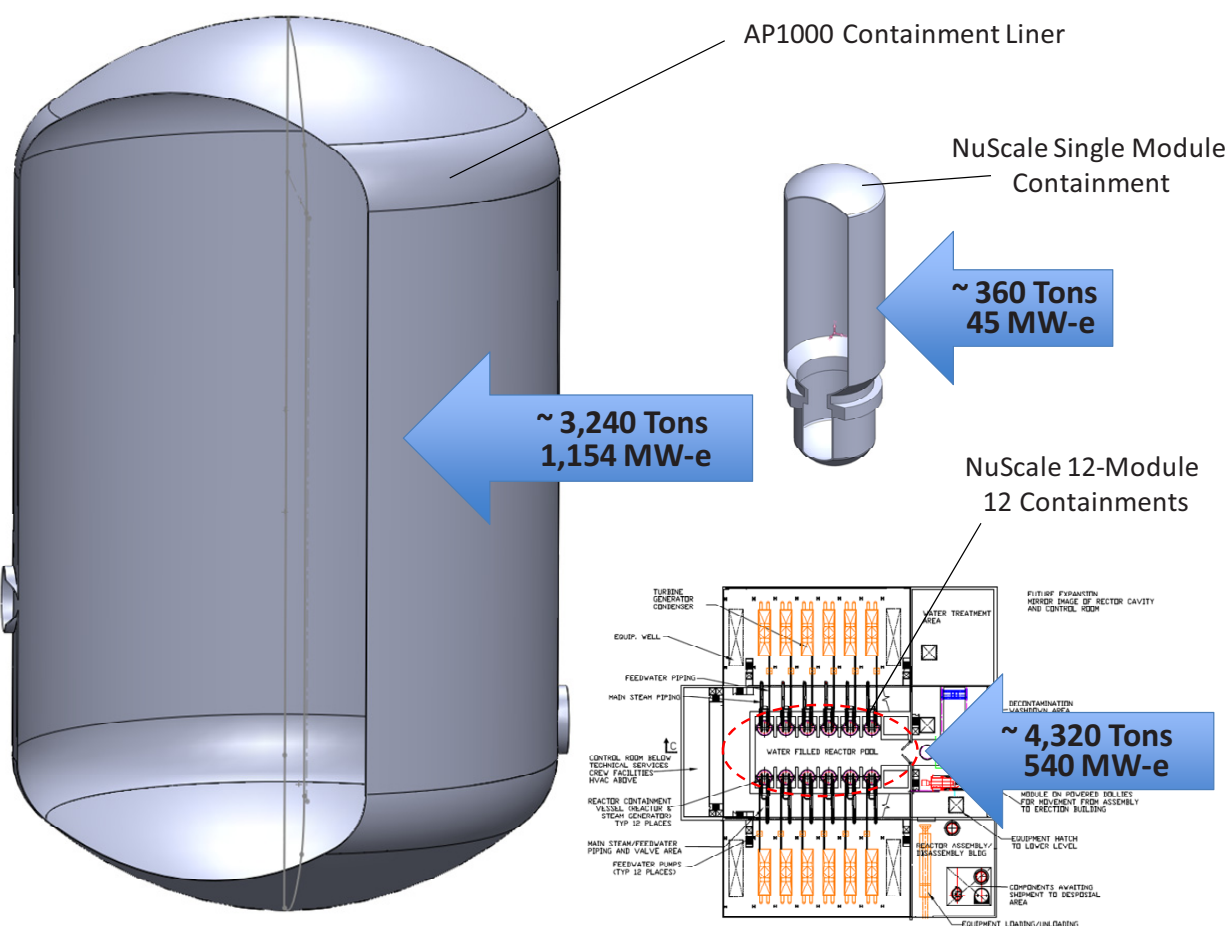

The chart in Figure 17 is extracted from a 2009 NuScale presentation, and, on a MWe basis, it appears to significantly underestimate the total amount of carbon steel required for the NuScale containment as compared with the AP1000. In fact, according to analysis based on a $44.5 \mathrm{~mm}$ thick ( $\sim 1.75$ inches) AP1000 container liner and the NuScale dimensions provided in Figure 8, the NuScale containment would result in approximately 8 tons/MWe, instead of the $\sim 2.4$ tons/MWe shown through publicly available presentation material (these calculations are approximate). 
Figure 17. NuScale vs. AP1000: Forgings, Containment Steel, and Valves

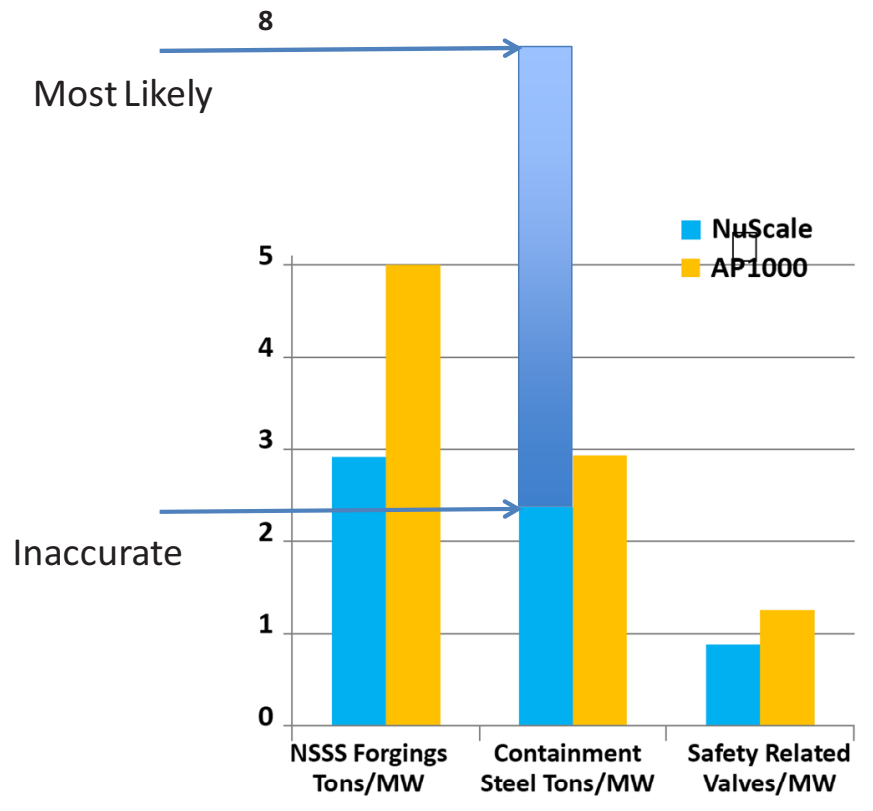

Containment Heat Removal System (CHRS) and Decay Heat Removal System (DHRS)

During normal operation the containment is fully submerged in the cooling water contained in a pool formed by the reactor cavity. Normal operation pressures exerted on the containment walls are characterized by the combined effect of a near vacuum inside the containment and gradually increasing pressure proportional to the relative depth from the pool surface ${ }^{6}$. In this design two independent and passive decay heat removal configurations are proposed.

In one configuration, during shut down operations, decay heat removal is achieved by partially flooding the annular compartments formed by the RPV and the containment so as to provide a heat transfer media enabling exchanging thermal energy between the core inside the RPV and the cooling water in the pool across multiple pressure vessels. With reference to Figure 18, as the containment's wall is formed by thermally conductive materials, and its external surface is fully submerged in the cooling pool, decay heat can be removed according to the following simplified procedures:

- The RPV is depressurized so as to allow venting of steam from the RPV vent-valves through the RPV volume dedicated to the pressurizer into the containment;

- Steam expanding into the volume above the RPV top hemispherical head condenses upon natural cooling mechanisms

6 With increasing depth from the surface of the pool the pressure head increases proportionally, thereby manifesting as forces applied to the containment walls directed inward toward the center of the containment with maximum at the bottom containment head located at approximately 23-25 meters of depth with respect to the pool surface. 
induced by the containment walls as they are maintained at lower temperatures by the cooling water in the pool;

- Condensate (water) flows downward and into the "containment sump" through the sump-valves (open during these processes), thereby maintaining the bottom containment flooded and enhancing heat transfer from the core across the RPV walls, into the flooded areas, and across the containment walls through the cooling water in the pool;

- As water in the sump is heated by the core while cooled by the containment walls it undergoes a passive recirculation flow that maintains core cooling, as long as:

- The core remains submerged under all credible scenarios;

- Vent- and sump-valves operate as designed and do not represent flow restrictions impairing passive re-circulation mechanisms for all transients at different mass-flow-rates;

- Pressure differentials across RPV and containment interfaces do not overcome generally weak passive driving forces - thereby possibly impairing siphoning of coolant from the flooded containment into the RPV;

- A minimum water volume in the pool remains available for cooling even after prolonged decay heat removal conditions this implies that water pool evaporation is mitigated by external cooling means (i.e. actively driven pumps and heat exchangers), or this water is replenished by external cooling water sources;

The design is equipped with depressurization mechanisms configured to vent steam via 4 redundant main steam valves discharging into the cooling pool via spargers. To conserve cooling water the steam vented through the two sparger sets (see Figure 18 and Figure 19 ) is condensed back into the cooling pool, thereby increasing the temperature of the cooling water in the pool. As steam is discharged at the top of the cooling pool and in the absence of active mixers the results could be the formation or "stratification" of layers of hot water at the top of the pool (see Figure 18 and Figure 19). Passive coolant recirculation systems might be impaired by localized pockets of hot water in the top regions of the cooling pool. 


\section{Figure 18. Decay Heat Removal Scheme Based on Containment Sump Cooling}

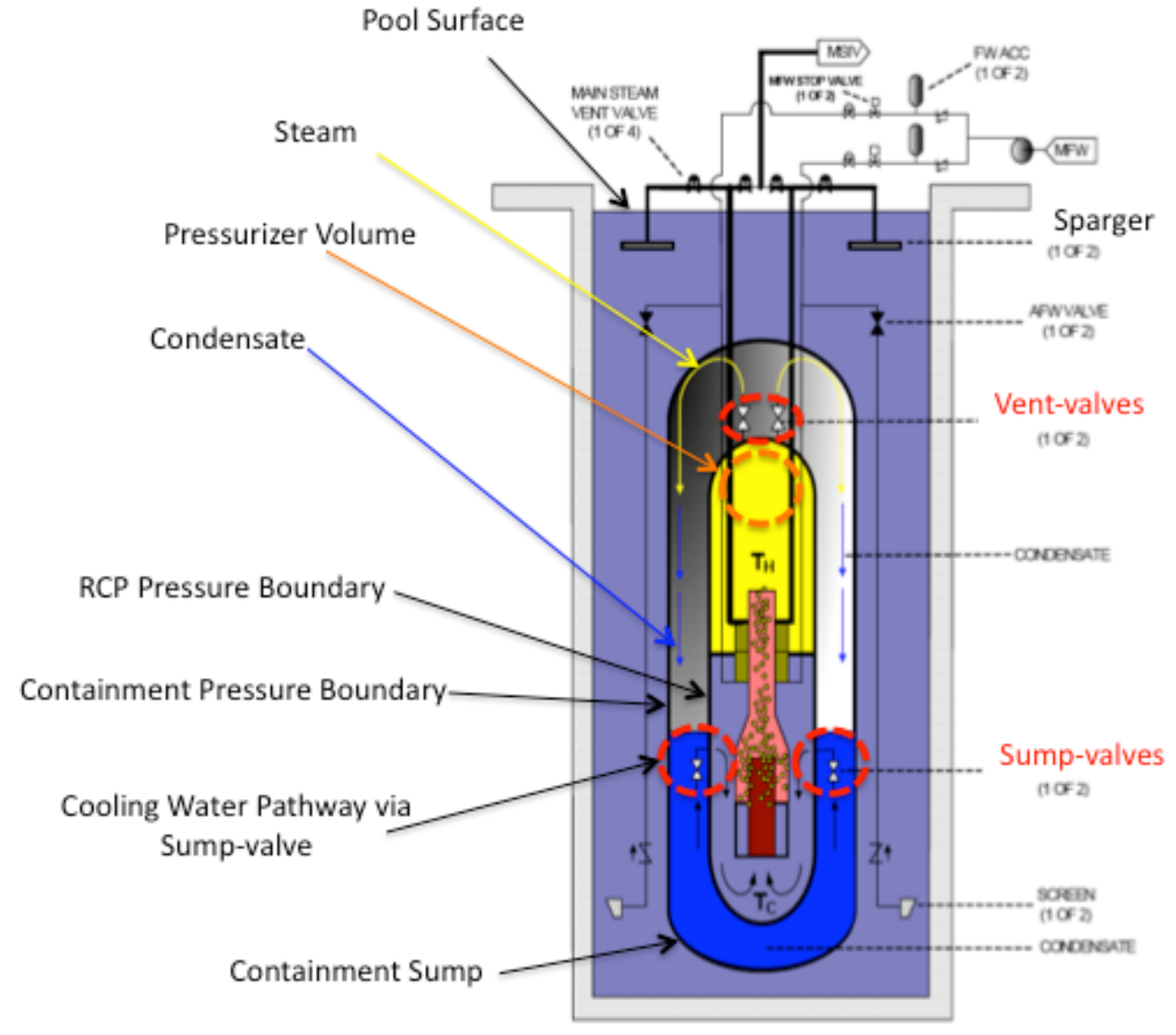

Additional sources of cooling water are provided by means of pressurized feedwater accumulator tanks. The accumulators are pressurized by the feedwater pump(s) (respectively FWACC and MFW in Figure 19) with suction possibly connected to a feedwater reservoir not shown in the diagram. Overall, this configuration assumes that the total volume of cooling water contained in the reactor cavity pool is sufficient to avoid boiling-off with subsequent loss of water via evaporation when all combined heat loads are released in the cooling pool for prolonged amounts of time.

The main advantage offered by this decay heat removal scheme is represented by the design claimed ability of maintaining the core submerged and cooled without relying on electrically-driven pumps for coolant circulation. As this design relies on passive cooling mechanisms that do not require AC motive power, it also does not require safety related Electric Diesel Generators (EDGs). However, provisions ensuring minimum electric energy availability while the station is under potential Loss Of Offsite Power (LOOP) and/or under Station Black Out (SBO) events, will be required as "active power" (based on reliable AC sources) is needed to actuate and control the various valves, feedwater pumps, and other vital systems during accident scenarios that may occur under LOOP/SBO events. 
In case core cooling via passive recirculation with a partially flooded containment is not achievable, the design offers another independent decay heat removal mechanism. In this alternative configuration decay heat is removed by utilizing the integral steam generators as heat exchangers thermal-hydraulically reconfigured so as to thermally couple the cooling water in the pool directly with the primary coolant circuit within the RPV. Similarly to the configuration previously described, this alternate core cooling mechanism relies on passive gravity-driven recirculation. In this cooling scheme the primary circuit remains pressurized to avoid steam formation and to ensure passive siphoning throughout the primary circuit as a result of cooling occurring in the top portions of the RPV. In these regions of the RPV hot coolant from the core flows upward as a result of decreased coolant density and as it flows through the integral steam generators it cools down by thermal exchange with the secondary side of the steam generators. This side is thermal-hydraulically connected to the external or secondary loop normally feeding the power conversion unit (i.e. turbine-generator). Under these conditions the steam generators inlet and outlet are reconfigured through opening and closing of selected valves so as to allow for cold cooling water from the cooling pool to circulate through piping outside of the containment (see Figure 19). This dedicated piping system is connected to screens positioned at the bottom of the cooling pool and to the inlet headings of the steam generators at its respective opposite ends. Under this cooling scheme the pressure on the tube side of the steam generators is significantly lower ${ }^{7}$ than the primary circuit pressure. As a result, cooling water is passively withdrawn from the cooling pool by passive siphoning effects and flashes to steam once circulating through the steam generator, thereby effectively cooling the water circulating in the primary circuit. Steam exiting the steam generators outlet headings then vents at relatively low pressure inside the cooling pool wherein it condenses (and increases the water temperature in the cooling pool).

7 With reference to Figure 19, the pressure at the exit of the steam generator is given by the cumulative effect of atmospheric pressure in addition to the pressure head represented by the depth at which the steam spargers are positioned from the free pool surface. 
Figure 19. Decay Heat Removal Scheme Based on Steam Generators Cooling

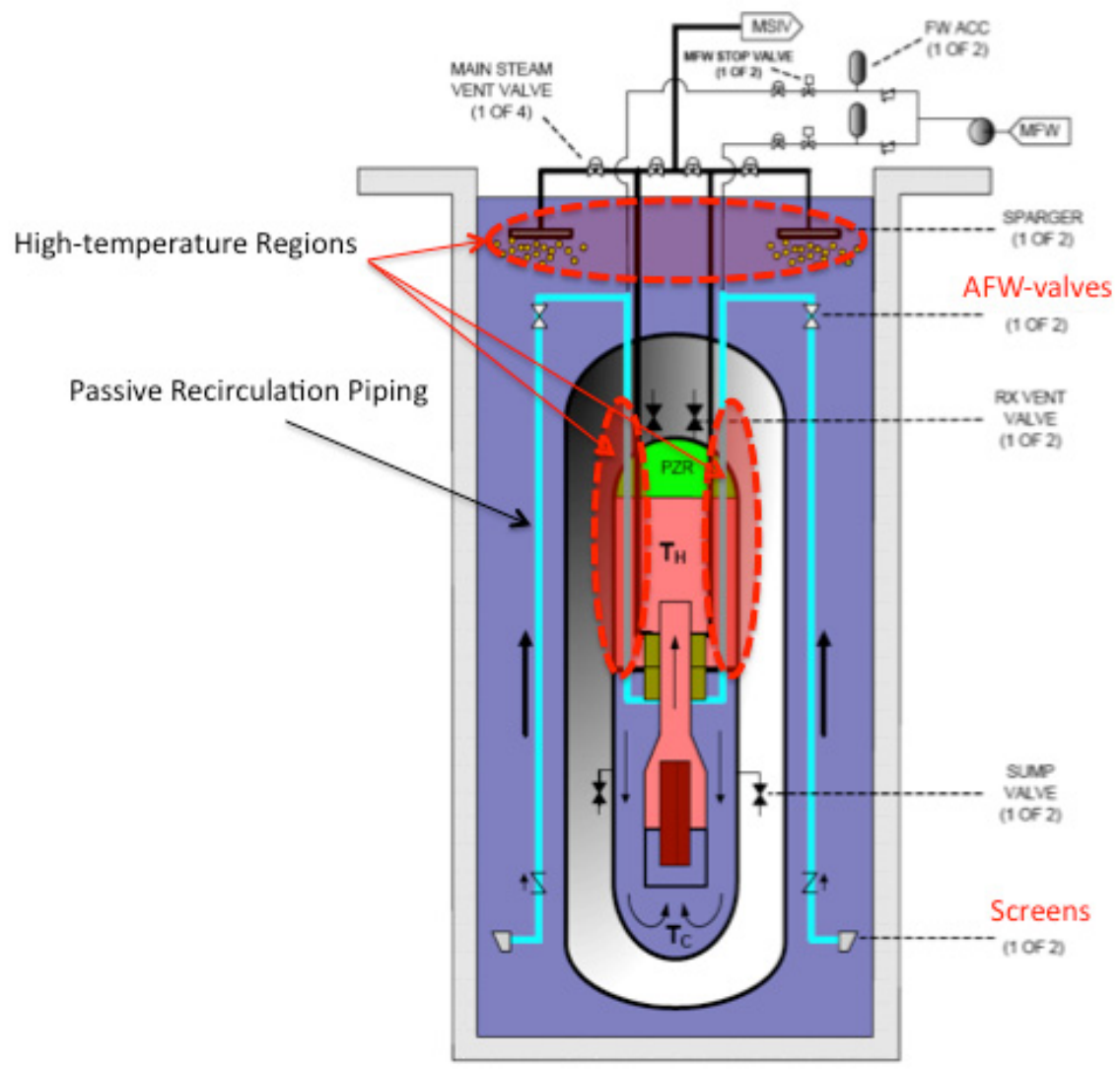

As illustrated in Figure 19, the decay heat removal considered by this scheme employs a different set of valves operated while the sump- and vent-valves are maintained in their closed position. Most importantly, it assumes that the pressure gradients across the piping from the screens at the bottom of the pool to the inlet of the steam generators result in a gravity-driven coolant recirculation flow. This implies that the pressure at the screen inlet is always greater than that at the outlet nozzles of the steam spargers and that the passive recirculation flow is able to overcome fluid frictions caused by valves, pipe restrictions, elbows, as well as the exposure to pockets of heated water (generated by the venting steam at the top of the pool), and/or direct pipe walls heating while passing through the pressurizer if the hydraulic penetration is located on the top hemispherical RPV head with inadequate insulation. If these hydraulic connections are as indicated in Figure 20 - all of these diagrams are extracted from publicly available literature - the problem of exposure of this piping to hot pocket of cooling water in the pool is significantly mitigated. More generally, to ensure that the top portions of the "Passive Recirculation Piping" indicated in Figure 19 and Figure 20 remain unaffected by increased pool temperatures, possibly localized at the top regions of the pool, thermal insulation might be required. Insulating and maintaining these systems sealed through multiple pressure boundaries penetrations, represent a very high potential to develop into challenges. 
Figure 20. Optimized Decay Heat Removal System via Steam Generators

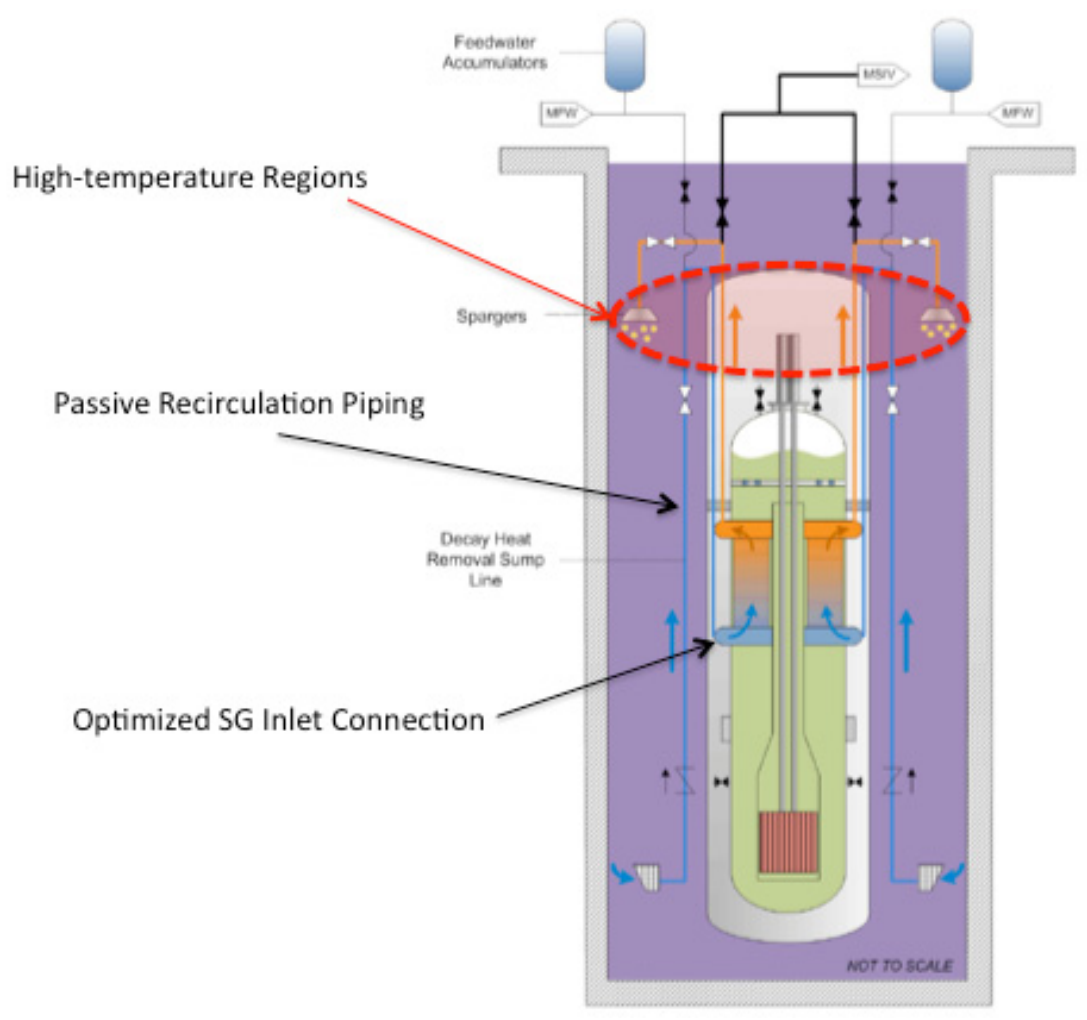

Overall, the passive decay heat removal systems proposed by this design are highly simplified when compared to similar PWR systems utilizing active (electrically-driven) heat removal mechanisms entirely relying on forced coolant circulation. Since access to inspect, monitor, and maintain the actuators of critical components as represented by the steam vent-valves, or sump-valves is limited, perhaps executable only through robotics, the reliability and associated PRAs for these components will most likely have to be analyzed on a system-specific basis. Under all credible accident and transient scenarios, some of the passive-driven safety aspects of this design have a high probability of not been sufficiently similar to work executed on large LWR designs also relying on passive safety features (i.e. AP600 and AP1000) as referenced by the NuScale design. Also for these reasons, there is a high probability that the NRC review process will require system-specific testing and validation that could affect the NuScale timeline. These observations are based upon reviews of highly simplified technical diagrams as the ones shown in Figure 18, Figure 19, and Figure 20 found in publicly available literature. More accurate and detailed analyses will be achievable once NuScale formally submits documentation forming a complete application for the NRC design certification. 


\section{Integrated Reactor Pressure Vessel (RPV) Technical Specifications}

The RPV is formed by forged carbon steel cylindrical and hemispherical structures welded and flanged with lined stainless steel cladding to protect the internal surfaces from the normally corrosive effects induced by the coolant. Figure 21 illustrates the RPV integrated internals. In this design there are four Control Rod Drive Mechanisms (CRDM) serving a total of 16 control-rod clusters, positioned on top of the RPV hemispherical head via penetrations through the RPV walls. The CRDM will be provided by EMD, a business unit of Curtiss Wright Flow Control Co. The integral steam generators are formed by helical coils (technical specifications provided in Figure 21), and are equipped with inlet/outlet hydraulic connections for a total of 2 feedwater-lines, and 2 steam-lines. Two independent integrated once through helical coil steam generators are mechanically suspended through cross structures connected to the RPV and utilize stainless steel and nickel-chromium alloys for components under high velocity flow. NuScale plans to employ a total of 1,000 tubes per steam generator with average tube lengths of approximately $73.2 \mathrm{ft}(22.3 \mathrm{~m})$. Steam venting valves and feedwater valves are located inside the containment pressure boundary.

Figure 21. Integrated RPV Technical Specifications

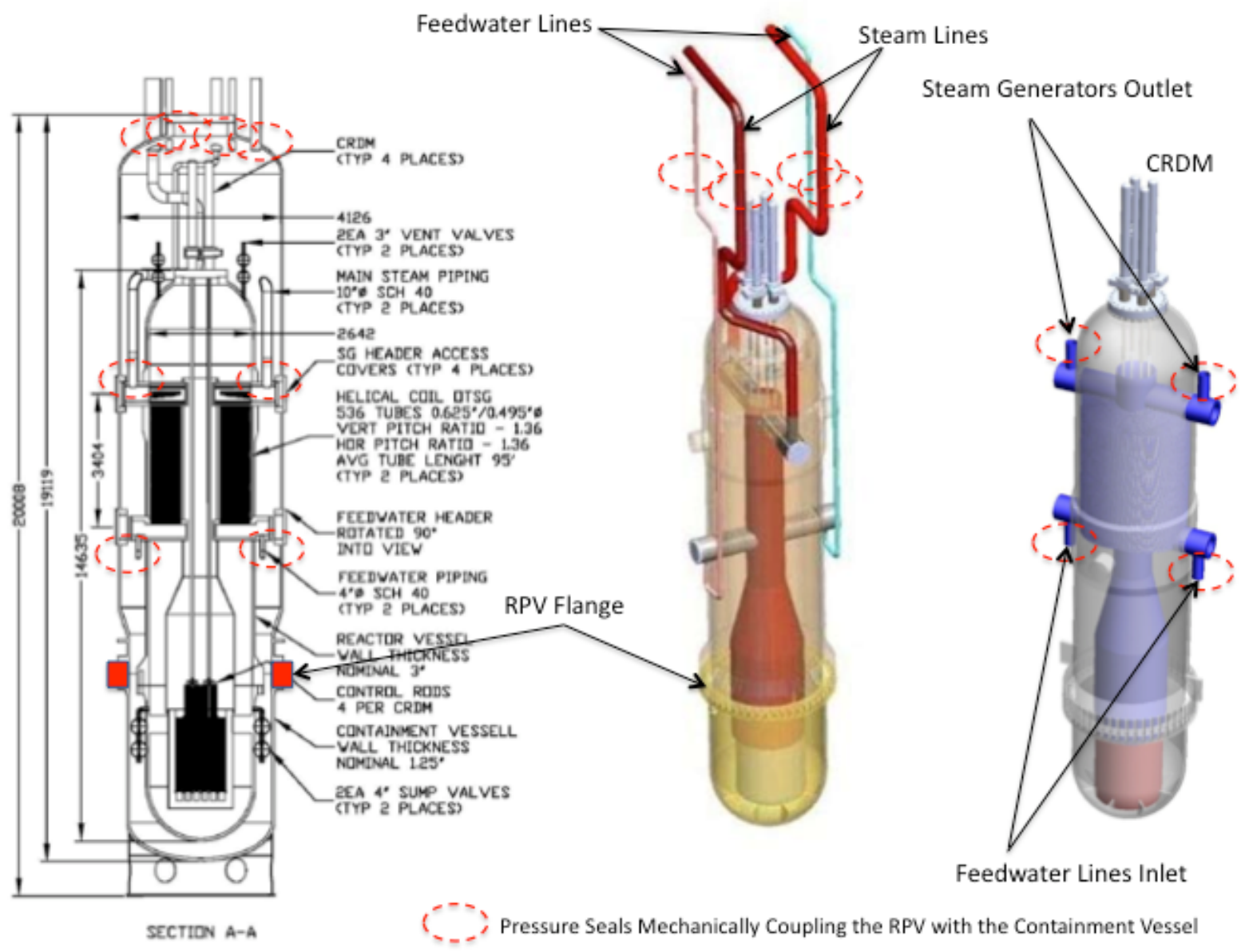

From a design preliminary review it appears that the actuators for these valves will operate under a vacuum (normal operation), or under water when the containment is 
flooded. Both environments will not prevent operating these valves electrically, pneumatically, or hydraulically. For example, as some valves will need to be throttled they can be motor-assisted (electrically driven), pneumatically, or electro-magnetically driven via solenoid normally actuated and controlled for fully open or fully closed operation. Most likely electrical connections providing actuating power as well as sensors/encoders signals for control purposes are provided through dedicated penetrations through the RPV and the containment pressure boundaries.

Removal of the top RPV structures via disconnection of the bottom flange provides access to the core for refueling and maintenance operations. Two reactor vent- and sump-valves are also located in the annular compartments formed by RPV and the containment.

\section{Core Specifications}

The core characteristics of the NuScale design are those of a conventional PWR core with 24 fuel assemblies formed by $17 \times 17$ standard PWR assemblies with fuel rods and assemblies length of 6 feet - approximately half the length of typical large PWR cores. Operating pressure for this core is approximately 1,500 PSI (typical PWRs operating pressure is approximately $2,200 \mathrm{PSI}$ ) at a core outlet coolant temperature of $575^{\circ} \mathrm{F}$ $\left(\sim 301^{\circ} \mathrm{C}\right)$, and a coolant mass flow rate passively driven at approximately $4.8 \mathrm{Mlb} / \mathrm{hr}$ $(\sim 600 \mathrm{Kg} / \mathrm{s})$. The NuScale core is illustrated in Figure 22. 
Figure 22. 24-assemblies in NuScale 160 MWt Core

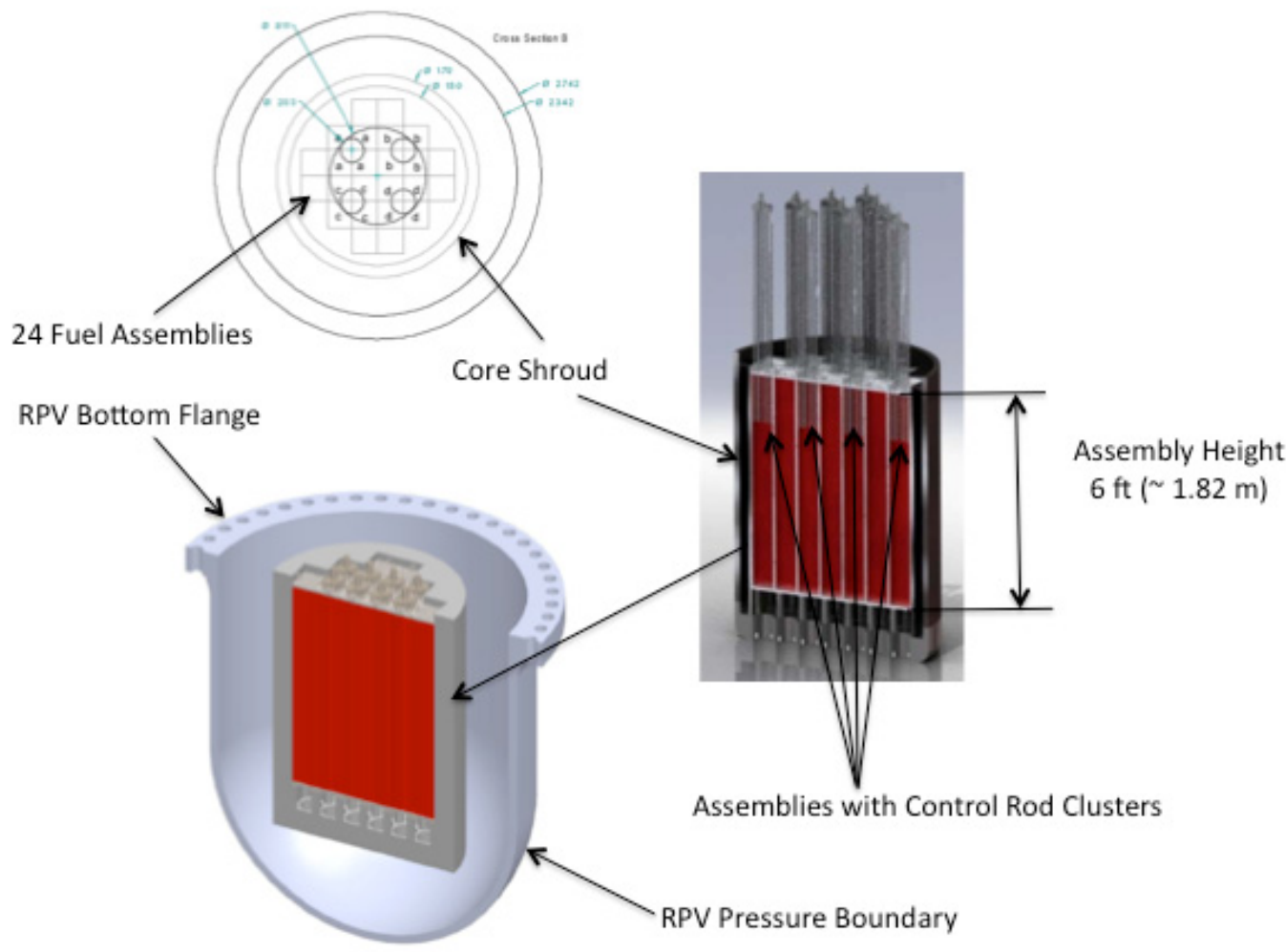

As the thermal-hydraulic performances of this design are based on passive recirculation (no electrically-driven recirculation pumps) of the coolant through the core, loadfollowing capability will be somewhat limited by the ability of the core to rapidly and safely adjust its power ratings to electrical demand variations.

To access the core, or any component, even external to the NuScale RPV (i.e. control rod drive mechanisms, sump-, vent-, AFW-valves), will require removal of the top portions of the containment and all of its hydraulic and electric connections. During refueling operations the decay heat removal system maintains long-term core cooling. Through reviews of publicly available documentation ${ }^{8}$, refueling occurs according to a sequence summarized in a NuScale presentation slide reproduced in Figure 23.

\footnotetext{
8 Downloadable at: www.nuscalepower.com/pdf/NRC preapp mtg 072408 DESIGN 2 no animation .pdf
} 
Figure 23. NuScale Refueling Process

\section{Refueling Process}

- Reactor shutdown using normal feedwater

- Decay heat removal transferred to passive DHRS

- Containment partially flooded

- Module disconnected from all piping and instrumentation

- Module is connected to crane and transferred to refueling pool

- Lower containment is removed

- Lower reactor head is removed

- Core is shuffled/reloaded

- Replace lower reactor head and containment

- Module is transferred back to reactor bay

- Module is reconnected

- Containment is drained and module is restarted

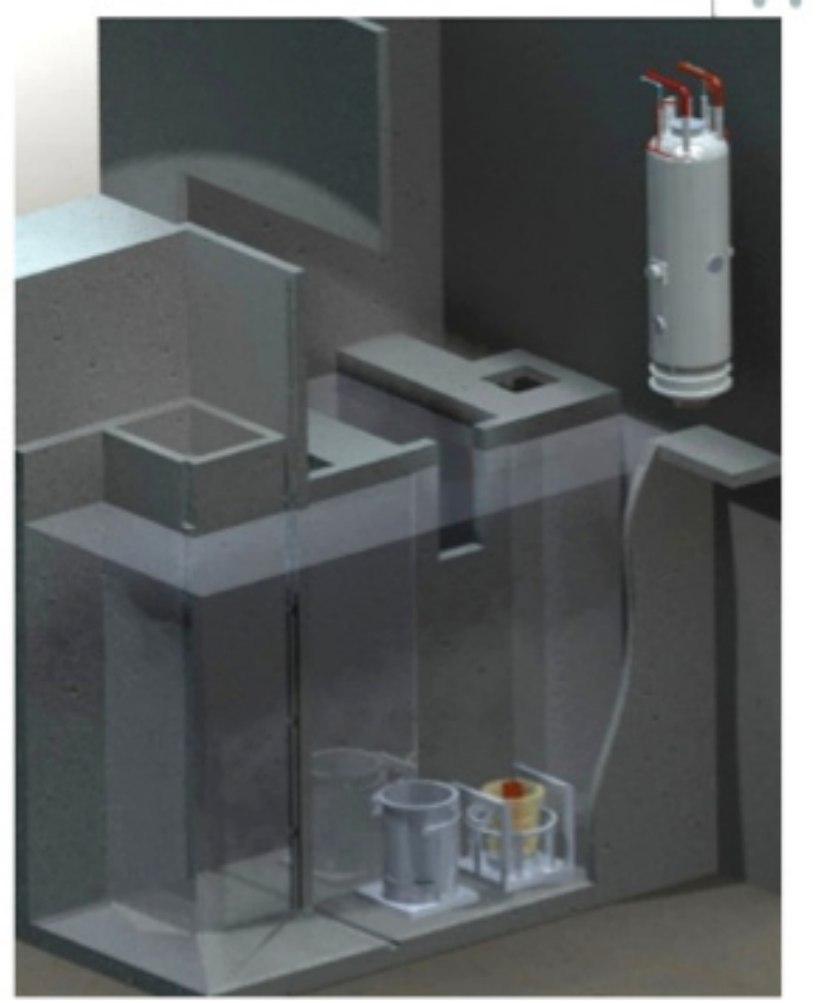

Source: Slide 12 NuScale Presentation, July 24, 2008

According to this slide, by comparing the design features discussed under the report section dedicated to "Containment Heat Removal System (CHRS)" with the "Refueling Process" sequence illustrated in Figure 23 it becomes unclear how the module can be hydraulically disconnected from the various thermal-hydraulic systems while at the same time ensuring decay heat removal via the Decay Heat Removal System (DHRS). More specifically, Figure 18, Figure 19, and Figure 20 illustrate how two independent passive cooling mechanisms accomplish the functions of decay heat removal. To ensure that these passive cooling mechanisms operate as designed, a delicate balance between various key parameters involving pipes/elbows dimensions, total pool elevation, coolant temperature gradients from pool bottom to surface, and several others must be maintained within reasonable margins and under various core-cooling scenarios. Additionally, core cooling must be maintained while disconnecting the top containment structures (inclusive of core instrumentation providing real time core data), transferring of these structures to a refueling pool, and removal of the bottom containment head. All of these operations seem overly complex and represent significant core-cooling mechanisms departures from the designed natural convection flow patterns achieved with the containment and RPV operating as indicated in Figure 18, Figure 19, and Figure 20. Further, according to the sequence indicated in Figure 23, as the core is inside the RPV's bottom hemispherical head and fully contained within the bottom containment head, it appears that the whole 
open core would be lifted underwater and removed from the bottom containment hemispherical head. Again, it is unclear how all of these operations can occur while maintaining decay heat removal systems piping and ancillary equipment connected at all times. At this time there is insufficient information to qualitatively analyze and assume that adequate decay heat removal can be provided if the whole core is positioned at the bottom of the cooling pool (without the engineered cooling provisions represented by the DHRS).

\section{Modularity and Multiple Module Complex}

The NuScale modular design is offered as a single module coupled with a dedicated electric power generation unit completed with Balance of Plant (BOP), switchyard, and auxiliary facilities, thereby forming a turn-key electric power station only needing to be connected to the bulk power grid. However, for most customers, the company is envisioning the NuScale plant to consist of multiple modules built in a series. Figure 24 provides a top view illustration of a 12-module complex for an electric power station rated at $540 \mathrm{MWe}(12 \times 45 \mathrm{MWe}$ per module $)$.

Figure 24. 12 Module NuScale Plant Configuration

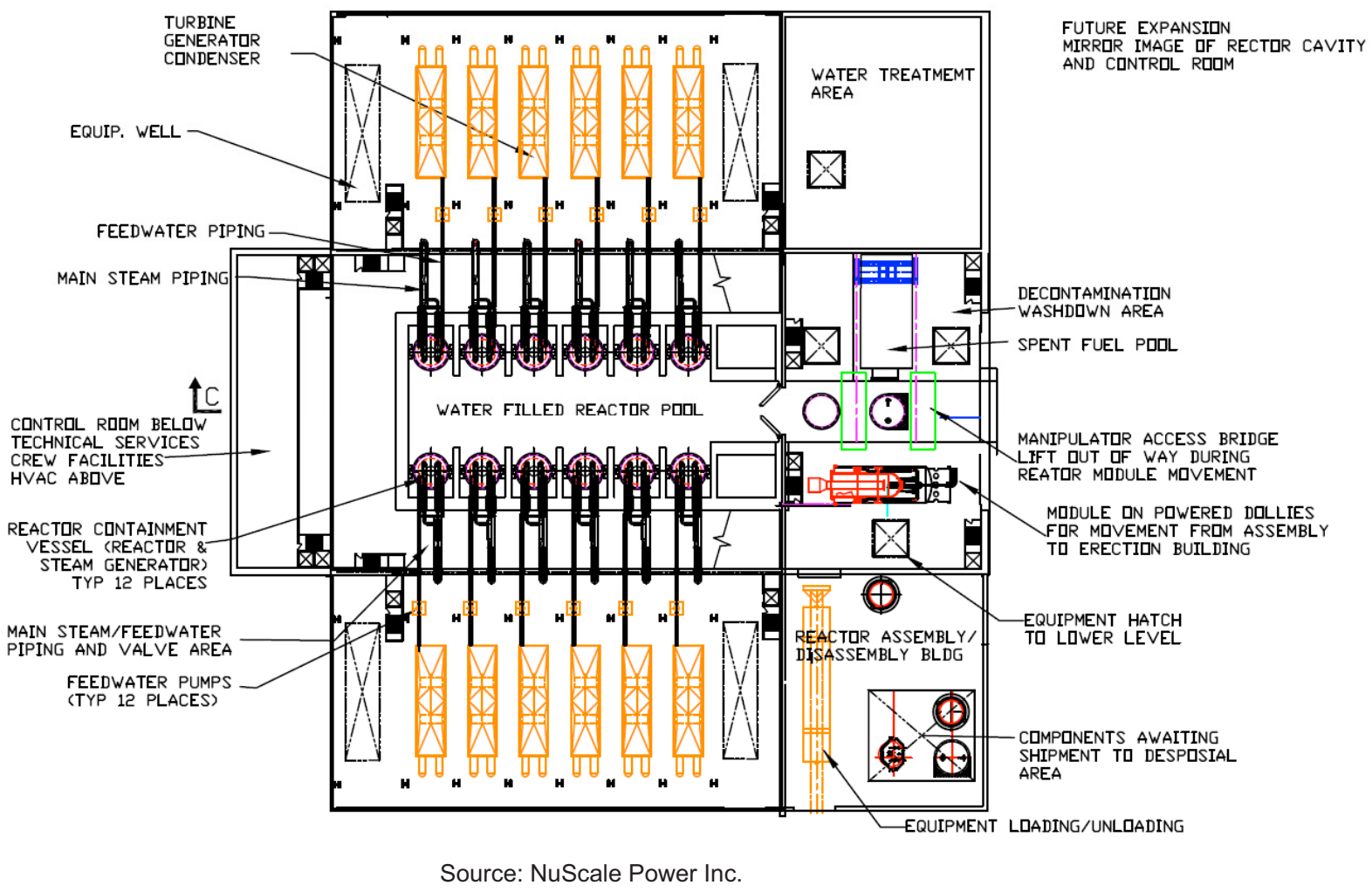

As shown in Figure 24, modularity of this design allows full integration and scaling so as to form a station complex with total electric power production capabilities proportional to the number of modules electrically connected essentially in a "parallel" configuration. Each module is provided with its dedicated turbine-generator set and cooling towers while sharing the water filled reactors pool, spent fuel pool, control room, and other 
facilities and equipment dedicated to movement of assemblies, refueling, disposal, and maintenance.

For the 12-module 540 MWe configuration shown in Figure 24, if operating at the thermodynamic efficiency of $\sim 28 \%$ to produce an electric output of $540 \mathrm{MWe}$, the net thermal power generated by all cores will be approximately 1,920 MWt. If co-generation or heat-processing features are not provided, approximately 1,380 MWt of the total heat energy produced by the station will need to be rejected via cooling towers into the environment.

One of the advantages of modularity is represented by the possibility of gradually scaling the electric power station from a few modules to the number required by electric demand. Figure 25 shows a 6 -module station scaled up to 12 integrated modules by essentially adding cooling towers, expanding or scaling switchyard equipment, and proportionally increasing the total plant footprint.

Figure 25. Scaled-up NuScale Power Station

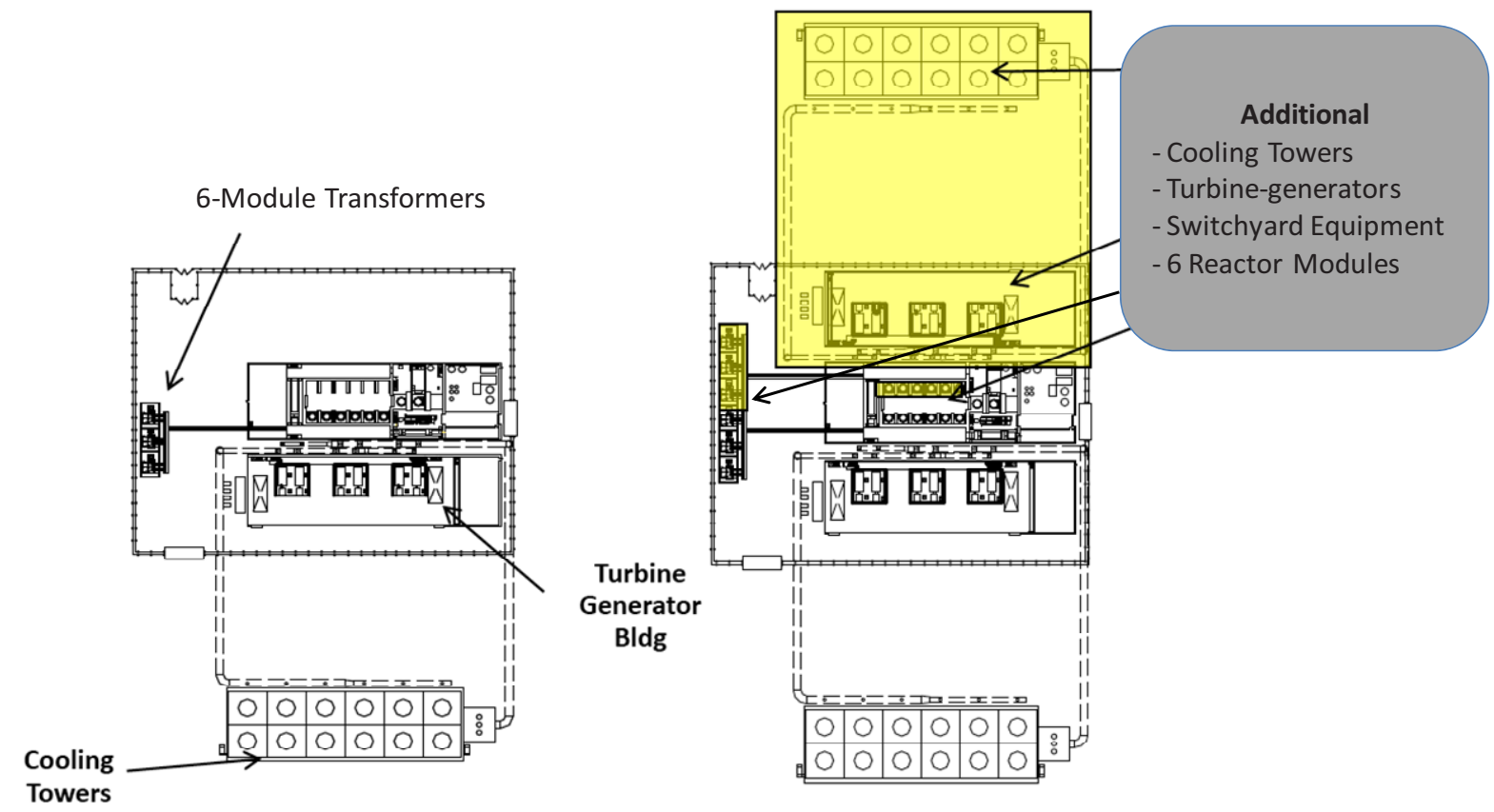

For this particular configuration, the total plant footprint is approximately as shown in Figure 26 while dimensions providing plant equipment elevations with respect to ground level are provided in Figure 27. 
Figure 26. 95,000 $\mathrm{m}^{2}$ 12-Module NuScale Power Station

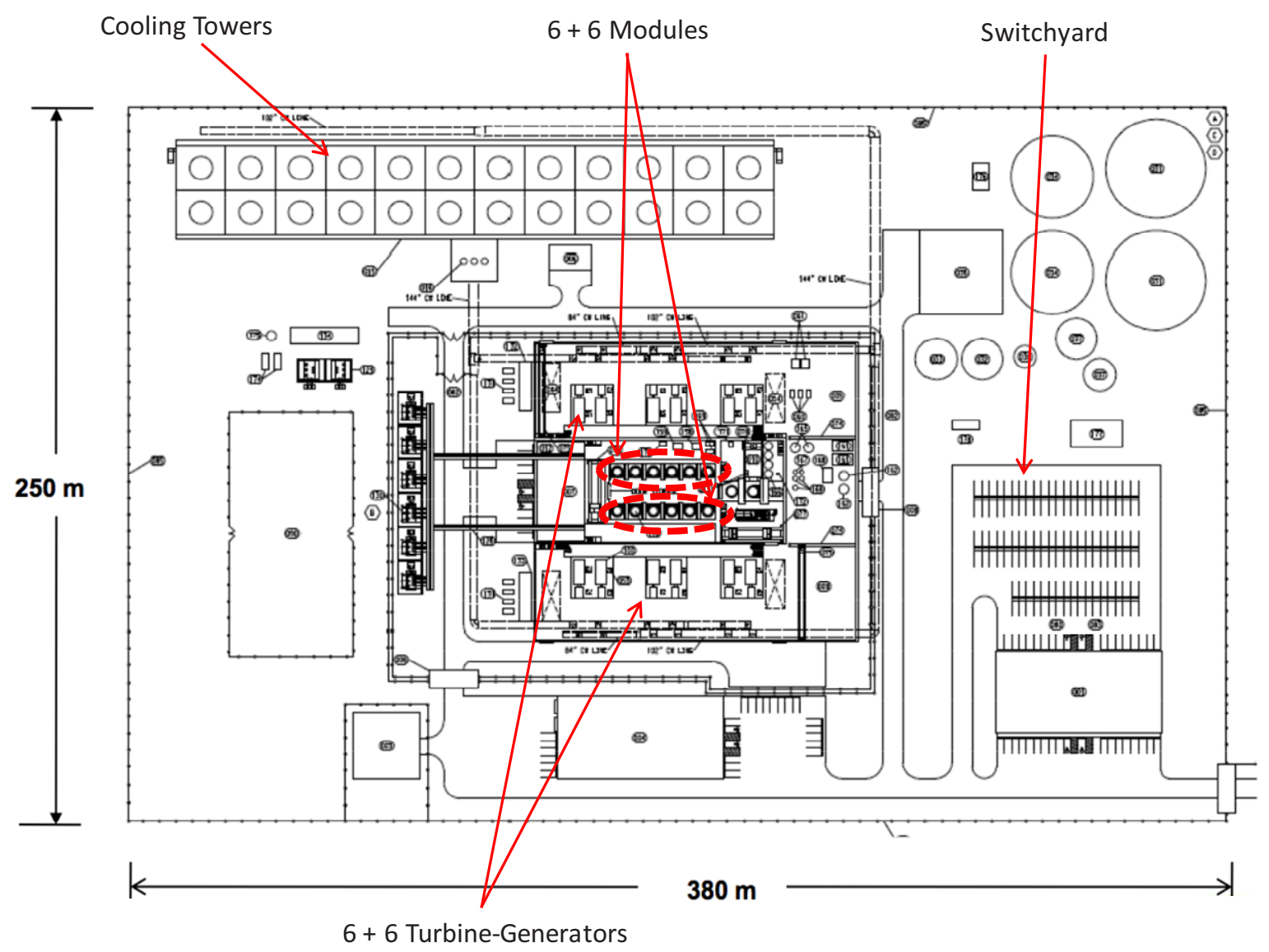


Figure 27. Symmetric Modules Grade-referenced Elevations for NuScale Power Station

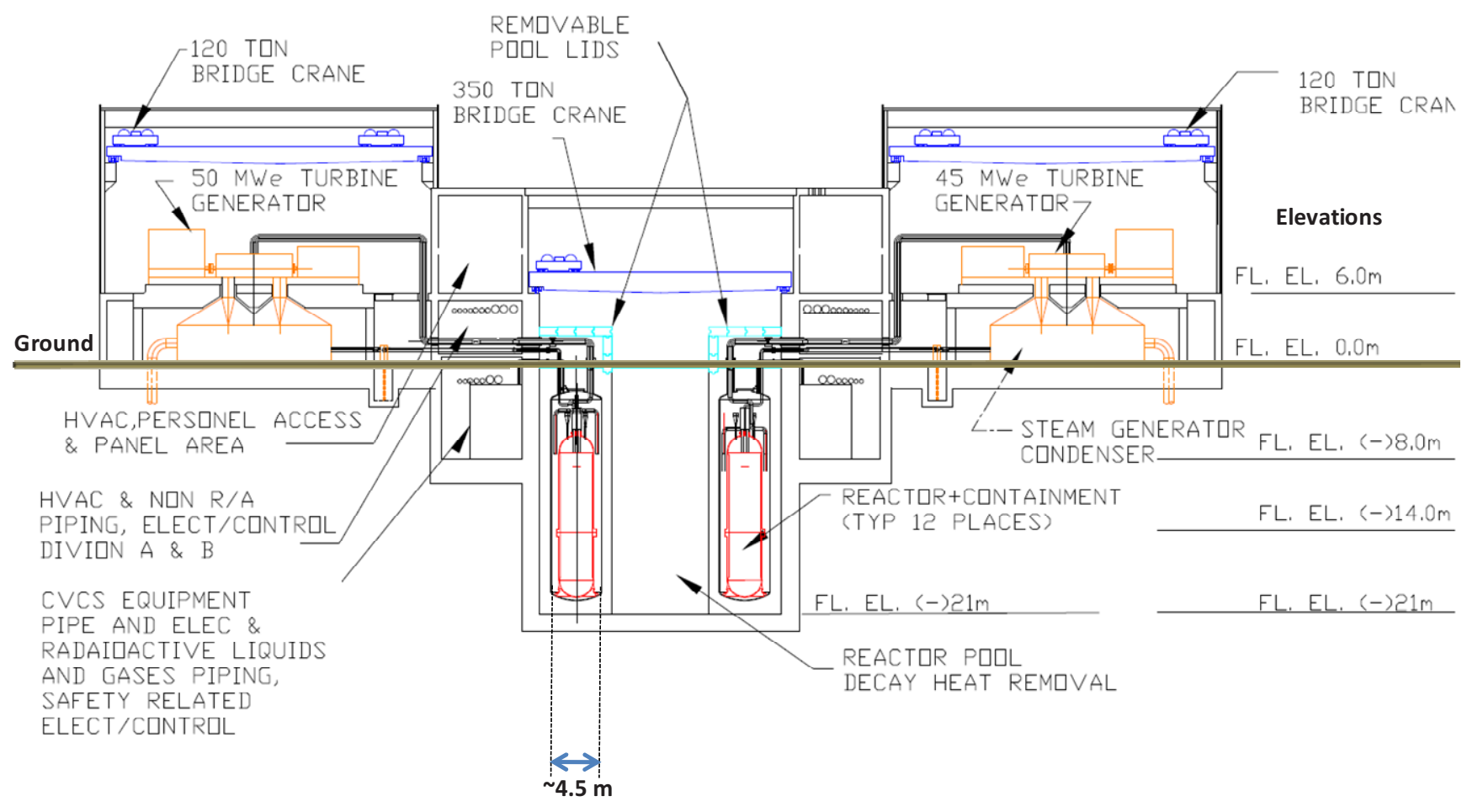

\section{Safety Features}

Most large PWR and BWR designs include a containment surrounding the whole steam supply system. Regardless of the variations characterizing different containment designs, this engineered safety feature is generally represented by very large volumes formed by reinforced steel-lined concrete structures. The purpose of the containment is to ensure that radioactivity potentially released by the LOCA, or directly by the core into the containment volume will not escape into the environment under all credible accident scenarios.

After the September 11, 2001 events, more restrictive standards addressing the impact of modern aircraft crashes on nuclear installations have been proposed and are under development. In addition to the damages possibly caused by the mechanical aspects characterizing various air-crash scenarios, the energetic impact represented by large amounts of jet fuels released near, or inside various power plant structures will pose significant challenges to passive and active safety features. On June 12, 2009, the NRC promulgated the Aircraft Impact Rule (74 FR 28112) requiring design and license applicants for new nuclear power reactors (small and large) to perform a rigorous assessment of their designs to identify design features and functional capabilities that could provide additional inherent protection to avoid or mitigate the effects of a modern aircraft impact. Accordingly, all SMR designers will be required to identify and incorporate design features and functional capabilities that avoid or mitigate, to the extent practical and with reduced reliance on operator actions, the effects of modern aircrafts 
impact on key safety functions. As for all SMRs applying for a U.S. NRC license, NuScale designers will be required to show that, with reduced operator actions:

- The reactor core remains cooled, or

- The containment remains intact, and spent fuel pool cooling or spent fuel pool integrity is maintained.

A conventional containment is designed to withstand pressures in the 60 PSI-100 PSI ( 4 bar-7 bar) range, possibly generated in the unlikely event of a Large Break Loss Of Coolant Accident (LBLOCA). The large volume is necessary to limit the peak pressure induced by the energy contained in the coolant once discharged into the containment volume, for example, as a result of a large coolant pipe failure. From a design standpoint, the containment total volume is fundamentally proportional to the inventory of coolant that could be discharged as a result of a LBLOCA, the energy stored in the coolant at the moment of the accident, and the possible cumulative effects on containment pressure caused by LOCA-induced events as, for example, hydrogen generation ${ }^{9}$ and ignition. Containments are also equipped with features that provide active or passive cooling of the containment surfaces or inner volumes to ensure the containment pressure does not exceed the designed maximum pressure. The impressively large volumes and the additional pressure limitation features represent very high construction and maintenance costs.

The NuScale design offers a significantly smaller containment structure formed by a carbon-steel pressure vessel that, to satisfy containment peak pressure requirements (i.e. resulting from LBLOCA), does not require the concrete super structures seen in large reactor designs. In case of a LBLOCA, and to compensate for the reduced containment volume proposed, the NuScale containment is designed to withstand much higher pressures. According to NuScale publicly distributed information, the design pressure for this safety feature is 450 PSI ( $\sim 30$ bar), detailed containment specifications are provided in the paragraphs dedicated to the "Containment Technical Specification". To withstand such design pressure the containment vessel's walls might have to be provided with increased thicknesses when compared to containment's steel-liners adopted by conventional PWR or BWR containments. One mitigating aspect that allows for a relatively lower thickness for the NuScale containment is reflected by the fact that this system operates fully submerged in the cooling pool, and, as a result, material stresses induced by high-temperature are very unlikely.

Although the NuScale containment will be capable of sustaining higher pressures than conventional containment systems, it appears that the top and at least one side of this containment do not offer adequate air-crash protection. More accurate observations on the adequacy of the containment system with respect to NRC air-crash standards under development will be available once NuScale submits technical assessment addressing the Aircraft Impact Rule (74 FR 28112).

9 As a result of a LOCA hydrogen gas can be produced as a result of three main generation mechanisms: 1- Chemical reaction occurring with high-temperature steam and zirconium in the zircaloy fuel cladding, 2- Containment spray if the coolant exiting the spray nozzles contains sodium hydroxide which could react with certain metals (i.e. aluminum), sodium hydroxide is utilized to remove iodine from the containment atmosphere, 3- hydrogen from radiolytic decomposition of water. 
In addition to safety features characteristics of large reactor designs and inclusive of Shutdown Accumulator Systems (SAS), the NuScale design passive safety features are engineered to ensure decay heat removal through the:

- Decay Heat Removal System (DHRS), and

- Containment Heat Removal System (CHRS)

Technical details about these passive safety features are illustrated in Figure 18, Figure 19, and Figure 20.

Because the RPV is fully contained in a submerged containment system, and the annular spaces formed by the RPV and the inner walls of the containment are kept under a vacuum, the design does not require combustible gas (i.e. hydrogen) control safety features.

The "defense-in-depth" concept represents an approach to designing and operating nuclear facilities in a manner that prevents and mitigates accidents that could result in the release of radiation or hazardous materials. Key to this approach is to create multiple independent and redundant layers of defense to compensate for potential human and mechanical failures so that no single layer, no matter how robust, is exclusively relied upon. Defense-in-depth includes the use of access controls, physical barriers, redundant and diverse key safety functions, and emergency response measures. As the NuScale core is in essence located inside multiple pressure vessels representing physical barriers, and is surrounded by stored cooling water that ensure decay heat removal for a prolonged amount of time, the design is fully in agreement with the defense-in-depth approach. Because of the innovative partially buoyant containment and RPV system, the design offers additional barriers to the escape of radioactivity. The conventional barriers characteristic of most large and small-scale designs are offered by the fuel-cladding, the RPV, and the containment. For the NuScale design the additional barriers are represented by:

- The water inside the containment cooling pool

- Reinforced concrete structure forming the pool

- Containment pool top shield - possibly designed in compliance with air-crash protection requirements (or will be amended to comply with air-crash protection requirements)

- Structures forming the reactor building

The schematic to the left of Figure 28 is extracted from a NuScale presentation and summarizes the NuScale design engineered barriers to the potential escape of radioactivity. According to this information, the design appears to provide a top shield to protect the containment and RPV. However, as qualitatively illustrated in Figure 28, it is not clear how a top shield could effectively protect the containment and RPV from scenarios resulting in impacts to the open areas offered by the cooling pool. As discussed in previous paragraphs, for refueling operations the containment seems to require a fairly 
large open space for the whole structure to be lifted via crane and repositioned inside the open side of the cooling pool. The dashed-blue lines in Figure 28 denote the potentially vulnerable portions of the cooling pool as they appear to expose an entire side of the containment to foreign objects that could penetrate the not heavily reinforced structures of the nuclear island building. These potential vulnerabilities are consistent for a single module as well as for multi-module station configurations. Even attempting to conserve this design configuration and assemble a movable top shield covering the whole open portions of the cooling pool with anti-air crash features, or submerged reinforced "doors" closing the open side of the containment system, appear complex, challenging, and expensive for the design configurations shown. Higher resolution on these aspects of the design will be clearer once NuScale submits the Design Certification Document (DCD) to the NRC.

Figure 28. Defense-in-Depth and Engineered Barriers for Radioactivity Escape

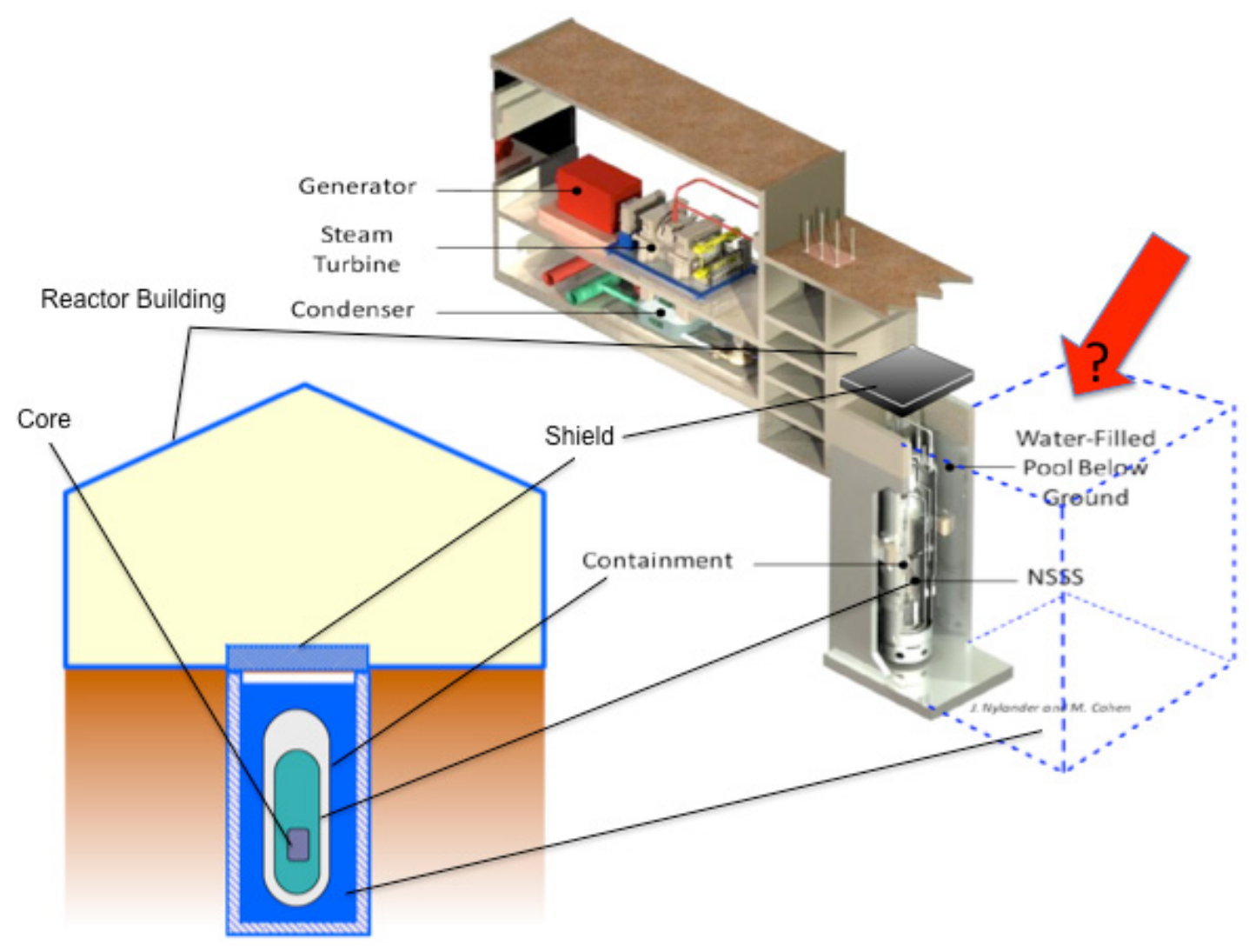

\section{Safety Features Summary}

The following summarizes the design's overall safety features:

- The design implements passive safety systems that use natural circulation for emergency feedwater cooling, decay heat removal, and containment cooling - this eliminates the need for primary 
pipes and pumps and any failures associated with pipe breaks and pump failures

- Except for vital equipment in the control room and some electrically or electro-pneumatically activated valve actuators, no external power is required to operate these systems, there is only minimum need for emergency power on site, and no need for emergency power off site

- The submerged containment vessel is designed to withstand pressure transients produced by a complete and simultaneous rupture of any or all of the reactor piping internal to the containment vessel

- As the entire containment-RPV structure is slightly buoyant, it is expected to show good performance when subjected to seismic forces

- Each 45 MWe NuScale power module houses just about 4\% of the fuel inventory of a conventional nuclear reactor, thereby proportionally reducing the potential for a radioactive release into the environment (caused by a single module) 


\section{Digital Instrumentation and Control (I\&C) Systems}

The NuScale design will utilize digital Instrumentation and Control (I\&C) and electrical systems as adopted by modern LWRs, with embedded redundancies and physical separation of safety critical systems. The envisioned layout for the NuScale multimodule control room is shown in Figure 29.

Figure 29. Multi-Module NuScale Control Room

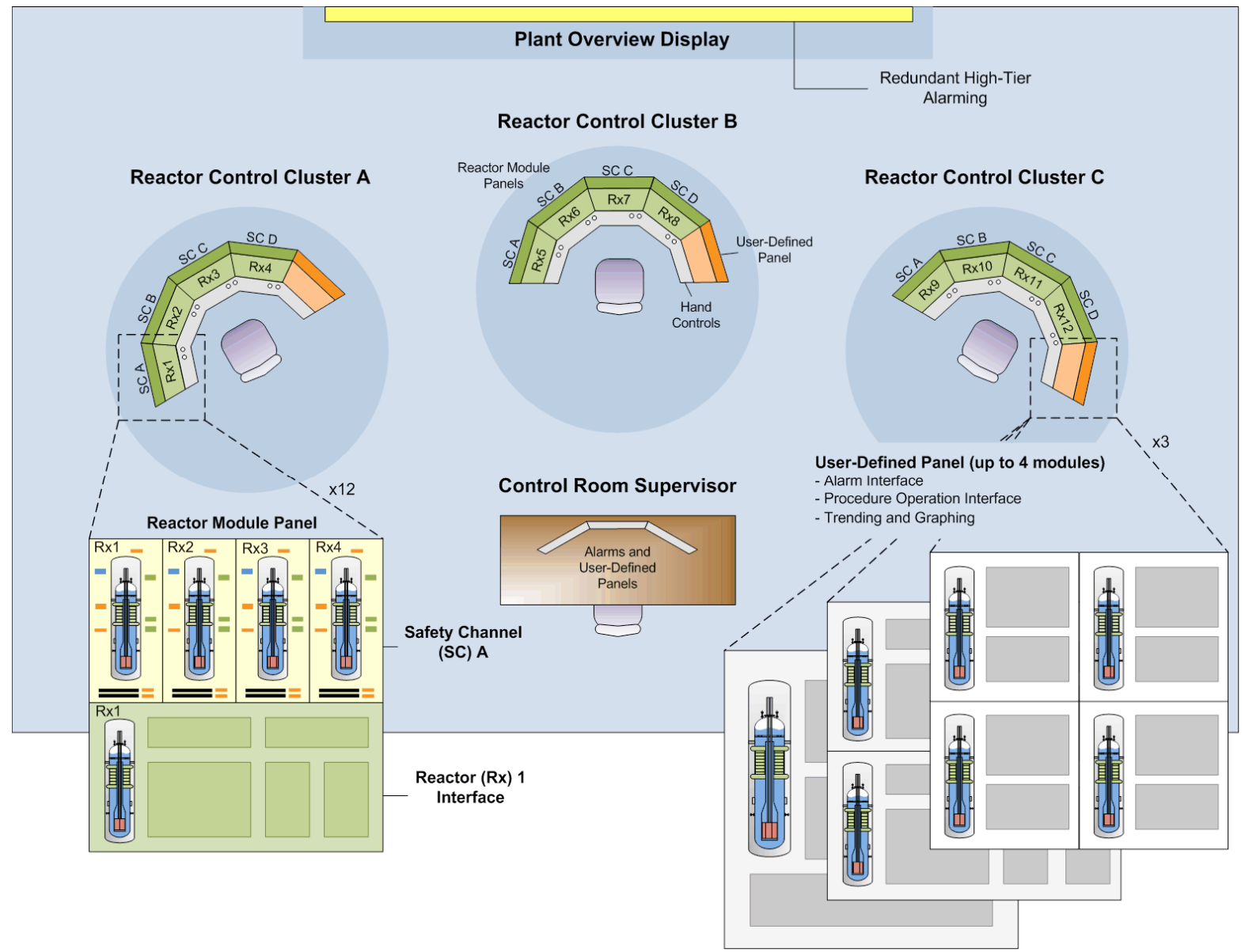

Source: NuScale Power, Inc.

When comparing the NuScale planned I\&C systems configuration and operation with modern Generation III and III + control rooms and related I\&C systems, the most evident departure is represented by this design's intention to group Multi-Module Operations so as to have clusters of modules controlled by a single console and relative operators in a common control room. Multi-module configurations will possibly share some systems, for example the same cooling pool space and coolant. Although very unlikely, if an accident were to occur during refueling of one-out-of-n module, for example, by dropping and subsequent breakage of a fuel bundle, it could potentially spread radioactivity in the cooling pool, thereby affecting all modules. For all SMR designs employing clusters of reactor units sharing common equipment and structures, the so called "sympathetic" reactor tripping will require analyses as problems developed in one 
unit can propagate and lead to all modules shutdown, which, in turn, could destabilize the bulk power grid.

Determination of safety impacts and mitigation strategies for potentially unforeseen design flaws - only detectable after reasonably long time of operation - and the perturbations caused by the interactions among multi-module systems will represent new challenges requiring specific PRAs and validation possibly evolving into development and implementation of new risk matrices, guidance, and regulations.

Finally, the core frequency as defined and calculated for a large LWR might require customization and different analyses approaches when applied to all of the SMR designs proposing multi-module stations as offered by the NuScale multi-module systems discussed. Significant investigation resources will have to be dedicated to determinations on whether multiple cores somewhat connected by sharing equipment, including digital I\&C systems, can adopt conventional core damage frequency calculation approaches, and how clusters of reactors can be simultaneously monitored, controlled, and operated by a single operator. All of these innovative aspects have the unfortunate consequence of potentially developing into delayed regulatory processes.

\section{Fuel Characteristics and Fuel Supply}

NuScale has yet to submit details of its fuel design beyond what has been described in the Core Specifications section. It is known that the company has internal staff working with well-established fuel design consultants (e.g. Anatech Corp of San Diego) on the fuel design for the NuScale reactor. While the 17x17 standard PWR assembly is a proven concept, the shortened length of approximately $6 \mathrm{ft}$ as proposed by NuScale could present some significant new challenges. The fuel itself will incorporate standard $\mathrm{UO}_{2}$ fuel pellets of up to $5 \% \mathrm{U}^{235}$ enrichment levels; however, the fuel assembly made of Zircaloy tubing and other stainless steel components could be problematic at the shorter length. Specifically, the standard spacer grids used in other PWR fuel assemblies may not function as expected under this configuration, as the shorter length could cause different pressure drop, different turbulences impacting the heat transfer coefficient, stagnation point issues among other problems. Fuel efficiency may also be impacted. While these issues are not unique to the NuScale design, the lack of adequate testing of any new half length PWR assembly is a potential concern. Given that NuScale has yet to identify a fuel supplier, it is unclear how such final design and testing will be acquired. Moreover, PWR fuel suppliers in the U.S., such as Westinghouse and AREVA, may not find their interests served in supply NuScale fuel, and therefore fuel design and manufacture may have to be done outside the United States. In this case, NRC licensing issues may arise, as most foreign fuel vendors are not licensed in the United States. Ultimately, the fuel aspects of the NuScale reactor must be addressed in order to apply for NRC design certification and eventual commercialization. 
Figure 30. NuScale Plant Spent Fuel Pool

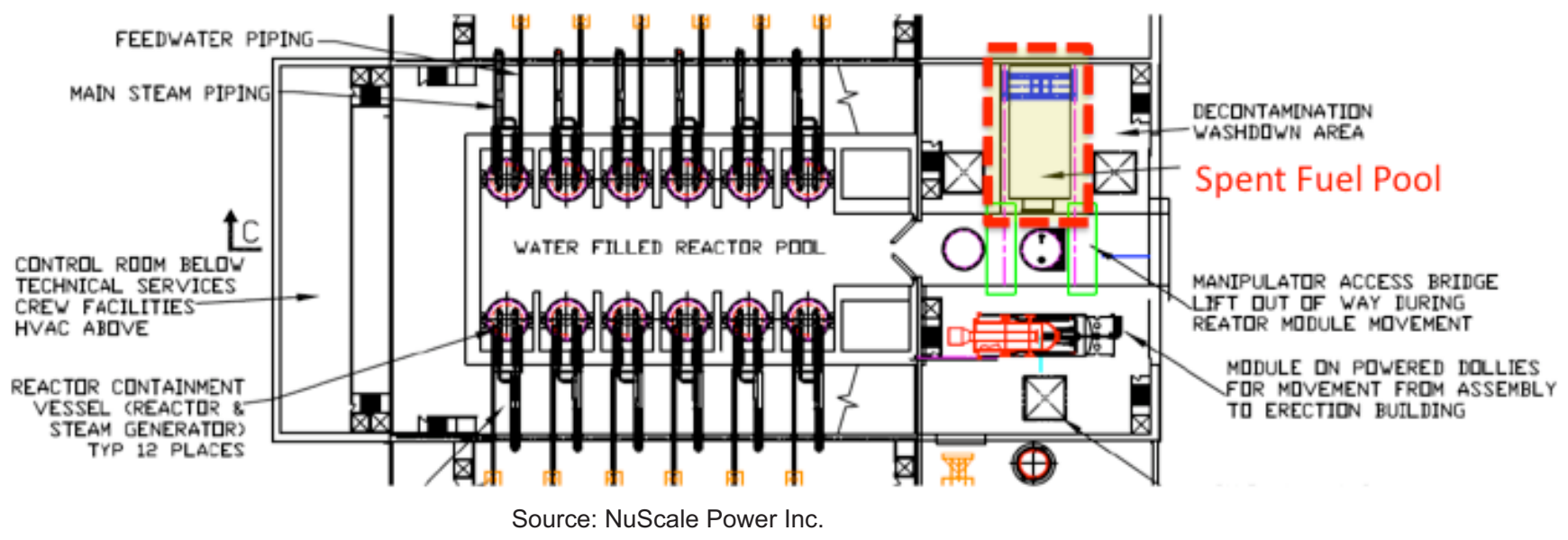

Figure 30 illustrates the Spent Fuel Pool (SFP) configuration with respect to a multimodule station. Once spent fuel bundles are extracted from any of the modules they will be temporarily placed in the spent fuel pool according to procedures adopted for LWRs. As shown by Figure 30, modules form a 540 MWe NuScale station with each module undergoing refueling every 24 months, thereby inducing a containment-RPV module transfer from its operating position to a refueling position and location through the "Water Filled Reactor Pool" every two months. This will imply heavy-weight crane activities and equipment transfer traffic in these areas.

The impact of accident scenarios on any of the operating modules while one or multiple modules are being refueled also represent significant novelty in relation to PRAs. As the fuel adopted in this design is very similar to conventional fuel utilized in LWRs the spent fuel will be handled with standardized procedures. As for all designs, the SFP storage volume, as well as short-and long-term disposal of spent fuel bundles will be determined by the utility purchasing the plant.

\section{Construction and Manufacturing Issues}

The reactor module, consisting of the containment, piping connecting the RPV through containment penetrations, and the RPV itself, can be entirely fabricated at existing manufacturing facilities in the U.S. As coolant pressure in the primary integrated and steam pressure in the secondary loop is appreciably lower than that of a typical PWR, the RPV wall thickness will not represent major forging challenges.

The power generation system is greatly simplified employing an off-the-shelf singlepressure turbine-generator set with the turbine venting to a condenser served by proportionally scaled condensate and feedwater pumps. The integral steam generators should not pose engineering and manufacturing challenges. As the containment is fully 
submerged and constructed with carbon-steel, it will require coating to avoid corrosion due to the chemical action of the coolant in the cooling pool and potentially fast fluid motion near the containment exterior walls due to most likely unavoidable vibrations and fluid velocity driven by natural convection mechanisms.

Most of the components can be manufactured and assembled at the factory and shipped as complete modules for final assembly at a selected site. All other sub-systems involving the nuclear-island, as well as the turbine-island, the balance of plant, and switchyard do not manifest particularly challenging construction steps that have not been already mastered by construction methodologies currently in place for LWR systems.

\section{Supply Chain Issues}

NuScale is working with a long list of industrial partners that are expected to be enlisted in the overall supply chain for the reactor once licensing is completed. Principal among those companies already mentioned are:

- General Dynamics/Electric Boat

- Northrop Grumman

- Kiewit

- Curtiss-Wright

- Studsvik

- Oregon Iron Works

- EnergySteel

- Precision Custom Components (PCC)

All of the above firms are active in either the commercial nuclear industry or suppliers to the U.S. Navy's nuclear propulsion activities. Some companies, such as General Dynamics may be willing to be the key supplier of the reactor vessel and other NSSS components for the NuScale design. Various companies could be available for other key components (e.g. Curtiss-Wright for pumps, PCC for reactor vessel internals, etc.). However, the crucial issue to consider for NuScale (or any similar startup SMR firm without in-house manufacturing capabilities) is that any suppliers will need assurances that it will have a substantial revenue stream out of the relationship. For example, if using a nuclear navy supplier like General Dynamics for the NSSS components, this will require major re-tooling of its existing factory (or even construction of a brand new dedicated factory), which naturally has added costs. To do so for a pilot demonstration NuScale plant could be problematic, and the supplier may prefer to only enter this space if given good assurances that subsequent reactor orders will follow. NuScale might find itself needing to resolve a situation where utility customers require a demonstration unit to be operational before placing an order for one or more modules, while, at the same 
time, the key manufacturers will require assurances of multiple orders before signing the contract to supply the components. 


\section{Attachment H:}

Sampling of Advanced SMR Vendor Designs and Concepts*

(taken from DOE public presentation material)

\section{Brookhaven Technology Group}

- Deployable Electric Energy Reactor (DEER)

- $10 \mathrm{MWe}$ - Uranium Hydride Fuel

\section{General Electric}

- Power Reactor Inherently Safe Module (PRISM)

- 311MWe - Sodium-Cooled Fast Reactor

\section{Hyperion Power Generation}

- Hyperion Power Module (HPM)

- $30 \mathrm{MWe}$ - Lead-Bismuth-Cooled Fast Reactor

\section{Sandia National Laboratory}

- Right Sized Reactor (RSR) Sodium-Cooled Fast Reactor

- $100 \mathrm{MWe}$ - Sodium-Cooled Fast Reactor

\section{TerraPower}

- Traveling Wave Reactor (TWR)

- $350 \mathrm{MWe}$ - Sodium Fast Reactor

\section{Westinghouse - Toshiba}

- Toshiba 4S (Super Safe, Small and Simple)

- $10 \mathrm{MWe}$ - Sodium-Cooled Fast Reactor 


\section{Attachment I: \\ Summary Description, U.S. Department of Energy Small Modular Reactor Program}

The Department of Energy (DOE) believes there to be a need and a market in the United States for Small Modular Reactors (SMRs). The DOE Office of Nuclear Energy's Small Modular Reactor program was a new start program in FY 2011 intended to advance licensing and commercialization of evolving SMR designs.

The SMR program was structured to accelerate deployment of more mature SMR designs based on light water reactor (LWR) technology and conduct necessary research, development, and demonstration (RD\&D) activities to advance understanding and demonstration of innovative reactor technologies. The program elements are funded separately out of a new budget line that supports an industry partnership program for LWR SMR deployment, and the Reactor Concepts research and development (R\&D) budget, respectively. Basic program elements are:

LWR SMR Licensing Technical Support - Although several SMR concepts are based on proven LWR reactor technologies, they have not been designed, licensed, or built for commercial deployment. DOE believes these LWR SMRs can be commercially deployed within the next decade. The LWR SMR Licensing Technical Support program supports certification and licensing activities for LWR-based SMR designs using cooperative agreements with industry partners to accelerate SMR deployment. The scope of work covered under the program includes completing design certifications, site permitting, licensing, first-of-a-kind engineering activities, and associated Nuclear Regulatory Commission (NRC) reviews and approvals for SMR projects proposed under a solicitation. DOE hopes that development of standardized SMR designs will also result in increased presence of U.S. companies in the global energy market.

SMR Advanced Concepts R\&D - SMRs designed using advanced and innovative concepts, such as those based on fast spectrum neutrons or high-temperature reactors, may offer added functionality and affordability. This program element supports laboratory, university, and industry projects to conduct nuclear R\&D on capabilities and technologies that are unique and supportive of advanced SMR concept development in the mid- to long-term. SMR Advanced Concepts R\&D activities focus on four key areas:

- Develop evaluation assessment methods for advanced SMR technologies;

- Develop and test materials, fuels, and fabrication techniques;

- Resolve key regulatory issues identified by NRC and industry; and

- Develop advanced instrumentation, controls, and human-machine interfaces.

The R\&D program element also includes evaluation of advanced reactor technologies that offer simplified operation and maintenance for distributed power and load-following applications, and increased proliferation resistance and security.

Specific DOE SMR program accomplishments are anticipated to include: 
- Solicit, competitively select, award, and cooperatively manage project(s) with industry partners for cost-sharing certification and licensing activities of the most promising LWR SMR concept(s) for near-term deployment.

- Conduct research, development, and testing of innovative advanced technologies, structures, systems, and components necessary for licensing.

- Establish national laboratory and university R\&D activities to advance innovative technologies.

- Support development of new/revised nuclear industry codes and standards (e.g., ANS, ASME, IEEE, ASTM, etc) necessary to support licensing and commercialization of innovative designs.

- Develop recommendations, in collaboration with NRC and industry, for changes in NRC policy, regulations or guidance to license and enable SMRs for deployment in the United States. 